\title{
Using the Enrichment Triad Model to Explore Place and Support Curriculum in One Rural Gifted Program
}

\author{
Myriah Mae Miller \\ West Virginia University, mtasker@mix.wvu.edu
}

Follow this and additional works at: https://researchrepository.wvu.edu/etd

Part of the Curriculum and Instruction Commons, Elementary Education Commons, and the Gifted Education Commons

\section{Recommended Citation}

Miller, Myriah Mae, "Using the Enrichment Triad Model to Explore Place and Support Curriculum in One Rural Gifted Program" (2019). Graduate Theses, Dissertations, and Problem Reports. 7375.

https://researchrepository.wvu.edu/etd/7375

This Dissertation is protected by copyright and/or related rights. It has been brought to you by the The Research Repository @ WVU with permission from the rights-holder(s). You are free to use this Dissertation in any way that is permitted by the copyright and related rights legislation that applies to your use. For other uses you must obtain permission from the rights-holder(s) directly, unless additional rights are indicated by a Creative Commons license in the record and/ or on the work itself. This Dissertation has been accepted for inclusion in WVU Graduate Theses, Dissertations, and Problem Reports collection by an authorized administrator of The Research Repository @ WVU.

For more information, please contact researchrepository@mail.wvu.edu. 


\title{
Using the Enrichment Triad Model to Explore Place and Support Curriculum in One Rural Gifted Program
}

\author{
Myriah M. Miller
}

\author{
Dissertation submitted \\ to the College of Education and Human Resources \\ at West Virginia University \\ in partial fulfillment of the requirement for the degree of \\ Doctor of Education in \\ Curriculum and Instruction
}
Sharon Hayes, Ph.D., Chair
Carla Brigandi, Ph.D.
Audra Slocum, Ph.D.
Melissa Sherfinski, Ph.D.

Department of Curriculum \& Instruction/Literacy Studies

\author{
Morgantown, West Virginia \\ 2019
}

Keywords: gifted education, place-based education, The Enrichment Triad Model Copyright 2019 Myriah Miller 


\title{
ABSTRACT \\ Using the Enrichment Triad Model to Explore Place and Support Curriculum in One Rural Gifted Program
}

\author{
Myriah Miller
}

Rural teachers of students with academic talents require support and learning opportunities specific to rural places and gifted pedagogy. Yet, research shows, in practice they receive neither which results in lower knowledge and use of research based gifted frameworks, models, and curricula. Additionally, curricular practices that are insular to students' lived experiences and identities marginalizes rural Appalachian realities and existences. Therefore, the purpose of this research was to build a conceptual foundation of gifted pedagogy for teachers specific to rural places that allowed them to support students' cultural needs and create curricula rooted in gifted education best practices for meaningful and longitudinal learning. Since no such framework previously existed, place-based education and Renzulli's Enrichment Triad were used to meet the two-fold purpose. Gifted teachers in one rural Appalachian county received 10 hours of training on the hybrid framework.

Using narrative inquiry, this case study explored how one teacher, who had deep connections to place, learned and utilized the place-based Enrichment Triad in her rural Appalachian elementary gifted program. Data collected included teacher, student, and parent interviews and classroom observations. Data were analyzed using a socio-cultural narrative analysis and narrative thematic analysis. Results from analysis created thick descriptions of the teacher's journey to teaching, her existing practices, her experiences learning and implementing the framework, and her future curricular intentions. Developments in the teacher's practice included establishment of scope and sequence, a sharing of power, and embracement of students' identities through internal motivation supports. Other curricular factors such as becoming a facilitator and limited intentions of continuing place inclusions were noted. Results also indicated an impact on students' affective developments, autonomous practices, and positionings within the curriculum and their place.

Collectively, these findings indicate merit for place-based education and the Enrichment Triad in a small rural gifted program. Findings also suggest that written and unwritten policies of place impact a gifted teacher's positioning, structural conceptions and programmatic enactments. Lastly, a teacher's strong sense of place does not assure purposeful inclusion of a place sensitive curriculum. Implications for future curricular learning and support for rural gifted teachers to meet their rural talented students' needs are discussed. 


\section{Dedications}

To my children, Torrah (6), Layden (4), and Maeve (2)

May you be blessed with both roots and wings.

And know that your roots do not mean you need to stay, but also your wings do not mean you need go. 


\section{Acknowledgments}

I would like to begin by thanking my committee. The completion of my dissertation would not have been possible without the continued support and nurturing of my chair, Dr. Sharon Hayes. Her patience and unwavering dedication to the development of my scholarship cannot be overestimated. I am also especially indebted to my mentor, Dr. Carla Brigandi. Her personal and professional standards of excellence challenged, motivated, and empowered me to achieve beyond what I previously perceived possible. I truly value her guidance and her friendship. I am also grateful to the other members of my committee, Dr. Audra Slocum and Dr. Melissa Sherfinski. Their advice and feedback proved invaluable to the research and the final product.

I would also like to recognize my family, as this journey would not have been possible without them. A special thanks to my parents, Rick and Susie Tasker. Words cannot encapsulate the indebtedness I feel toward them for their unending love and support. Throughout this challenging process, they made my life quite a bit easier. I would also like to thank Mary Kaye Staggers and David Webb for their encouragement, support, and childcare. Without these four, loving, and supportive people, I would not have persevered. Thanks should also go to my children who, through their unconditional love, provided me with serenity during the inquietude of graduate school. Lastly, I would like to recognize my husband, Jason, who supported me through this process, both mentally and financially. It has been a long journey, and I thank and love him for sticking with me through it all. 


\section{TABLE OF CONTENTS}

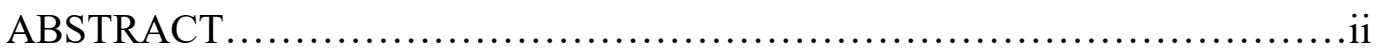

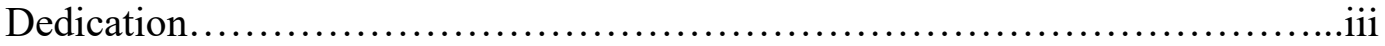

Acknowledgements..................................................

Table of Contents.....................................................

List of Figures and Tables..............................................

CHAPTER 1: INTRODUCTION TO STUDY..............................1

Pilot Study ................................................... 5

Situating the Study in Appalachia......................................

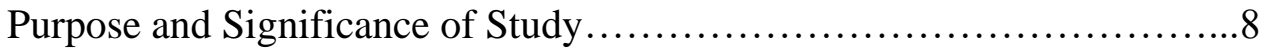

CHAPTER 2: LITERATURE REVIEW .................................. 10

Exegesis of Terminology........................................ 10

Overview of Gifted Programs..................................... 11

Gifted Programs Nationally...............................11

Rural Gifted Programs....................................13

Place-Based Education...........................................16

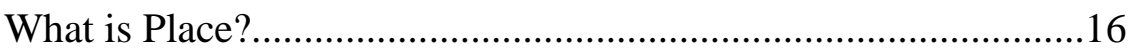

Constructs of Place......................................20

Finding "Place" in Schools: What is Place-based Education?.......21

Emerges from Attributes of Place....................23

Multidisciplinary.................................24

Experiential......................................24

Broader Than "Learning to Earn"......................25

Connects Place with Self and Community...............26

Impact on Teacher Practice and Student Learning.........27

Concerns with Place-based Practices.........................27

Pedagogy of Place: Combating the "Brain Drain" of Talented Youth.....29

Perceptions of Staying and Leaving.........................30 
Shifting Perceptions of Staying or Leaving ..................33

The Enrichment Triad Model.......................................34

Description of the Enrichment Triad.........................37

Type I Enrichment................................38

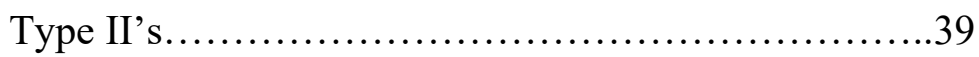

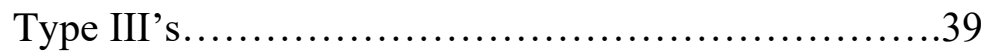

Theoretical Underpinnings of the Enrichment Triad..................41

Constructivist Foundation..............................41

Three Ring Conception of Gifted Behaviors................42

Research on the Enrichment Triad..........................46

Adherence to the structure...........................46

Self-efficacy.................................47

Creative Productivity and Type III....................47

Post-Secondary and Career Goals.....................48

Academic and Life Skills..........................48

Interest......................................49

Teachers......................................50

Merging of Place-Based Education and the Enrichment Triad.........51

CHAPTER 3: METHODOLOGY .................................... 54

Theoretical Perspective.......................................56

Methodology: Case Study.......................................59

Research Context...........................................62

Place in Context.......................................66

The Participants and their roles.................................66

Teacher Participant............................................68

Student Participants....................................69

Parent Participants......................................69

Researcher's Role......................................70 
Subjectivity Statement........................................... 71

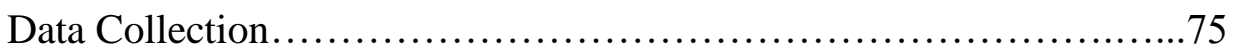

Interviews.........................................................

Observations................................................. 81

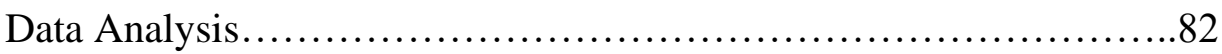

Socio-Cultural Narrative Analysis..............................82

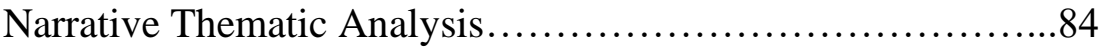

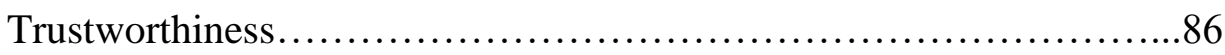

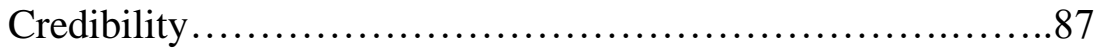

Transferability .............................................. 89

Confirmability .................................................... 89

Verisimilitude............................................. 90

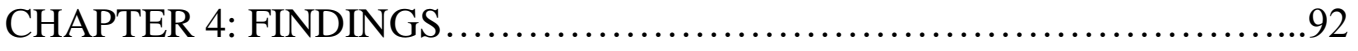

Jane's Educational and Teaching Experiences........................93

Finding Her Fit.........................................98

Jane's Sense of Place Influencing her Creation of

Place in the Classroom................................103

Pre-existing Curricular Frames................................ 104

STEM............................................... 105

Competitions and Contests.............................107

Implementing the Place-based Enrichment Triad Model..............111

Learning the Place-based Enrichment Triad Model.............111

Enacting the Place-based Enrichment Triad Model............115

Support and Collaboration During Implementation............118

Jane's Classroom and Curricular Development.......................124

Developing Curricular Scope and Sequence..................124

Re-visioning Curriculum..................................128

Sharing of Power..................................... 128 
Becoming a facilitator

Incorporating the place-based Enrichment

Triad in future curriculum.

A Teacher's Use of Place and the Enrichment Triad Model.

Students' Affective Growth in New and

Challenging Experiences

Students' Navigation of Interpersonal and

Collaborative Discourse 148

Students' Perception of Interpersonal Growth 153

Cogency of Place in Curriculum 155

Tangible Curriculum................................156

Students Evolving Identities as Learners................159

Jane's Evolving Understandings of Student Identities.....162

A Place's Influence on the Conceptualization of Gifted Education...167

Certification Hurdles for Teachers Obtaining

Gifted Endorsements. 167

Diminished Student Participation and Identification. 169

Undervaluing of Gifted Education in Place. 173

Colleagues' Perceptions of the Gifted Position.... 175

Conclusion 177

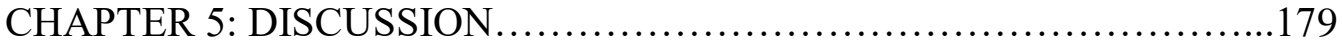

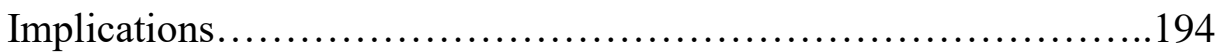

Limitations................................................. 198

Final Thoughts...............................................199

Coda.........................................................199

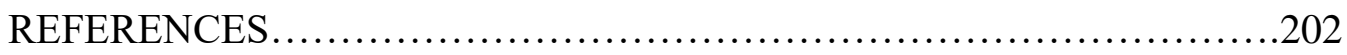

Appendix A: Email Recruitment Script..............................228

Appendix B: Teacher Interview Protocols.............................229 
Appendix C: Phone Call Follow-up Script..................................233

Appendix D: Student Interview Protocols.................................234

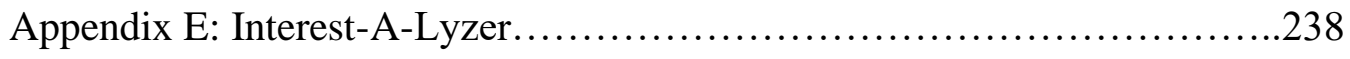

Appendix F: Guide for Place-based Discussions and Topics.................247

Appendix G: Management Plan.............................................249

Appendix H: Parent Interview Protocol..................................250

Appendix I: Rev.com Confidentiality Agreement.........................251 


\section{List of Figures and Tables}

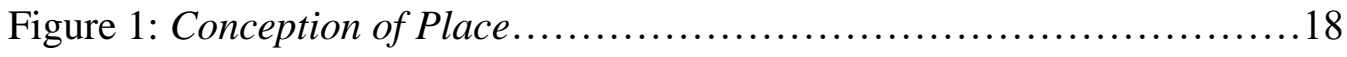

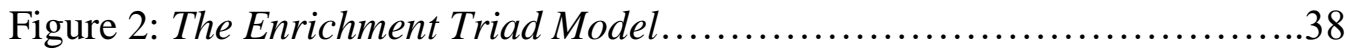

Figure 3: Three Ring Conception of Giftedness...........................43

Figure 4: Socio-Cultural Narrative Analysis.............................84

Figure 5: Example Delineation of Codes to Categories to Theme................86

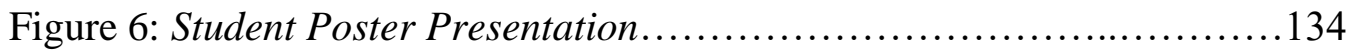

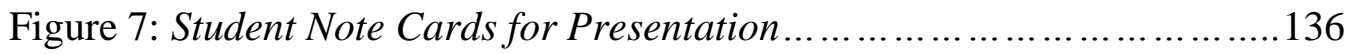

Table 1: Place-based Education and the Enrichment

Triad Complimentary Table .............................52

Table 2: Student demographics.......................................69

Table 3: Data Collection Timeline .................................... 78 


\section{CHAPTER 1: INTRODUCTION TO STUDY}

The genesis of this dissertation research focus was multilayered and spanned institutions, roles, and time. After finishing my Masters' degrees, I anticipated the opportunity to have my own classroom with 20-plus students entrusted in my care. However, the competitiveness of teacher positions within a university town that housed a reputable teacher preparation program shifted my professional journey. Instead of teaching in a general education classroom, I accepted the first offer I received and began teaching students with academic talents in my hometown.

Before being hired for this position, I had little to no experience with talented students. I remember the day before my interview, googling "teaching gifted students." I found an article that must have appealed to me because I distinctly remember printing and memorizing what I thought could be "buzz words" to use with the hiring committee. During my interview, the human resource representative informed me that I would have to complete additional coursework towards a gifted endorsement because neither my elementary education degree nor my reading degree qualified me to teach students with academic talents. My response was "Of course! I enjoy taking classes," but in actuality, I just wanted a job. With no foundational or pedagogical knowledge on how to serve students with talents, I was charged with that duty. I began teaching with an out-of-field authorization, which specified that I would take six credit hours a year in gifted education until I earned my certification. Since my entrance into gifted education, teachers in my Mid-Appalachian state no longer have to take coursework to become certified. Instead, once a teacher earns initial certification, they are able to take a Praxis exam in gifted education and are then considered qualified to teach students with academic talents.

"Gifted Teacher," as the job title read, foreshadowed the ability, creativeness, and commitment I needed to navigate the complexities of being a teacher of students with academic 
talents in small rural schools. My transition into special education was plagued by the challenges of balancing paperwork, meeting committee deadlines, learning about and actualizing Individualized Education Plans (I.E.P.), the expectations of the four schools I served, and accommodating the needs of my diverse students, grades one through six. Moreover, I also grappled with designing curricula as I had the freedom to choose the content, pedagogies, and assessments I used with my students. In an honest, reflective critique, I admit that the curriculum design for each class was often an afterthought. While I did take coursework in gifted education, the in-practice practicalities and restraints I encountered often trumped engaging in a continual improvement of the curricula. In the moment, though, I believed that I was "challenging" my students with enjoyable activities — in actuality, my curriculum was a "puff piece" that housed no longitudinal or meaningful experiences.

After a few years of teaching students with academic talents, I decided to further my education and began working towards my doctorate. As I engaged with my coursework, I was intrigued by the intersection of gifted and rural education. Literature searches for empirical studies and book recommendations from professors led me to three defining works. These works were most influential in the formulation and initial articulation of my interests in rural Appalachian gifted programs. What follows is a synopsis of each work and a description of its influence on my work.

In his groundbreaking work Learning to Leave: The Irony of Schooling in a Coastal Community, Michael Corbett (2007), a former teacher turned scholar, delineated generational outmigration patterns and the disjointed value systems between community life and school expectations, as well as gendered roles within these two systems. Set in Digby Neck, a rural coastal town in Nova Scotia, Corbett studied three age-banded cohorts of leavers and stayers 
between 1963 and 1998. The powerful findings of this study illustrated that schools prepared students to leave and perpetuated an ideal that success was elsewhere. Unfortunately, schooling failed to foster the dreams and aspirations of those who chose to remain in their rural place resulting in these students developing apathy towards schooling or becoming early dropouts. Given the traditionally male gendered economic staple, fishing, many women in Nova Scotia received a kinder hand in school. They were markedly more successful and continued into higher education at higher rates than their male counterparts. However, increased education did not equate to increased economic capital for either men or women in this rural fishing community. Thus, Corbett (2007) called for a "need to adopt a more place-sensitive focus" (p. 269). Place for the purposes of this research was defined as "spaces which people have made meaningful" (Cresswell, 2015, p. 12). Corbett's (2007) findings spawned my own curiosity of how place might inform curricula in Appalachia.

Serving Gifted Students in Rural Settings (Stambaugh \& Wood, 2015), an edited book, proved influential as I determined the direction of my research. The authors collectively explored the diversity and complexity of gifted programing rooted in the rural contexts. Whereas Corbett (2007) demonstrated that youth in Digby Neck were often socialized to leave, Stambaugh and Wood (2015) introduced me to the notion of "brain drain." According to Howley, Howley, and Showalter (2015), academically talented students are expected and institutionally encouraged to leave their rural places for "success" in their global destinies. These authors postulate that "rural schooling should encourage, support, and actively facilitate rural adulthoods for rural students" (p. 23). Moreover, Richard and Stambaugh (2015) delineate a "rural essence" that was woven through place, tradition, family, and religion. Although I have also noticed narratives that do not fit this essence, understanding rural culture through this essence proved invaluable as it provided 
me with an understanding of how, generally speaking, rural places and people differ from their urban counterparts.

Lastly, an empirical article by Azano, Callahan, Missett, and Brunner (2014) provided an insightful glimpse into the rarely explored contextual nature of rural teachers of the academically talented. Azano and colleagues (2011) conducted a study piloting a scripted third grade gifted curriculum, the CLEAR curriculum, with teachers across the nation. The results indicated that rural teachers in gifted programs proportionately reported lower fidelity of implementation (FOI) than their suburban and urban peers. FOI is "the extent to which delivery of an intervention adheres to the protocol or program model" as it was originally intended, designed, or scripted (Azano et al., 2011, p. 695). Specifically, "while rural teachers represented slightly less than one fourth of the teachers in the larger sample, they represented almost half of the total number of teachers in the 'low fidelity' group” (p. 91). Perplexed by this finding, Azano et al. (2014) conducted a qualitative study to understand the phenomena. The findings of this study, which will be further explored in the literature review in Chapter 2, demonstrated rural teachers of academically talented students have "complex and demanding teaching loads" (p. 95). This finding resonated as I previously experienced many of the complexities the study illuminated during my tenure as a rural, gifted teacher.

The influence of these works in the field of rural and gifted education as well as multiple conversations with and guidance from a professor of gifted education, Dr. Brigandi, led me to wonder how gifted programs were enacted in my place, rural mid-Appalachia. I knew my story of being a rural gifted teacher, but what influenced other teachers' practices? Because there are many conceptions of giftedness (Plucker, Burroughs \& Song, 2010), I was curious as to how giftedness was conceptualized in my place and what influenced those conceptualizations. 
Additionally, Richards and Stambaugh (2015) claimed rural people embrace a strong sense of place, or a strong connection to the places they live; therefore, I also wondered if place made its way into the curriculum as a conscious endeavor. All of these wonderings led me to design and conduct a pilot study that explored rural gifted programming in Appalachia.

\section{Pilot Study}

The purpose of the exploratory qualitative case study was to understand rural gifted educators' perceptions of giftedness and how these perceptions manifested themselves in practice. I wanted to gain insight into and understanding of cultural influences and realities of rural gifted classrooms. The following research questions guided the pilot study:

1) What are rural gifted educators' perceptions of giftedness?

2) What do rural gifted classrooms look like in practice?

While this study was exploratory, the intersectionality of place and culture provided a lens for the design of the study and data analysis. Consideration of gifted students' knowledge and experiences with place holds little significance in the decontextualized accountability rhetoric and practice, however, Greenwood (2011) suggested places are pedagogical and "that places shape us" (p. 634). Rather than understanding curricula and classrooms in isolation, they inevitably intersect with the narratives and discourses of the places where they reside. This included teachers' and students' identities, values, and lived experiences (Gruenewald, 2003). In other words, my study aimed to provide insight into the intersectionality of gifted programming in a rural Appalachian place.

Although data analysis is ongoing, preliminary findings from my pilot study substantiate the limited research that exists on rural gifted programs, which in turn paralleled my own experiences. Rural teachers of students identified as gifted and talented are not aligning their 
programs with research-based gifted and talented frameworks (Azano et al., 2014; Miller \& Brigandi, forthcoming). Moreover, frameworks for gifted education in general are not designed explicitly for rural places and often do not address the complex contextual nature of rural gifted programs, including the needs of rural gifted education teachers and their talented students (Ayers-Paul \& Seward, 2016; Azano et al., 2011; Lewis, 2015). This then limits fidelity of implementation (Azano, et al., 2014). The fact that many teachers are unaware of frameworks that support talented students further illustrates the need to prepare gifted education teachers and educate talented students (Miller \& Brigandi, forthcoming). This lack of awareness may be due to the fact that only one state currently requires any preservice coursework in gifted and talented (National Association for Gifted Children [NAGC] \& The Council of State Directors of Programs for the Gifted [CSDPG], 2015). Many states, such as West Virginia, provide alternate routes to certification (WVDE Policy 5202, 2019), and once, in practice, teachers are not provided with appropriate in-service learning opportunities that focus on gifted pedagogy (Brigandi \& Miller, 2018; Miller \& Brigandi, forthcoming). Many teachers in rural gifted education programs struggle to develop curricula and instruction that meets the needs of their unique students without these learning opportunities. This can result in "hodge-podge" curricula that is neither challenging nor meaningful to students (Borland, 2012; Brigandi \& Miller, 2018; Miller \& Brigandi, forthcoming).

The gifted education teachers in my study often piecemealed curricula and instructional materials through searches on the Internet and social media sites, or books purchased online (Miller \& Brigandi, forthcoming). Little attention was paid to the pedagogical needs and best practices for talented learners or the places in which they were situated. A place-based practice infused in an evidence-based model for gifted education, however, might work to address this 
two-fold issue. Place-based education contextualizes what talented students are learning in meaningful experiences, and the Enrichment Triad Model (Renzulli, 1977) differentiates these experiences based on interest, creativity, task commitment, and even ability, all constructs important in talented learner curricula. Both of these models will be discussed further in Chapter 2.

Based on preliminary findings of my pilot study, there are a number of themes (pedagogical support, curricular support, isolation, and decontextualized practice) I wished to explore in more depth. It seems that the most appropriate first step is to provide gifted teachers with professional development on gifted education pedagogy that respected and valued place in schools. I wanted to understand how teachers of talented students make sense of the pedagogy introduced in the professional development and to hear their stories as they navigate the process of developing curricula and implementing instruction that is informed by their place. I also wanted to explore students' perspectives of place and how a curriculum that embraces place influenced their learning, schooling, and lives. Thus, my dissertation was imagined.

\section{Situating the Study in Appalachia}

My decision to situate the study in Appalachia arose from my coursework, specifically a course entitled, Identity, Place, and Literacy in Appalachia. Appalachians encounter many stereotypes that, for some are true, such as those who live in poverty or have roots in coal mining. Other more pervasive notions of Appalachian people such as they are isolated, backward, unintelligent, and in general the unworthy 'other' (Lewis, 1999; Shapiro, 1978) not only misrepresent and homogenize a group of people, but may have profound and lasting implications for the lives of Appalachians and one's sense of place. In fact, a dichotomy of falsetruths portrays Appalachia. It is either represented in a romanticized light, as unfailing 
community and familial ties, or as a place and people that time has forgotten. A change in perspective reveals a people of talent and wealth that cannot, or should not, be measured in monetary terms. As I explored the phenomenon of Appalachian "othering” (Lewis, 1999; Shapiro, 1978) and how it worked to subordinate the area, people, and culture from the dominant American equivalent, I became interested in shifting this narrative and decided that using place in the curriculum would become one of the focuses for my work.

\section{Purpose and Significance of the Study}

Rural teachers of students with academic talents require support and learning opportunities specific to rural places (Azano \& Stewart, 2016) and gifted pedagogy (Howley, 1986; Brigandi, Weiner, Siegle, Gubbins, \& Little, 2018b; Brigandi \& Miller, 2018). However, in practice they receive neither (Burton, Brown, \& Jonston 2013; Miller \& Brigandi, forthcoming) resulting in lower knowledge, use, and fidelity of implementation of research based gifted frameworks, models, and curricula (Azano et al., 2014; Bain, Bourgeois, \& Pappas, 2003; Callahan, Moon, \& Oh, 2017; Miller \& Brigandi, forthcoming). Additionally, today's accountability measures have isolated and decontextualized curriculum from students' lived experiences and identities and have undermined the rural existence (Theobald \& Wood, 2010) resulting in a devaluing of rural places and perpetuating a success mantra that results in the exodus of rural youth with academic talent from their rural places (Bartholomaeus, 2006; Corbett, 2009; Theobald \& Wood, 2010).

My study was designed to address these complexities and (a) answer rural gifted education teachers' calls for support (b) provide professional learning opportunities specific to gifted education and (c) support rural talented learner's curricular and sociocultural needs. I explored how one gifted education teacher made sense of Renzulli's (1977) Enrichment Triad 
Model and how she used it to design curriculum that was informed by place. I storied the teacher's experiences and examined the impact on her practice as well as on student learning. The following research questions guided my study:

1) How does one teacher of a small rural Appalachian pull out gifted programs make sense of the Enrichment Triad Model and how does she use it in her classroom and curricular development?

2) How does a teacher's use of place and the Enrichment Triad influence teaching and student learning in rural Appalachian gifted classrooms?

3) How does place influence a gifted program's structure and enactment in a rural Appalachian school?

My research was important for the field of gifted education because it added to the discussion of rural Appalachia and gifted education in three ways. First, it was one of the only studies that focused on the teacher's conception, understanding, and in-practice use of the Enrichment Triad in rural contexts. There have been few studies that examined the complexities of being a rural teacher of academically talented students (Azano, et al, 2014; Brigandi, Gilson, \& Miller, 2019; Miller \& Brigandi, forthcoming), but calls within larger educational literature to understand teachers' experiences and perspectives (Grafam, 2006). Additionally, there was only one recent study that focused on the teacher's perspective within the Enrichment Triad Model (Brigandi, Gilson, \& Miller, 2019).

Second, minimal research in gifted education focused on rural talented students' unique needs and complexities in contextual programming. By situating the study in rural Appalachia and exploring the use of place in the classroom, rural students had the rare opportunity to share what they value about their gifted programs and their place. Lastly, given the subjective and 
contextual curricular change barriers (Azano, et al., 2014; Brigandi, et al., 2019; Brigandi \& Miller, 2018) my research study provided a next step in understanding change in practice that PD can support (Brigandi, et al., 2019; Brigandi \& Miller, 2018) and the teacher's experiences and needs as they go through this learning process.

\section{CHAPTER 2: LITERATURE REVIEW}

\section{Exegesis of Terminology}

Throughout this literature review, I refer to students who have above average abilities in multiple ways. I use the socio-educational finite term "gifted" when I reference students who are identified as academically gifted or creative producers. Intellectually or academically gifted students demonstrate "schoolhouse" abilities, such as "test-taking, lesson-learning, or academic giftedness or talents" (Reis \& Renzulli, 1994) and achievements and thus aligns with traditional schools' valuing system (i.e., high intelligence quotient, IQ [Renzulli, 1982]). However, conceptualizing giftedness through cognitive and achievement measures such as IQ tests perpetrates a static and innate supposition of giftedness. In contrast, giftedness focused on behaviors and outcomes that position students as "creative producers." A creative producer is a person who "tends to be or have the potential to become a producer (rather than consumer) of original knowledge, materials, or products and who employ thought processes that tend to be inductive, integrated, and problem oriented" (Reis \& Renzulli, 1994). Intellectually or academically gifted and creative producers are frequently used terms in practice and research in gifted education. Therefore at times throughout the paper I needed to use these labels, especially when referencing literature or students identified as gifted.

Secondly, I claim that youths with talents are those students who have a higher than average ability in a given area, not just in schoolhouse giftedness (Reis \& Renzulli, 1994). This talent may or may not be recognized, and students may or may not be given the opportunity to 
display their talents due to their place's or school's cultural conception of giftedness. In places like West Virginia, gifted students are grossly under-identified (WVDE, 2014), not necessarily for lack of talent. Outdated notions of intelligence, national normalizing ideas of giftedness (see Azano et al., 2017), and rigid, school bound conceptions of giftedness (Moon \& Brighton, 2015) all contribute to this inequity. For example, Sternberg's conception of practical intelligence is a type of intelligence that is different from academic intelligence, but often not endorsed in schools (Sternberg, Wagnor, Okagaki, 1993). A rural Appalachian student who does not speak formal dialect and does not enter school with traditional school readiness skills is likely to be overlooked as being gifted. Yet, culturally lensing what it means to be gifted, allows acknowledgement of other types of giftedness within the cultural norms such as a student's demonstration of practical intelligence - a talent often required and lauded by rural Appalachians. Therefore, I use the term "students with talents" to keep an open conception of what "giftedness" could mean in rural Appalachia because those identified as gifted and talented may not be the totality of who is capable of demonstrating gifted behaviors (Renzulli \& Reis, 1997, 2014; Reis, 1981).

\section{Overview of Gifted Programs}

\section{Gifted Programs Nationally}

Students with academic talents require interventions specific to their academic, cognitive, and affective needs. Traditionally, these needs are met through enriched and accelerated services (Brigandi, 2015; Renzulli \& Reis, 1997, 2014), often referred to as gifted programs. While no federal mandate requires students with academic talents to be identified or serviced, many states employ child find measures and service programs (National Association for Gifted Children [NAGC] \& Council of State Directors of Programs for the Gifted [CSDPG)], 2015). The 
following section begins with a snapshot of what gifted education looks like nationally, and then narrows to discuss rural schools and rural gifted programs.

A recent national study of 1,566 urban, suburban, and rural schools illustrated a picture of current practices in gifted education (Callahan, Moon, \& Oh, 2017). Data were reported by grade bands (i.e., elementary) and findings addressed identification of racial and socioeconomic subgroups of students. Although, absent from the study were analysis of other factors that influence gifted identifications and services, such as geographic location or populace variance (i.e., rural).

Findings from the large scale study indicated most states required identification of students for gifted and talented programs using specific methods and designated criteria (NAGC \& CSPD, 2015). In practice, however, the methods produced large variances of students' identification rates. Some districts reported up to $10 \%$ of their students identified as gifted while others, like some rural Appalachian regions, were drastically lower ranging between 1\%-2\% (Callahan, Moon, \& Oh, 2017; National Center for Education Statistics [NCES], 2008). Not surprisingly, students in poverty were the most underrepresented group of identified students with Blacks and Hispanics trailing closely behind (Callahan, Moon, \& Oh, 2017). Underrepresentation of rural Appalachian students could be in part explained by the fact that only half of the districts reported having a plan in place for addressing talent development for historically underrepresented students---such as those from poverty and certain races. Underidentification from this lapse in policy is consequential because many students in rural Appalachia live in poverty, and more specifically generational poverty (Spotlight on Poverty and Opportunity, 2018; Richards \& Stambaugh, 2015) and students from impoverished backgrounds are less likely to be referred for gifted education (Hamilton, et al., 2018). 
Current researchers and scholars concur on a broadened conception of giftedness beyond IQ (Reis \& Renzulli, 2010). Yet, the prevailing definition for giftedness in elementary schools was intellectually gifted (the definition of giftedness will be further explored in the last section of this chapter; Callahan et al., 2017) and thus measured by intelligence quotients (NAGC \& CSPD, 2015). Concerning programming, quality standards such as the NAGC (2010) Pre-K-Grade 12 Gifted Education Programming Standards did not guide many elementary, middle, or high school programs, $53 \%, 39 \%$, and $28 \%$ respectively, but two-thirds did report having district mandated gifted frameworks to support their practice with a variety of material resources. The top three frameworks reported were Tomlinson's (2001) Differentiation Model, Renzulli's (1977) Enrichment Triad Model, and Kaplan’s (2005) Depth and Complexity Model. Service delivery models and times varied across levels with part-time pull-out methods being the most common in the elementary years. Service times varied from one hour to four hours per week and professional development in gifted education ranged from 15 minutes to 4 days throughout the school year.

Reviewing this large-scale study and its findings showed how gifted and talented programs operate on a national scope. To further understand gifted programs, the following section delineates the literature on rural schools and rural gifted programs.

\section{Rural Gifted Programs}

An online library search for empirical articles focused on gifted education in Appalachia within the last 20 years provided dismal results. After searching in the ERIC/EBSCO host database, using the terms Appalachia AND Gifted; Appalachia AND Talented Students; Appalachia AND Gifted Students; Appalachia AND Gifted Programs resulted in only a few studies. A university librarian suggested searching in an alternate database. Google Scholar did 
not return markedly more studies. While there may be studies that focus on gifted programs in Appalachia, the authors did not explicitly place Appalachia or gifted in the identifying tags. The void in literature may be due in part to authors using more generalizable or popular tags such as "rural." Given that rural Appalachia, the context of this study, is not exceptional to rural America (i.e., people in poverty in rural Appalachia do not differ significantly from people in poverty in other rural areas), the following will be a synopsized review of rural gifted programs.

A review of literature showed disparities in funding, schools, teachers, and student perceptions and degrees of identification between rural and suburban or urban places. To begin, “rural schools, small schools, and schools with larger economically disadvantaged populations allocate proportionally less fiscal and human resources to gifted education services" compared to suburban and urban schools (Kettler et al., 2015, p. 99). In general, funding for rural schools and especially for teacher salaries continue to be a challenge (Hammer, Hughes, McClure, Reeves, \& Salgado, 2005; Plucker, 2013).

Rural teachers of students with academic talents require support and learning opportunities specific to rural places (Azano \& Stewart, 2016) and gifted pedagogy (Howley, 1986; Brigandi, Weiner, Siegle, Gubbins, \& Little, 2018b; Brigandi \& Miller, 2018). However, in practice they receive neither (Burton, Brown, \& Jonston 2013; Miller \& Brigandi, forthcoming). The recent revitalization of the Every Student Succeeds Act [ESSA] (2015) allows federal funds to be used by states/districts for professional development specific to gifted education, as well as the identification and services of gifted students (Every Student Succeeds Act, 2015.). While this legislation is fairly recent, it is unclear how the mandate will shape local educational agencies' visions and actions. Currently though, teachers of students with academic talents reported feeling isolated (Azano et al., 2014; Burton, et al., 2013; Floyd, McGinnis, 
Grantham, 2011; Miller \& Brigandi, forthcoming) and burdened with complex roles. For example, gifted teacher/case manager of students with academic talents as well as students with learning disabilities (Azano et al., 2014; Croft, 2015; Hammer et al., 2005; Miller \& Brigandi, forthcoming).

To continue, students are identified proportionately less in rural places, and especially in schools with greater proportions of low income students (Azano, Callahan, Brodersen, \& Caughey, 2017; Hamilton, et al., 2018; Montoya, Matias, Nishi \& Sarcedo, 2016; Plucker, 2013; Seal \& Harman, 1995). Students living in sparsely populated counties (Seal \& Harman, 1995) and those that are Black or Hispanic (Montoyai et al., 2016) are even less likely to be identified. This could be in part to teachers' traditional or textbook conceptions of giftedness, which include large vocabularies, early literacy, and extensive experiences, which are all "proxies for higher socioeconomic conditions" (Moon \& Brighton, 2015, p. 473). In other words, if teachers, the most common referent (Callahan et al., 2017) cannot conceive giftedness beyond middle-class, white norms, then students from rural, poverty stricken areas will be pervasively underidentified.

Rural identified students who participate in gifted programs report increasingly less interest, challenge and in some cases less enjoyment in their gifted classes than their urban or suburban gifted peers (Gentry \& Rizza, 2001; Heggoy, Battle, \& Grant, 1995). To combat these deficits, researchers suggest incorporating choice (Gentry \& Rizza, 2001) and student interest into the curriculum (Delcourt, 1993; Heggoy et al., 1995).

Finally, schools in rural places are valued as part of the community. For example, schools are often community hubs in rural places (Richards \& Stambaugh, 2015). They are a connection to the community and its residents and they act as cultural and social centers (Seal \& Harman, 
1995). This fact is crucial in fostering a pedagogy of place within rural schools, a point that will be expanded further in the next section.

This review of rural gifted programs was brief and limited to the sparsity of literature found on the topic; however, it created a foundation for understanding the complexities of gifted education programs in a rural Appalachian place.

\section{Place-Based Education}

Although the terminology is relatively new, place-based education incorporates tenets of established practices such as problem-based learning, a whole child approach, service learning, culturally relevant and culturally conscious curriculum, environmental education, and others (Knapp, 2005). Despite its newfound name, the constructs of each of its related practices house a meta-defining criterion: place. This section will work to explore the conceptions of place and place-based education, and the purpose of using place-based education with rural youth with talents.

\section{What is Place?}

There is no apodictic theory of place (Cresswell, 2015) that can guide educational discourse; however, most concur that an "understanding of [place] is key to understanding the nature of our relationships with each other and the world" (Gruenewald, 2003a, p. 622). Place is essentially "spaces which people have made meaningful" (Cresswell, 2015, p. 12). To interpret place, however, a consideration of the interactions within places must occur. Therefore, one can think of place as the intersection of the human and nonhuman world and the connection between the spheres of environment, self, community (micro \& macro), home, and school. Places work to link these constructs in the ecological sphere where humans and non-humans inevitably interact 
(see Figure 1). Moreover, these places are inherently social, political, and historical and from this notion, Gruenewald (2003a) asserts that they are pedagogical as well.

While places are at once common and taken for granted (Gruenewald, 2003a), because places are everywhere and place itself is not consciously considered (Duhn, 2012), our existence and interactions within these places occur in an intradependence (Theobald, 1997).

Intradependence is "[to] exist by virtue necessary relations within a place" (Theobald, 1997, p.7). Intradependence can be likened to collectivism where goals, resources, interests, and priorities are interconnected between and concerned with the relationship of self and others. From this intradependence, it can be said that places are pedagogical in that we learn from and within the places we inhabit. Places teach us about the world (the social, political, economic), form our identities, and shape how we fit in the inter- and intra- connected system (Gruenewald, 2003a). For example, dating back to the coal towns and reliance on scripts, a societal gendered standard existed for rural Appalachian men and women in coal mining communities. From this conception, men's and women's perceptions about their roles in the home, in the workforce, and the value of schooling were influenced by this gendered economic staple. Places shape us (Gruenewald, 2003a). Places, however, are constantly and continually interacting with macroplaces, or with the "outside," (Nespor, 2008; Massey, 1994). Thus, places also exist in an interdependence or relations between places. Place in Appalachia houses "the dual realities of the region; cultures are rooted in common traditions and histories, but the area is also part of a dynamic and mobile society" (Terman, 2016). In some areas of rural Appalachia, self-sufficiency is valued and practiced through foraging, growing, hunting, and preserving one's own food. Yet, the seeds they plant, jars they steam, and rifles they use are brought to rural Appalachia entwined in an extensive network of interdependence. 
Some theorists claim that the mobility of globalism creates tensions in the fixity of place (i.e., David Harvey), however others such as Massey (1994) claim that a reactionary notion is problematic because the fluidity of the global may not be anxiety provoking (Cresswell, 2015). Moreover, a fixity of place is problematic in that places are temporally constructed (Coughlin \& Kirch, 2010), do not maintain a single identity, are not solely inward-looking, and attachment to place is not a reduction to the length of tenure or us/them binary (Nespor, 2008; Massey, 1994).

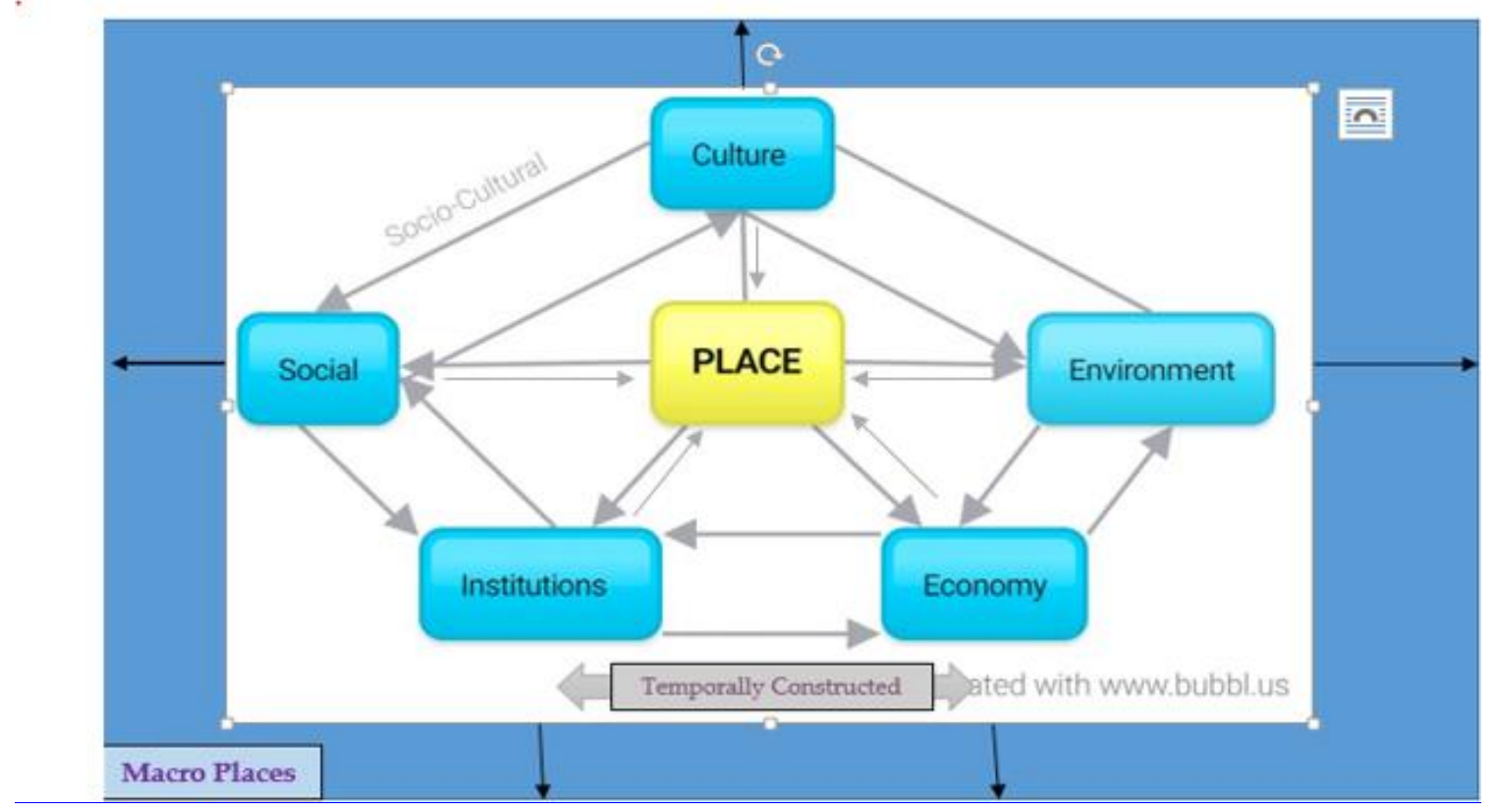

Figure 1: Conception of Place

Beyond the notion of globalization, people are also agents of influence on the places in which they live. People play a role that affects the physical surrounding, the environment, and the shape of the culture and economy as well as the forming of histories (Cresswell, 2015). To return to a coal mining analogy in rural Appalachia, coal companies, and thus people in "places" who work for coal companies have shaped the physical environment (i.e., mountaintop removal), influenced the economy (i.e., recent reduction in mining jobs, thus less local economic stimulus) and impacted the environment (i.e., air pollution). Everything is enacted and occurs in place, "all 
experiences are placed... and places themselves are not inevitable or predetermined, but... they are the product of intended and unintended consequences" (Greenwood, 2013, p. 93, 98). In other words, people and places reciprocally influence each other (Greenwood, 2011).

Unfortunately, stakeholders in today's schools are failing to embrace place in general, much less considering the various ways in which place can be viewed. For example, with its individualistic values and neoliberal agenda, schools neglect the transactional value within place and have a myopic view for the global (macro). The existing intradependence and interdependence within place are disregarded in school curriculum; thus failing to recognize the power of place. Traditionally, schools have often been termed as being "placeless," or isolated to the contexts and culture in which they are situated. In this paper, though I proceeded on the notion that schools are not placeless, but that they sometimes structurally and systematically insulate themselves from the cultural and social space in which they reside. This shift in perspective allowed me to understand rural talented students' experiences and identities both within their school place and outside of school place.

\section{Constructs of Place}

The cyclical interconnectedness of (a) place as pedagogy, (b) place as curriculum, and (c) place as an outcome in the educational context of place-based education are interwoven within rurality and the following discussion. Yet, each is a distinct piece of place; therefore, for a better understanding of the nuances between them, though, each construct is discussed in turn here as a primer.

To begin, place as pedagogy can be understood in two ways. In school, pedagogy is how teachers enact their curriculum - the ideologies, strategies, and practices that are used in the classroom to facilitate learning. Incorporating place as a pedagogy, teachers embrace the local 
and students' identities and the process of learning is rooted in the experiences of various facets of place. Place as pedagogy in curriculum "emphasiz[es] hands-on, real-world learning experiences" (Sobel, 2004) that are experiential and student-centered (Comber et al., 2001; Smith, 2004). Second, place as pedagogy is also conceptualized as the process and practices within families, communities, and culture that essentially teach youth. To analogize place as pedagogy, it can be associated to the bioecological systems theory (Bronfenbrenner \& Morris, 2006) that claimed people are socialized by many influencing factors within their lives. What we learn and how we learn is enacted in the everyday practices of our lives and our places.

Place as curriculum often isolates school learning topics and practices from the historical and current realities of the natural, cultural, political, communal, and geographic aspects of the place in which the students reside. Therefore, place as a curriculum includes "using the local community and environment as a starting place to teach concepts in language arts, mathematics, social studies, science, and other subjects across the curriculum” (Sobel, 2004)

Place as pedagogy and place in curriculum create both academic and nonacademic outcomes. The use of place with academic outcomes increases classroom achievement (Sobel, 2004). Place as "nonacademic outcomes"

helps students develop stronger ties to their community, enhances students' appreciation for the natural world, and creates a heightened commitment to serving as active, contributing citizens." In addition, community vitality and environmental quality are improved through the active engagement of local citizens, community organizations, and environmental resources in the life of the school. (Sobel, 2004, p.7) Pedagogy of place's nonacademic outcomes also includes students' collection of personal, yet culturally influenced, funds of knowledge ([FoK] Moll, Amanti, Neff, \& Gonzalez, 1992; 
Edmonson \& Butler, 2010; Zipin, 2009). Within place-based education the collection, valuing, and inclusion of student's FoK is the focal point of curriculum. Moll et al. (1992) conceptualized FoK as a precise understanding of students' possession of culturally learned knowledge. FoK emphasizes

strategic knowledge and related activities essential in households' functioning, development, and well-being. It is specific funds of knowledge pertaining to the social, economic, and productive activities of people in a local region, not "culture" in its broader, anthropological sense, that we seek to incorporate strategically into classrooms (p. 139).

Students' FoK are directly linked to their identities and cultural capital within their place, homes, and realities. As the following literature review will show, students' FoK are not only ignored in traditional school practices, but often viewed as deficiencies. In contrast, place-based education bridges students' lived understandings or FoK and academic practices. In a placebased curriculum, students' FoK are not seen as deficits in school's valuing systems, instead they are utilized and celebrated within the context of schooling. FoK are the products of place pedagogies, but they also become the focal point in place-based curriculum, illustrating the cyclical and interconnected nature of place pedagogies, curriculum, and outcomes.

\section{Finding "Place: in Schools: What is Place-based Education?}

In a society that is overly concerned with progress and globalized competitiveness and in a school system that is driven by standardized curriculum and high stakes accountability, a consideration of students' current contexts and lived situation are detruded (Gruenewald, 2003b; Slater \& Griggs, 2015; Theobald \& Wood, 2010). Richardson (1987) claimed today's schools function on "standardized knowledge associated with established disciplines, reliance on 
teachers as primary information sources, assessment procedures based on ease of marking and justification, and the control of students" (Smith, 2007, p. 190). Contrarily, place-based education is the antithesis to the one size fits all agenda of current politico ideology. Place-based educators have begun looking towards place for learning opportunities and "once one begins to appreciate the pedagogical power of places, it is difficult to accept institutional discourses, structures, pedagogies, and curriculums that neglect them" (Gruenewald, 2003, p. 641). Place conscious practices are grounded in the values, culture, history, and environment of the local community, and provides a foundation for curriculum development that can span across contexts, across contents, and across abilities (Ayers Paul \& Seward, 2016; Comber, 2016; Comber, Thomson, \& Wells, 2001; Graham, 2007; Greenwood, 2011; Sobel, 2004; Woodhouse \& Knapp, 2000). It can be both a celebration of a place's existence through culture, history, environment, and people (Sobel, 2004), but it can also be an opportunity to problem find and focus. Therefore, a duality of appreciation and transactional learning occurs within place-based education.

Woodhouse and Knapp (2000) claimed that place-based practices (a) emerge from the particular attributes of place, (b) are inherently multidisciplinary, (c) are inherently experiential, (d) are reflective of an educational philosophy that is broader than "learning to earn", and (e) connect place with self and community. Additionally, Azano (2011) and McInerney, Smyth, \& Down, (2011) claimed that place-based practices positively impact teacher practice and student learning.

\section{Emerges from attributes of place.}

While it seems obvious given its name, a place-conscious curriculum "emerges from the specific attributes of place" (Woodhouse \& Knapp, 2000). It is not a curriculum that can be scripted and prescribed, and therefore distributed amongst the masses (Smith, 2002). Places are 
inherently different—no two places are entwined in the same historical story, political experience, or sociological existence. The same can also be said about the spaces within places (Grunewald, 2003). Despite being in the same physical place, students' experiences within place can vastly vary supporting the notion that there is more than one way of knowing place and a sense of place is subjective.

Because knowing and understanding place is subjective (Moll et al., 1992), place-based education must be flexible, fluid, and inherently individualized based on the students' identity constructs (i.e., the degree of connection to place), motivations, interests, abilities, activists or transformative spirits, as well as the individual capital a student may or may not possess. Therefore, place-based education is a framework to root curriculum in the realities of places and the lived experiences, or FoK, of the students. While teachers are still bound to adhere to quality measures and learning standards, place-based educators re-envision the content in which skills are learned. In other words, while still practicing under the same standards the content studied is "specific to the geography, ecology, sociology, politics, and other dynamics of that place" (Sobel, 2004: Woodhouse \& Knapp, 2000, p. 2) and of the student (Moll et al., 1992; Edmonson \& Butler, 2010; Zipin, 2009).

\section{Multidisciplinary.}

Place-based education is inherently interdisciplinary. It naturally transcends theories and contents. All subject matters from art, history, language arts, science, and any other can incorporate a place-conscious perspective. For example, young writers are often encouraged to write what they know, and a focus on place can support literacy development while also promoting awareness of community (Brooke, 2003; Comber et al., 2001). Place-based education can also transcend ability levels because the framework allows for differentiated experiences. 
Students' interests in and connections to place may dictate the level or depth and with which lens (i.e., informative or transformative) they study the specific attributes of place. In fact, in an evaluative review of four place-based education programs, Powers (2004) found that all teachers markedly showed more reliance on interdisciplinary teaching.

\section{Experiential.}

Even in today's standardization, there is a push for student-centered classrooms where students are not passive recipients of knowledge, but are active participants in their learning experiences. Place conscious practices inherently embody this best practice in that students must be actively engaged in the study of place (Comber et al., 2001). In a review of literature, Smith (2002) identified five ways in which place-based education is enacted. First, cultural studies have been a common way to collect the histories of places and people. For example, Smith cites one classroom's collection and use of parents' and grandparents' oral histories working in the mines in rural Appalachia. The stories that students gathered were then published in a journal. This use of place-based education is a type of cultural journalism.

Next, a popular strand in place-based practices is environmental or natural studies. Natural studies look at the local natural phenomena for its curricular foundation. A simple illustration of this would be to investigate local animal habitats as opposed to those animals that reside elsewhere. Additionally, place-based education can be pursued as a real-world problemsolving journey where students and teachers problem find in the school or community, and investigate issues with resolution goals. Another pathway to place-based education identified by Smith is internships and entrepreneurial opportunities where students experience community life through the professionals living it. Moreover, the entrepreneurial opportunities afforded through transformative approaches to place-based education encourage creative production. Lastly, and 
the most comprehensive approach is induction into community processes where such an immersion leads to an active role in decision making. Reviewing Smith's (2002) constructs, Knapp (2005) asserts that all these conceptions of place-based education are examples of "experiential learning because they are situated in the context of community life and involve active student engagement"' (p. 280).

\section{Broader than "Learning to Earn."}

'Global citizenry' is a top hot-button accountability phrase used in schools to justify standardization. Despite its civic connotations, global citizenry embodies competitiveness that pushes the notion to be the 'best' through attainment of capitals such as money and status. The training that happens in schools towards a 'learning to earn' mantra is juxtaposed to collectivist cultures or people, such as specific regions in Appalachia, that do not solely embody this ideal of success (Gore, Wilburn, Treadway, \& Plaut, 2011; Jones, 1994).

Collectivist cultures are noted by strong ties to place, a sense of community, resilient family and kinship relations and values, and emphasize the good of all (Gore et al., 2011; Richards \& Stambaugh, 2015). Not long ago success in rural places was measured by who a person was, such as what they did for others, how integrated they were in their community or familial commitments. Success was judged on the overall 'goodness' of the person (Jones, 1994). Contrastingly, individualistic cultures, like broader America, focus on individual gains and achievements which are valued or at least take prevalence over the good of family or community (Gore et al., 2011). In dominant American culture, monetary accumulation is synonymous with success.

Individualistic routines in school structure, such as how learning is enacted (i.e., individual work, separate grades, competitive spirit) are directly related to how success is 
perceived: as an individual pursuit. The individualistic ideals of schooling often are disconnected from the collectivist ideals experienced in rural Appalachia. In a sense, school is perpetuating the message that if talented students want to fulfill the prophecy of success, they need to reject their community, and collectivist values and embrace dominant culture's individualistic values (Azano, 2011; Theobald, 1997). This message is even further compounded for rural students with talents because of the perpetuation that students with talents have the responsibility to pursue and obtain these individual achievements despite their heritage, despite their collectivist cultural values (Azano, 2011; Gore et al. 2011). As Azano, (2011) points out "there is a perceived trade-off for many rural families in educational attainment: valuing education at the expense of devaluing or undermining community" (p.1). Instead, place-based education pursues a "good life" (Howley, Harman, \& Leopold, 1996) by "prepar[ing] people to live and work to sustain the cultural and ecological integrity of the places they inhabit" (Woodhouse \& Knapp, 2000, p. 2).

\section{Connects place with self and community.}

Place-based education is about connecting outwardly to our immediate places (Sobel, 2004) and then beyond to the inter-relatedness of places (Nespor, 2008), but importantly it is also about allowing an inward look to see how these two visions have worked to create or influence each other. The primary tenet of place-based education recognizes influences between places and people, thus supporting the connection between self, communities, schools, families, and cultures, as well as being multigenerational and multicultural (Woodhouse \& Knapp, 2000, p. 2). The connotation of "community" asserts a homogeny or sharedness. This study looks at community not as a dichotomy to diversity, but inclusive to it. A community as a whole includes 
ideologies and peoples that are consistent, but also those that diverge creating micro and macro communities (Theobald \& Siskar, 2007).

\section{Impact on teacher practice and student learning.}

While still early in its momentum, Mclnerney, et al. (2011) claim that the empirical work on place-based education elevates engagement in the curriculum, increases civic engagement, improves achievement, and encourages an intellectually challenging education. Others claim it promotes sustained motivation, increases performance for students with exceptionalities (Powers, 2004), and place-based education itself acts as a forum in which students can engage in a dialogue of cultural norms (Azano, 2011). Through the use of place-based education in science, there have also been significant gains in students' place attachments and place meanings (Semken \& Freeman, 2008). Further studies using place-based curriculum in a whole school model indicate that teachers have been shown to increase their access to local resources, increase service-learning in their curriculum, teach across contents, collaborate with peers, and more aptly demonstrate teacher leadership and professional growth (Powers, 2004). Because of the potential impact on students' learning and identity constructs, recent literature proposes incorporating place-sensitive curricula and pedagogy in teacher education (Azano \& Stewart, 2015; Azano \& Stewart, 2016; Howley \& Howley, 2005; Hudson \& Hudson, 2008; White \& Reid, 2008).

\section{Concerns with Place-based Practices}

Place-based educators assert that the places we live in are pedagogical and educational and should incorporate these lived experiences in the classroom. Two tenets for critique of place based education include acknowledging that (a) there is a need for a critical lens of place and (b) place-based education is, at times, myopic and romanticized (see McInerney et al., 2011; Theobald, 1997). 
Recent place theorists and researchers have begun to use critical pedagogies of place, a merger of place-based education and critical pedagogy. Gruenewald (2003a) suggests that by bridging complimentary, critical pedagogy, a lens focused on oppression, marginalization and power inequities (i.e., race, class, gender), and place-based education, a practice that uses local spaces and practices as fields of learning, a holistic consideration of conservative and transformative notions emerge. The combination produces a critical analysis with a cultural lens and social critique (Graham, 2007; Gruenewald, 2003a; 2003b). Realized in the classroom, students are asked to critically assess their lived situations, culture, and place, and call in to question dominant or hegemonic practices (Graham, 2007; Gruenewald, 2003a; 2003b).

Even though researchers have begun to examine critical pedagogy of place's value, the literature is sparse on the implications of both place-based education and critical pedagogy of place for rural talented youth. Empirical gifted literature focused on place in the curriculum is in its infancy. Therefore, I chose to frame the study around place-based education, as opposed to critical pedagogy of place, as a foundational springboard into the discussions. Additionally, for teachers new to the ideology of place and critical lensing, place-based education is an entry level, first step towards a curriculum that values place. It is to be noted though that place-based education potentially embeds tenets of critical pedagogy of place with work towards transformative ends; however teacher subjectivity and open interpretations of place-based education does not guarantee this.

A second critique claims place-based education is myopic and romanticized (see McInerney et al., 2011; Theobald, 1997). Although place-based curriculum focuses on the student's immediate ecosphere, it does not assert that learning is capped there. Instead, the curriculum should first be rooted in the student's place, culture, and local contexts (Sobel, 2004). 
Then, from this foundation, global and national knowledge can and should be integrated and built around students' tangible and relatable identities (Smith, 2002). In fact, from a transformative stance, if the local contexts, issues, and consequences are not connected with larger political happenings and other "forces of regional and global dimension [it] means that many well-intentioned efforts to transform communities are doomed" (McInerney et al., 2011, p.

11). Of course, these tenets could be integrated simultaneously, but the consequential message of place-based education is that students' schooling should recognize and value place: their place. From this valuing of place, then larger constructs, political ramifications and global impacts become relatable and situated (Greenwood, 2013). In their observations, Comber et al. $(2001 ; 2016)$ saw just this connection when they observed teachers' use of a pedagogy of place in their elementary classrooms. They noted teachers moved from "the personal, to the local, to the global" in a way that allowed for reflection and practice stemming from the "situated, specific, and the local to more abstract, imagined, hypothetical, and global” (p. 455).

\section{Pedagogy of Place: Combating the "Brain Drain" of Talented Youth}

Rural talented students are groomed to leave their rural places for bigger and better opportunities and often do so (Budge, 2006; Carr \& Kalafas, 2009; Corbett, 2007; Petrin, Schafft, \& Meese, 2014; Staunton \& Jaffee, 2014; Theobald \& Wood, 2010). This leaving, often termed the "brain drain," is defined as the outmigration of talented individuals from their rural communities for postsecondary education or employment opportunities (Artz, 2003; Ayers-Paul $\&$ Seward, 2016; Sherman \& Sage, 2011). Those that leave are often credited as being success stories, and those that remain are lauded as a type of failure (Budge, 2006; Carr \& Kalafas, 2009; Corbett, 2007; Howley et al., 1996; Petrin et al., 2014; Sherman \& Sage, 2011). Pedagogy of place can work to shift this mindset away from people and places as being foregone conclusions 
towards a version of a "happy life", a self-fulfilled life, as well as a successful life, in their rural places (Ayers-Paul \& Seward, 2016; Howley et al., 1996).

\section{Perceptions of Staying and Leaving}

Central, mainstream perceptions of success and the lack of opportunity especially in economically unstable rural places, like rural Appalachia, create a mindset that youths who are academically gifted have the means to get out of their rural areas and find success by way of their academic talent. Higher education is often seen as the stepping stone toward achievement, and local schools often act as agents of mobility and outmigration (Carr \& Kalafas, 2009; Corbett, 2010; Petrin et al., 2014, Sherman \& Sage, 2011).

Illustrating the effects of direct and indirect messaging about talented youth's mobility, one could refer to West Virginia, the only state that is wholly within the Appalachian region, and Kentucky a state that is synonymous with Appalachia--even though only the eastern part of Kentucky is within the Appalachian borders. Within these states, over $83 \%$ and $88 \%$ of adults , respectively, have high school diplomas, a number that is impressive considering the many "at risk" factors (i.e., high concentrations of people who live in poverty and at times generational poverty). On the other hand, the academic capital suggested by high school graduation rates does not translate to higher education. Only approximately $20 \%$ and $23 \%$ of adult residents have college degrees in these Appalachian states (Spotlight on Poverty and Opportunity, 2018). This

discrepancy illustrates (a) the mass exodus of educated youth to other places for educational and economic stability and how educated talented youth do not envision a successful life in their rural hometown or (b) how education is not seen as a valuable resource for those that choose to stay (Burnell, 2003; Corbett, 2007). In fact, between the years 1950 and 2000, West Virginia experienced an almost $-40 \%$ net out-migration (West Virginia Health Statistics Center, 2003 as 
cited in Bell \& York, 2010) and in the last 17 years, Kentucky has seen a 400,000 population decrease (Kentucky Health Facts, 2018). Although the economies of both West Virginia and eastern Kentucky are troubled, economic instability in and of itself is not what pushes students with talents to migrate out. Instead, it is the youth's perception of economic opportunity (Howley et al., 1996; Petrin et al., 2014).

While schools act as agents of mobility by sporting cultural blinders to the places in which they are situated, they may do so unintentionally. Petrin et al. (2014) found that teachers and schools often pushed academically talented students "out" of their home regions; however, this push was in hope of students' gaining education and experience to then bring back to their hometowns and reinvest in their places (Gore et al., 2011). The premise itself is not misguided, but the in-action practicality of talented students boomeranging back to place amongst popular narratives to leave is naive. High achievers do have strong attachments to place, but they are the most likely to leave and the least likely to return to their homes (Carr \& Kalafas, 2009). Students with talents are driven to leave based on perceived economic conditions more so than other external factors (e.g., teacher push) (Howley et al., 1996; Petrin et al., 2014).

Therefore, to bring youth back to place, their perceptions about their place must be shifted. By evaluating the places that one lives in, recognizing the particular, unique, and exceptional aspects that should be conserved as well as critically analyzing aspects that need to be transformed, transfigured, or reconstructed show how place becomes alive and malleable. It becomes a space that can be "remodeled" so youth can foresee a future in their rural place.

In his book Learning to Leave, Michael Corbett (2007) delineated rural Nova Scotian generational outmigration patterns and the disjointed value systems between community life and school expectations, as well as gendered roles within these two systems. In recalling an 
encounter with a former talented student, his recollection illustrated the mindset of "leaving is achieving" in rural places (Bartholomaeus, 2006; Theobald \& Wood, 2010). While reading the below excerpt, imagine if the message this young woman received in her curriculum was that academically talented students could create a space, a successful life, in their small towns. Imagine how this encounter might differ if she had opportunities to learn about the political, historical, economic, or environmental specialties of her place and had been given the tools to become a transformation agent if needed. Unfortunately, she did not have these opportunities and Corbett (2009) remembers:

When I asked her what she was doing, her eyes lowered, and she mumbled that she had, "just hung around home" and was, "doing nothing." She actually apologized to me for not leaving and going on to post-secondary education. She saw her decision to stay as an educational failure. Yet she loved where she was. She was happy to be raising her child in her home community. What she got from her schooling was the message that "smart kids," especially smart girls were supposed to leave. (p.5)

Contrary to popular belief, some talented students want to stay in their rural places (Wright, 2012). Yet, their schooling does not provide a chance to see how they can be successful in their rural places, thus perpetuating the "leave to achieve" mantra (Bartholomaeus, 2006; Theobald \& Wood, 2010).

\section{Shifting Perceptions of Staying or Leaving}

Is it any surprise that talented students choose to leave the places that are ignored and forgotten by the academic institutions in which they are prepared? A pedagogy of place works to shift the ideals that talented students have to fulfill a prophecy of mobility to succeed and also 
transposes the notion that talented rural Appalachians who remain in place must "accept the badluck bargain of low pay, low-status employment as the necessary price of their aspiration to cultivate local roots" (Howley, et al., p.150, 1996). Instead, place-based education not only celebrates the situational, contextual, and individualistic nature of place, but allows for inquiry and problem-based educational opportunities that empower rural learners to work towards sustainable futures for their communities and themselves. To stay in one's hometown, in one's rural place of attachment, is re-envisioned not as a failure or underachievement but as a selfpreserving, purposeful decision.

Our student's first teachers are the places in which they live: the people that surround them, the culture within which they are embedded. However, in current school culture, these learnings are undervalued and marginalized much like rurality is marginalized in American culture (Theobald \& Wood, 2010). Gruenewald (2003a) asserted that "a spatial analysis of schooling reveals that its most striking structural characteristic is the enforced isolation of children and youth from culture and ecosystem" (p. 625). By pushing back against current physical spatial understandings of learning (i.e., in the classroom) as well as ideological spatial understandings (i.e., global citizens), schools can begin to embrace rural identities and rural places. This transformation is not of external, individualistic, and global values or influence, but as hooks noted it is the people who embrace their places rather than assimilate towards the center that repositions themselves socially and opens up possibilities within these margins (as cited in Gruenewald, 2003a). For example, many complexities exist in and about rural Appalachia. Place-based education provides an opportunity for rural Appalachian students to study their culture, through place with a transformative and future-oriented lens allowing their place to be envisioned beyond the stereotypical external perceptions. 
In conclusion, place-based education embraces the often forgotten rural youth, roots learning in lived experiences and knowledge, aligns school and cultural values, and shifts perceptions of the spaces in which talented students can succeed. Because places change and no two places are alike, place-based education must be flexible, fluid, and inherently individualized based on student's identity constructs (i.e., the degree of connection to place), motivation, interest, ability, activist or transformative spirit, as well individual capital or FoK that students may or may not possess. While place-based education provides support for rural students, gifted youth additionally require rigorous curriculum developed with gifted pedagogy. The Enrichment Triad Model is a research-based gifted framework that welcomes place-based practices as a complement to its rigorous inquiry and interest based foundation.

\section{The Enrichment Triad Model}

Gifted Education boasts many research-based models and frameworks to guide gifted programs. The Enrichment Triad Model was chosen for this study because of the model's adaptability to rural contexts, its established credibility, its compatibility with place-based education, and its potential to combat apathy through engagement for rural youth.

The Pre-K-Grade 12 Gifted Education Programming Standards (NAGC, 2010) delineate educators are responsibility for "apply[ing] the theory and research-based models of curriculum and instruction related to students with gifts and talents and respond to their needs by [incorporating]... culturally relevant curriculum and by using a repertoire of evidence-based instructional strategies..." (p. 4). Despite this guiding standard, rural teachers of gifted and talented do not align their programs with research-based gifted and talented frameworks (Azano et al., 2014; Miller \& Brigandi, forthcoming). Further problematic, the frameworks were not designed explicitly for rural places and often do not forgive the complex contextual nature of 
rural gifted programs, the needs of rural teachers of students with talents, or the needs of rural students with talents (Ayers-Paul \& Seward, 2016; Azano et al., 2011; Lewis, 2015). This limits fidelity of implementation (Azano, et al., 2014). To compound the issue, many teachers are unaware of frameworks that support students with talents (Miller \& Brigandi, forthcoming) and research shows that teachers' general knowledge about specific models or best practices in gifted education does not equate to a use in practice (Bain, Bourgeois, Pappas, 2003; Brigandi et al., in press; Davalos \& Griffin, 1999; Starko \& Schack, 1989). The current divide between standards and practice illustrate the need to support teachers in their practice through professional development geared explicitly toward their contextual needs.

Additionally, this study comes on the cusp of research focused on incorporating place into gifted curricula (Ayers-Paul \& Seward, 2016; Azano, Callahan, Brodersen, \& Caughey, 2017). In the absence of gifted frameworks designed explicitly for rural students with talents, Ayers-Paul \& Seward (2016) recently created the Place-Based Investment Model (PBIM) that focuses on five pathways to talent development. While the individual constructs of "talent development pathways" are not new to gifted education, combined they are intended to fulfill the needs of rural talented students and support future success. Similarly, Azano et al. (2017) revised their existing third-grade reading units for academically gifted students to incorporate place. Believing that gifted programs should foster creativity outside of traditional school experiences and encourage purposeful and meaningful productivity, I chose to further this newly researched conception within the Enrichment Triad Model because of the model's inherent ability to incorporate place.

While the Triad's use has not been extensively researched in rural settings, its flexible design encourages such adaptations (Lewis, 2015). The model does not follow rigid, prescriptive 
guidelines and is potentially malleable to a gifted program's time and resource constraints - two noted barriers in rural gifted programs (Azano et al., 2014; Brigandi \& Miller, 2018; Brigandi et al., under review; Miller \& Brigandi, forthcoming).

Moreover, supported by over forty years of research (Brigandi et al., 2016), the Enrichment Triad has been shown to mitigate underachievement in talented youth (Baum, Renzulli \& Hébert, 1995; Emerick, 1995). This accomplishment is crucial because apathy and underachievement are perceived risk factors for rural youth with talents (Budge, 2006; Corbett, 2007; Bartholomaeus, 2006).

In conclusion, the Enrichment Triad Model (see Figure 2) is the curricular foundation for the comprehensive Schoolwide Enrichment Model (SEM). The SEM requires implementation at the school's structural level, but small rural schools are most likely to engage in part-time, pull-out services (Callahan, Moon, \& Oh, 2017; Borland, 2012; Howley, 1986). Therefore, the Enrichment Triad Model, as opposed to the comprehensive SEM, fits within current contexts of the rural gifted program. The Enrichment Triad is one of the most frequently used models in gifted education, is flexible in rural contexts, and supports achievement. The following section will describe the Enrichment Triad model further, the theoretical underpinnings, and conclude with a review of the research on the Enrichment Triad.

\section{Description of the Enrichment Triad}

In The Enrichment Triad Model: A guide for developing defensible programs for the gifted and talented, Renzulli (1977) acknowledged both a strength and a problem within gifted classrooms, generally. Positively, students reported enjoying their time in their gifted class and the freedom they had within the space; however, curricula for these enrichment programs were a motley collection of learning materials and strategies (Borland, 2012). From this Renzulli 
conceptualized a model that encouraged students to expand their horizons (Type I), present opportunities to acquire critical, creative, and problem-solving skills as well as general how-to skills (Type II) and provide the freedom and support to act as mini-professional, creative producers (Type III). The Enrichment Triad is the curricular foundation for the comprehensive Schoolwide Enrichment Model (SEM; Renzulli \& Reis, 2014, 1997). First designed for gifted programs, the Triad has been integrated into the SEM to promote enrichment opportunities and strengths-based approaches schoolwide and to all students.

The original Enrichment Triad and its morphism into the Schoolwide Enrichment Model (SEM) were initially specific to student interests and strengths but void of content specificity (Renzulli, 1977; Renzulli \& Reis, 1997; 2014). Today, the SEM and thus the Enrichment Triad has been conceptualized in domain-specific contexts such as mathematics (Gavin \& Renzulli, 2018) science (Heilbronner \& Renzulli, 2015), social studies (Brigandi, Waterson, Waicunas, \& Renzulli, 2018a), reading (Reis, Fogarty, Eckert, \& Muller, 2008), art (Bensen, 2014) and infused with technology (Housand, Housand, \& Renzulli, 2016). Moreover, the Enrichment Triad has been combined with other evidence-based pedagogical practices (Newman, 1991) to strengthen the goal of meaningful, long-lasting learning experiences. 


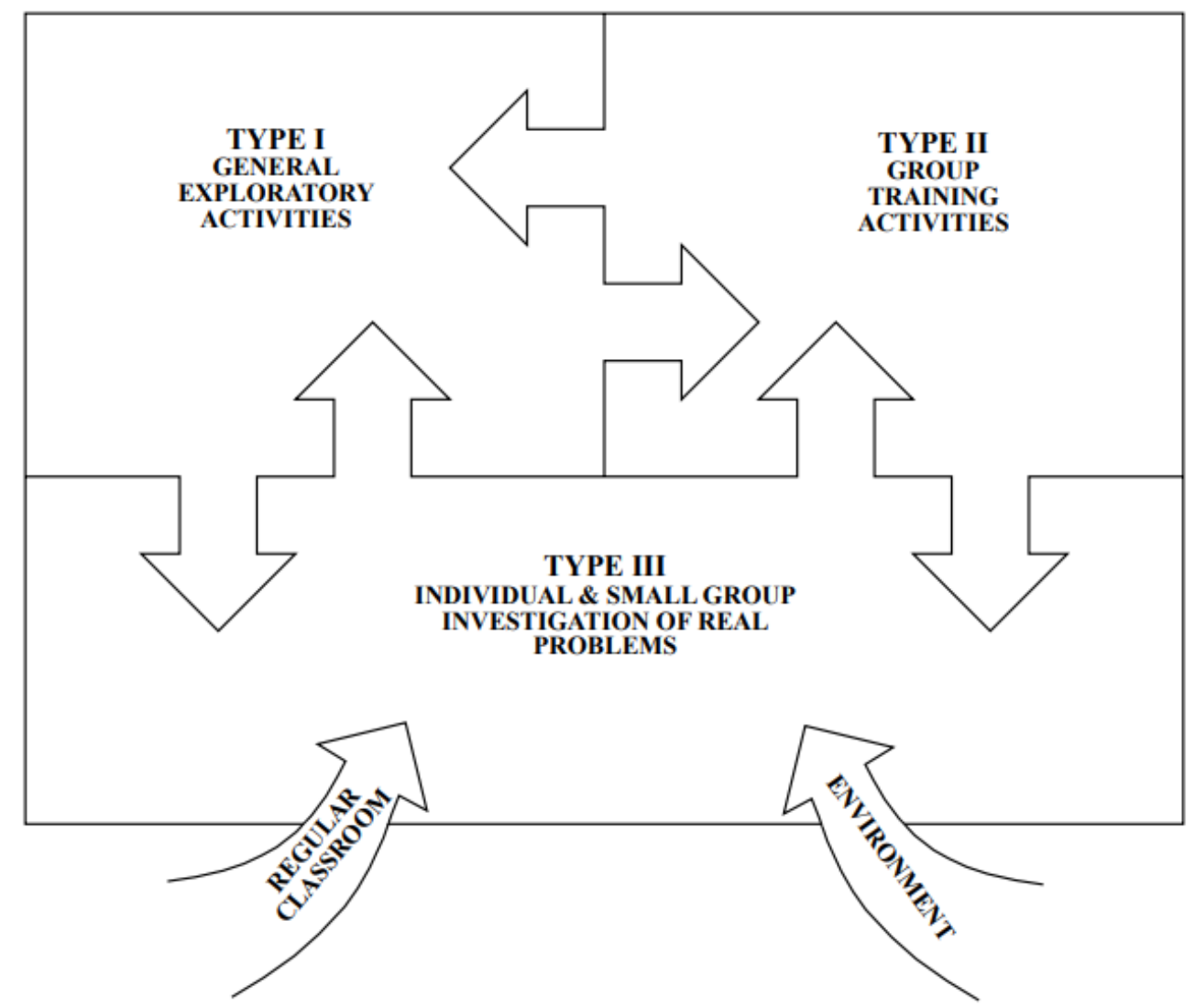

Figure 2: The Enrichment Triad Model. From The Schoolwide Enrichment Model: A How-to

Guide for Talent Development (3rd ed., p. 50), by J. S. Renzulli and S. M. Reis, 2014, Waco, TX: Prufrock Press. Copyright 2014 by Prufrock Press. Reprinted with permission.

Foundational to the Enrichment Triad are three distinct types of experiences that students engage in called Type I, Type II, and Type III experiences (Renzulli, 1977; Renzulli \& Reis, 1997; 2014). While all students engage in Type I and Type II experiences, Type III's are reserved for when students' interests and motivations are met with an equally strong desire to pursue the topic or problem. Next, each Type will be described in turn.

\section{Type I Enrichment}

Type I enrichment consists of general exploratory experiences to broaden students exposure to various experiences (Renzulli, 1977; Renzulli \& Reis, 1997; 2014). It is through this 
exposure that student interests are sparked or created and thus "Type I Enrichment serves as the 'launching point' for many students to further enrichment" (Renzulli \& Reis, 2014). Examples of Type I experiences include listening to speakers, watching demonstrations or films, reading the newspaper, engaging in learning centers, or going on field trips. Renzulli \& Reis (1997; 2014) suggest that in deciding what topics to explore for Type I's, it is worthwhile to ask students "What are some things that you are wondering about?" (1997, p. 122) or to give them an interest survey (i.e., If I Ran the School Survey) that illuminates their current interests. After students are exposed to and experience a Type I, the teacher and student meet and discuss student's enjoyment of the activity and the degree of interest in future learnings on the topic.

\section{Type II's}

While Type I activities are meant to capture, create or stimulate a student's interest, Type II endeavors are building skills that "move [students] from inspiration to action" (Renzulli \& Reis, 2014; p. 28). In other words, Type II experiences are skill-building experiences that are needed to conduct independent, in-depth inquiries and investigations (Type III). Type II skills can be applied across a variety of domains and focus on different thinking and feeling processes. Type IIs include general skill building such as cognitive and affective training, learning "how-tolearn" skills, using advanced research skills and reference materials, and developing communication skills. As with all parts of the Triad, this step is reflexive to the needs of the students and can be planned or emerge as a scaffolding to Type I or Type III experiences.

\section{Type III's}

Generally, Type I and Type IIs are group training activities while Type IIIs shift from a collective experience to specific, individualized or a small group endeavor. Not all students, at every opportunity, engage in Type III pursuits. Instead, when a student has a devout interest in a 
topic and commits to pursuing it, they will then engage in Type III productions. Renzulli and Reis (2015) have likened this process as "thinking, feeling, and acting like a practicing professional" (p. 154). Key concepts that underline a Type III include (a) "personalized learning by doing" (b) a "real purpose applied to production of a real product for an authentic audience" (c) transitions the "lesson learner to a first-hand inquirer" and (d) "synthesis and application of content, process, and personal involvement" (Renzulli \& Reis, 2015, p. 154).

Type III pursuits are tailored or personalized for each student based on their strengths, interests, and learning preferences and students learn by engaging in the process. Research has shown that individuals do not maximize their learning in traditional teacher-centered lecture models with most retaining a mere $15 \%$ of what they have seen or heard. However, when information is "personally experienced and practiced that understanding [is] increased to $80 \% "$ (Gibson \& Efinger, 2001, p. 52 referencing Jensen, 1996). Additionally, student products are authentically purposeful. Students do not write a report to be viewed only by the teacher or class. In a Type III investigation, students consider the audience at the outset with the purpose of making an impact on the intended audience. For example, if a student was working to preserve a playground slated for commercial building plans, the audience for this project might be the city council. Also, a Type III endeavor transitions the student from a lesson learner to a first-hand inquirer. Type IIIs inquests are not bound by teacher directed purposes with prescribed answers (i.e., produce a report on the Spanish Inquisition); instead students decide what questions need to be asked and ask questions without unilateral answers all the while seeking a purpose beyond "finding out about..." (Renzulli \& Reis, 1997, p. 235). Lastly, students formulate ideas and gather raw data. Similar to acting professionals, they synthesize and apply content while positioning themselves as stakeholders in the matter, as opposed to distant reporters. As Delcourt 
(1988, 1995) discerned, students transition from being consumers of knowledge to producers of knowledge.

\section{Theoretical Underpinnings of the Enrichment Triad}

\section{Constructivist Foundation}

The Enrichment Triad is built on a constructivist foundation. "Constructivism...points up the unique experience of each of us. It suggests that each one's way of making sense of the world is valid and worthy of respect as any other" (Crotty, 1998, p. 58). The Triad's foundation supports the notion that meaning-making is a personal and subjective experience. Students engage in experiences that are interesting to them and participate in Type III's that require personal meaning-making. A student's personal "truth" within their Type III experiences is subjective to their own (pre)conceptions and contexts, the lens they bring to the project (i.e., transformative), and other influences on their construction of knowledge. In summarizing how constructivism is embedded in the Enrichment Triad, Gibson and Efinger (2001) state the Triad is

[b]ased on the principles that each learner is unique, learning is more effective when it is enjoyed, learning is more meaningful when it is within the context of a real problem, and that knowledge results from students' own construction of meaning. The belief that students learn best when they are actively engaged in the learning process reflects the constructivist theory of learning (Gomez, 1996). The constructivist principles of instruction focus on enabling students to construct and use problem-solving strategies to develop their own meaningful understanding of ideas (Casareno et al., 1997). (p.51)

\section{Three Ring Conception of Gifted Behaviors}


The field of gifted education is wrought with a nonconsensus on the conception of "giftedness" (Plucker, Burroughs \& Song, 2010; Renzulli, 2002; Sternberg \& Davidson, 2005). There is not one overarching endorsed definition of giftedness in academia or practice (Plucker, et al., 2010; NAGC, 2015; Renzulli, 2002; Sternberg \& Davidson, 2015). While federal policy has tried to conceptualize and define what giftedness means in the public schools (Elementary and Secondary School Act, 1965; No Child Left Behind Act, 2001; Every Student Succeeds Act, 2015; NAGC FAQ, n.d.), states and districts are not bound by this definition which creates an even more fractured understanding of giftedness in schools (NAGC, 2015). For example, in Appalachia, the areas of giftedness addressed in policy in Kentucky includes intellectually gifted, academically gifted, specific academic areas, leadership, performing/visual arts, creatively gifted, with considerations of typically marginalized groups such as those of low SES, underachieving, geographically isolated/rural, culturally/ ethnically diverse, and disabled gifted, and ESL / ELL. In contrast, Virginia includes only intellectually gifted, academically gifted, the performing visual/arts, and a vague category of "other" whereas West Virginia's areas of giftedness are capped by the intellectually and academically gifted (NAGC, 2015). This disparity has led to a heavy reliance on traditional recognitions of giftedness (i.e., intellectually gifted; Callahan, Moon, \& Oh, 2017) and traditional measures of intelligence quotients (IQ) as determinants of giftedness (Azano et al., 2017; NAGC state definitions page, 2015; Miller \& Brigandi, forthcoming; Renzulli, 2002; Renzulli, 1982; Renzulli \& Reis, 2014). The problem is that to value IQ as the predominant determinate or measure of giftedness creates a false assumption that giftedness and IQ are one in the same (Renzulli, 1982).

Problematizing this idea that giftedness is a static, intrinsic, cognitive concept that has no temporal or contextual bounds, Renzulli (1978) began studying creative and productive people 
who achieved success in their given fields. Born from the findings, was his theory of Three Ring Conception of Giftedness (See Figure 3). Here Renzulli (1978) and later Renzulli and Reis, (1997, 2014) assert(ed) that it is the intersection of task commitment, creativity, and above average ability that produce gifted behaviors. It is the presence and interaction of all three traits, and not necessarily an equal distribution amongst the traits that produce gifted behaviors. In other words, Renzulli (1977) recognized that a student's gifts need not lie solely in the academic sphere or as an intrinsic quality. This newer understanding of how the behavior of giftedness is manifested through the intersection of creativity, above average ability, and task commitment, giftedness then is seen as "manifested in performances, rather than in test scores" (Delcourt, 1995). The following section will explore each of the intersecting spheres within the Three Ring Conception of Giftedness.

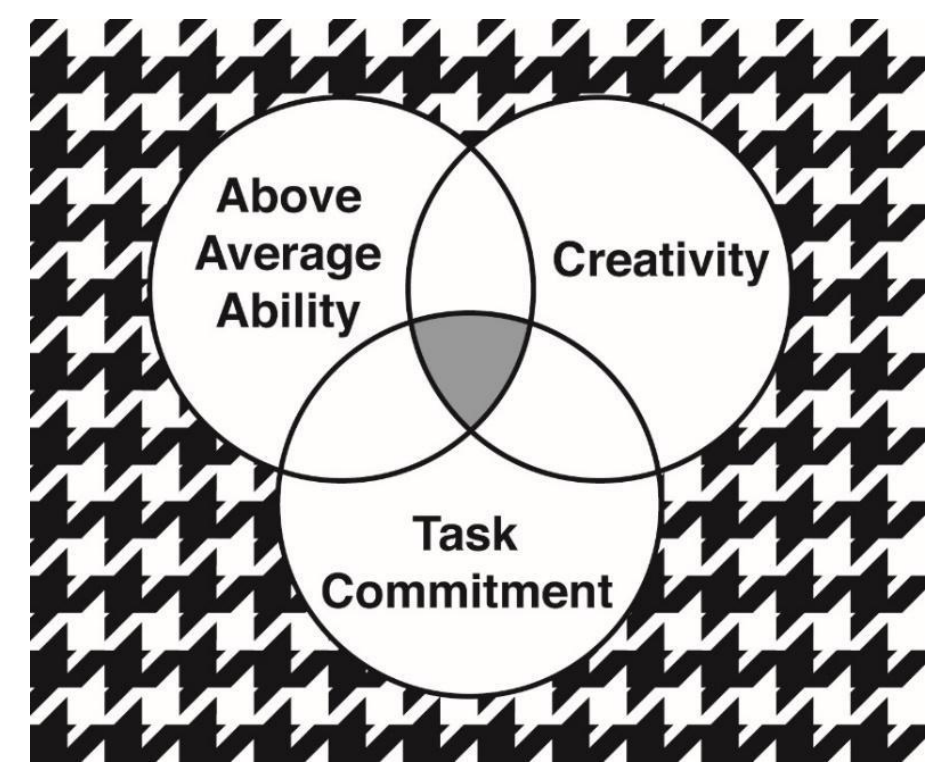

Figure 3.Three-Ring Conception of Giftedness. From The Schoolwide Enrichment Model: A How-to Guide for Talent Development (3rd ed., p. 22), by J. S. Renzulli and S. M. Reis, 2014, Waco, TX: Prufrock Press. Copyright 2014 by Prufrock Press. Reprinted with permission.

Task commitment is the "grit" applied to any given task. It is the willingness and fortitude to not only put forth effort but to sustain that effort for the duration of the task or 
activity. To support their inclusion of a non-intellectual cluster in the trait manifestation, Renzulli and Reis (1997) claimed there was a limited relationship between academic ability to creative/productive accomplishments, but constructs such as task commitment have repeatedly been present in highly productive people. A student can demonstrate task commitment in academic and theoretical conceptions, but he or she can also demonstrate it within practical or real-world engagements. Rural talented students often demonstrate higher task commitment in the latter (Helton, 2010).

The second trait in the cluster, creativity, "encompasses curiosity, originality, ingenuity, and a willingness to challenge convention and tradition" (Renzulli \& Reis, 2014, p. 24). The old phrase "thinking outside the box" articulates common views of creativity but creativity is also thinking "within the box" amidst structural, ideological, and contextual restraints. Therefore, creativity "is the ability to produce work that is both novel (i.e., original, unexpected) and appropriate (i.e., useful, adaptive concerning task constraints) (Sternberg \& Lupart, 1999, p.3). Although, traditionally understudied (Sternberg \& Lupart, 1999; Sternberg, 2006), Sternberg (2006) claimed creativity is neither domain specific nor domain general. Instead, it contains elements of both. General skills can be applicable across domains and individuals making creative contributions need to develop knowledge and skills with a specific domain (Type II's). Creativity can be developed to some degree (Type II \& Type III) and is often theoretically praised but practically ignored, especially in schools. In other words, there is little debate about the value of creativity (i.e., economic development relies on it) (Sternberg, 2006); however, curricular practices in schools tend to inhibit students' creative productivity.

The final trait and the most associated with cognitive representation is above average ability. In this case, though, above average ability can take on two definitions. First, general 
ability, or the "capacity to process information, integrate experiences that result in appropriate and adaptive responses in new situation and engage in abstract thinking" (Renzulli \& Reiss, p. 5, 1997) most closely aligns with traditional understandings of giftedness because of its association to tests of intelligence (Renzulli, 2005). Renzulli (2005) cites "verbal and numerical reasoning, spatial relations, memory, and word fluency" (p. 259) as examples of general ability. Specific ability is the application of general abilities to specialized areas of knowledge or performance. Achieving specific ability allows one to evaluate relevant information in conjunction with a process or product (Renzulli \& Reis, 2014). Renzulli (2005) claims:

[e]xamples of specific abilities are chemistry, ballet, mathematics, musical composition, sculpture, and photography. Each specific ability can be further subdivided into even more specific areas (e.g., portrait photography, astrophotography, photo journalism, etc.). Specific abilities in certain areas such as mathematics and chemistry have a strong relationship with general ability and, therefore, some indication of potential in these areas can be determined from tests of general aptitude and intelligence. They can also be measured by achievement tests and tests of specific aptitude. Many specific abilities, however, cannot be easily measured by tests, and, therefore, areas such as the fine and applied arts, athletics, leadership, planning, and human relations skills must be evaluated through observation by skilled observers or other performance-based assessment techniques. (p. 260)

This type of knowledge is what active professionals require in their fields to be creative and productive in their specific areas (Type III's). In the Three Ring Conception of Giftedness, ability comprises both general and specific abilities. 


\section{Research on the Enrichment Triad}

A review of the literature concluded that researchers of the Enrichment Triad have (a) urged for an adherence to the model's structure, (b) illustrated positive self-efficacy developments, (c) showed a relation between creative productivity and Type III productions (d) documented its influence on students' post-secondary and career goals (e) highlighted the Triad's influence on academic and general life skills (f) explored the role of interest in Type III's and (g) gave a glimpse into the teacher's role and influence within the model. Each of these themes will be further discussed in turn.

\section{Adherence to the Structure.}

Many gifted programs incorporate project and problem based learning in their curriculum and the Enrichment Triad Model fosters this learning in its Type III investigations (Renzulli, 1977; Renzulli \& Reis, 1997, 2014). The critical difference within the model is that students are engaged with Type I and Type II processes both prior and during Type III investigations (Renzulli, 1977; Renzulli \& Reis, 1997, 2015). Research has illustrated the importance of the structure and proposes fidelity to the model for the benefit of students and the quality of their products (Burns, 1990; Delcourt, 1988; Gubbins, 1982; Newman, 1991; Stedtnitz, 1985, 1986). 'Structure' is loosely termed here because the Triad is inherently flexible and reflexive to contextual and student needs. The literature is clear, though, the totality of the model best supports student growth (Burns, 1990; Delcourt, 1988; Gubbins, 1982; Newman, 1991; Stedtnitz, 1985, 1986).

\section{Self-efficacy.}

The relationship between self-efficacy and Type III's has also been evidenced in the literature. Some studies have shown that engagement in Type III products is interrelated to self- 
efficacy and that the higher a student's self-efficacy, the more likely they are to engage in Type III's. Reciprocally, the more students engage in Type III's, the stronger their self-efficacy in creative, productive tasks (Burns, 1990; Schack, 1989). As Stedtnitz $(1985,1986)$ found, participation in other parts of the model, such as Type I experiences, in and of itself does not increase creative, productive self-efficacy. Instead, as stated above, it is the interrelation of the three constructs, and an opportunity to succeed in self-selected interest based Type III's that fosters improved feelings towards self and school in general (Brigandi et al., 2018; Starko, 1986, 1989).

\section{Creative Productivity and Type III.}

Inherently, Type III fosters creative productivity, and the research illustrated a positive relationship between Type III endeavors and creative/productive activities. Students who participated in Type III's were more likely to engage in independent creative productivity both in and out of school (Burns, 1990; Delcourt, 1988; Starko, 1986, 1988). Also, school became meaningful when students perceived their academic activities as beneficial to their self-initiated, out of school, creative productivities (Emerick, 1995). Moreover, longitudinal studies indicated students who were active, creative producers in school became creative producers as adults (Delcourt, 1988, 1993; Hébert, 1993; Westburg, 2010) and characteristics found in successful creative producing adults were similar to those found in highly creative students (Delcourt, 1988).

\section{Post-Secondary and Career Goals.}

The Enrichment Triad has also been shown to positively influence students' postsecondary and career goals (Delcourt, 1988, 1993; Hébert, 1993; Starko, 1986, 1988; Taylor, 
1992). In his retrospective study, Hébert (1993) revisited students who had participated in the Enrichment Triad ten years prior and found that their post-secondary plans evolved from their Type III interests. Illustrating this sentiment, he reported that "a young girl worried about endangered species remained concerned about global and environmental issues in her college coursework" (Hébert, 1993 p. 25). In similar findings, other studies indicated positive associations towards post-secondary and career possibilities after completing Type III projects (Delcourt, 1988; Haensley, 1997; Starko 1986, 1988; Taylor, 1992).

\section{Academic and Life Skills.}

The Enrichment Triad's highly personalized, strengths and interest-driven conception has been shown to positively influence academic achievement and life skills. Study skills (Starko, 1986, 1989), work habits (Baum, 1988; Starko, 1986, 1989), strategic planning (Hébert, 1993), and all-around general skills (Delcourt, 1988) improved through student participation in the Enrichment Triad. Moreover, because the Triad is student-centered and student-driven, learning became meaningful, applicable, and life-long (Hébert, 1993; Starko, 1986, 1989; Westburg, 2010).

Engagement in Type III endeavors has been shown to increase academic achievement (Baum, 1988) and mitigate underachievement (Baum, et al., 1995; Emerick, 1995). Studying ten students with academic talents who reversed their underachievement, Emerick (1995) noted that when students could see a connection between their interests and school curriculum or activities, they were more apt to apply themselves. Moreover, when activities in school seemed directly beneficial to the student's endeavors outside of school, they viewed these learnings as meaningful and thus increased their motivation to achieve. In similar findings, 17 underachieving students who participated in Type IIIs, demonstrated increased academic achievements (Baum et 
al., 1995). A year later over $85 \%$ of study participants were no longer considered underachieving. If we consider Delcourt's (1988) postulate that creative, productive students are internally motivated to engage in self-selected, interest-based activities, like Type III's, but externally motivated in traditional school-based activities, then the findings illustrated above may not be surprising, but they are encouraging.

\section{Interest.}

A foundational tenet of the Enrichment Triad is that students' personal and individual interests drive a Type III project. Many researchers have examined different facets of interests within their studies (Brigandi et al., 2016; Delcourt, 1993; Gubbins, 1982; Hébert, 1993; Starko, 1986; Stedtnitz, 1985, 1986; Westberg, 2010). These studies have shown that Type I's increase a student's general range of interests (Stedtnitz, 1985, 1986), involvement and success in the Enrichment Triad increases academic interest and attitude towards school (Brigandi et al., 2018b; Starko, 1986, 1988;), and students' interests exhibited in Type III's were relative to subsequent interests in the future (Delcourt, 1993; Hébert, 1993; Westberg, 2010). While Gubbins (1982) found the degree of interest in a topic as an indicator of student Type III completion, Brigandi et al. (2016) identified that the type of interest also impacted the perceived value of Type III processes for students. For example, in their study of 10 gifted secondary school students, Brigandi et al. (2016) found two types of interests, longitudinal and identity-related interests, fostered a belief of beneficence, enjoyment, and sustained interest after project completion. In contrast, students who engaged in Type III projects based on emergent or newly formed interests reported lower levels of beneficence and lower interest. 


\section{Teachers.}

In gifted education literature, research focused on teachers of students with talents was sparse (Graffam, 2006) and such was the case within research on the Triad. In a recent trend though, Brigandi et al. (in press) have begun to rectify this absence. In a longitudinal case study bound by one teacher's elementary school gifted education classroom, Brigandi et al. (2019) explored how a teacher's participation in a yearlong professional development (PD) on the Enrichment Triad influenced change in her beliefs and practices. The results indicated that the PD successfully increased the teacher's understandings of gifted education, fostered flexibility toward change, and supplemented her instructional strategies. However, the teacher's knowledge of the model and her belief in its efficacy was not enough to change her practice (Starko \& Schack, 1989).

Although other studies have not directly addressed teachers of the gifted at the outset of their research, findings related to the Enrichment Triad have illustrated the teacher's importance (Brigandi et al., 2018b; Emerick, 1995). Teachers have been shown to be the most influential factor in reversing underachievement in academically gifted students (Emerick, 1995). Also, students who successfully completed a Type III project, had positive environmental perceptions Influential to these perceptions are teachers. Teachers who foster affective and cognitive development and self-regulation within the Triad create environments that support student success, (Brigandi et al., 2018b).

Like Brigandi et al. (2016) note, there has been a scant amount of research within the last few decades on the Enrichment Triad. The void of research, however, is not to be misconstrued that the model is irrelevant in today's programs and practices. In contrast, the model itself is widely used but currently nestled within a larger schoolwide framework (SEM). Formulating the 
theory that "a rising tide lifts all ships." Renzulli (1997) hypothesized that a strengths-based pedagogy like his Enrichment Triad, would benefit all students, thus the development of the Schoolwide Enrichment Model (Renzulli \& Reis, 1997, 2014). As Burns noted, the Schoolwide Enrichment Model (SEM) is well-known today and incorporated in thousands of schools both nationally and internationally (as cited in Reis \& Renzulli, 2003; Renzulli \& Reis, 2014). The SEM is complex and multilayered both in its support resources (i.e., Resources and Forms) but also in its embedded theory (i.e., Enrichment Triad). Although the Enrichment Triad is a foundational aspect to the SEM, current research has shifted away from the Enrichment Triad as a stand-alone entity and either focused on the SEM as a whole or newer aspects of the model such as SEM for reading. The systematic and structural shift that would need to happen to implement the SEM is beyond the scope of this research, but the use of the Enrichment Triad in the existing structures in a rural gifted program was both valuable and attainable.

\section{Merging of Place-Based Education and the Enrichment Triad}

The Enrichment Triad and place-based education, seemingly divergent in purpose and theory, are in fact comparable in the actualization of knowledge, student-centered and driven curricular development, teacher roles within the frameworks, the permeability of community and school, and the student's role of a mini-professional within the field of study.

In both frameworks, knowledge is not assumed to be possessed by an ultimate other (i.e., teacher) and the student a recipient of that knowledge. Instead, knowledge is created through inquiry, problem-solving, and a synthesis of ideas. In other words, the student transitions from being a consumer of knowledge to a producer of knowledge (Renzulli, 1997, 2014; Smith, 2002). This curricular transition also enables teachers to shift toward a facilitator's role (Smith, 2002). As facilitators, teachers guide students towards appropriate resources and provide students with 
opportunities to build the "skills and disposition of effective learner(s)" (Renzulli, 1977; Renzulli \& Reis, 1997; 2014 Smith, 2002, p. 593).

Smith (2002) noted that in place-based education "students' questions and concerns play a central role in determining what is studied" (p. 593). Student interests are what drive curriculum in place-based education which is also a core foundation for The Enrichment Triad Model (Renzulli, 1977; Renzulli \& Reis, 1997, 2014).

Table 1 Place-based Education and the Enrichment Triad Complimentary Chart

\begin{tabular}{|c|c|c|}
\hline & $\begin{array}{l}\text { Place-Based } \\
\text { Education }\end{array}$ & Enrichment Triad \\
\hline Teachers as facilitators & Potentially & Yes \\
\hline Flexible for Individualized Study & Potentially & Yes \\
\hline Student producers of knowledge & Potentially & Yes \\
\hline Driven by student interest & Potentially & Yes \\
\hline Student centered & Potentially & Yes \\
\hline $\begin{array}{l}\text { Engagement with the local (i.e. } \\
\text { culture, community, environment, } \\
\text { politics) }\end{array}$ & Yes & Potentially \\
\hline $\begin{array}{l}\text { Stakeholder inclusion (beyond } \\
\text { student and teacher) }\end{array}$ & Yes & Yes \\
\hline Real life simulation & Potentially & Yes \\
\hline Purposeful Products & Potentially & Yes \\
\hline Fosters Inquiry & Yes & Yes \\
\hline $\begin{array}{l}\text { Relevant to students lives and } \\
\text { identities }\end{array}$ & Yes & Potentially \\
\hline Meaningful & Yes & Yes \\
\hline $\begin{array}{l}\text { Transformative/Problem Solving } \\
\text { Purpose }\end{array}$ & Potentially & Yes \\
\hline Higher Order Thinking Processes & Potentially & Yes \\
\hline Multidisciplinary & Yes & Yes \\
\hline
\end{tabular}

In both models, creating and facilitating a relationship with the community is an essential component of successful implementation. These models are not meant to be enacted in the confines of a classroom with resources capped at textbooks and the internet. It is the permeability 
between school and the community (both human and nonhuman), that sets these models apart from insulated, decontextualized efforts of a curriculum. A most crucial component for both models is the student assuming the role of a mini-professional within the context. In most reallife scenarios, professionals do not rectify issues with easy answers and solutions. Issues are not solved at the end of the day and often requires many hours of brainstorming, collaboration, and labor. These models support real-life simulation and require products, just like a professional, to be shared with project stakeholders (Renzulli, 1977; Renzulli \& Reis, 1977; 1997) and the work is "assessed the same way as the work of any person is assessed: on the basis of its competence and its contribution to community well-being and sustainability" (Smith, 2002). Even though the formulation of each model differs in theory, the goals and in practice application of each are complementary in supporting student growth through collaboration with practicing professionals in real contexts, for a real purpose (See Table 1).

One final note to conclude the chapter, this review of literature does not contend placebased education and the Enrichment Triad are strictly for students identified as gifted and talented. In fact, this type of contextualized learning is crucial for all students thus, , "a rising tide lifts all ships." (Renzulli \& Reiss, 1997; 2014). Yet, because of the complexities of rural gifted education programs, the conflicting cultural values and messages of success and the lagging support for teachers of the gifted and talented (Azano, et. al., 2014; Brigandi \& Miller, 2018; Miller \& Brigandi, forthcoming), using the places we know as a foundation for challenging learning experiences can provide a pedagogical foundation for rural gifted programs where now none exist. It can shift thinking about a curriculum for the gifted in rural places from 'finding a lesson on the internet,' to using students' lived experiences and interests in the places they inhabit for conservatory or transformative purposes. Place-based education and the Enrichment 
Triad provides opportunities to pursue real-world, problem-based undertakings and inherently embeds tasks and thinking requirements that are sustained over time and in meaningful ways.

\section{CHAPTER 3: METHODOLOGY}

Rural Appalachian talented youth and their teachers experience complexities specific to rurality. Teachers in rural places report feelings of isolation (Azano, et al, 2014; Burton, Brown, Johnson, 2013) and are placed in service without adequate preparation or professional learning opportunities specific to gifted education (Brigandi \& Miller, 2018). In fact, most in-service trainings fail to consider pedagogical, curricular, or social and emotional needs specific to talented students (Brigandi \& Miller, 2018; Callahan et al., 2017). Moreover, talented youth in rural Appalachia are confronted with narratives of "othering" (Lewis, 1999; Shapiro, 1978). The places where rural talented students live are silenced in curricula by precedence of urban life or romanticized versions of rural life (Corbett, 2007; Theobald \& Wood, 2010). At the same time, a not so hidden curriculum perpetuates the notion that "leaving is achieving" (Bartholomaeus, 2006; Corbett, 2009; Theobald \& Wood, 2010) and the acquisition of success for many means that talented students leave their home place.

Therefore, the purpose of this study was two-fold. First, I aimed to answer rural gifted education teachers' calls for curricular support. Gifted teachers in one rural Appalachian county engaged in two professional development (PD) sessions. The sessions focused on Renzulli's Enrichment Triad Model, a research based enrichment framework for gifted students, and placebased education, an approach to curriculum rooted in local contexts. Of the twelve teachers invited to the sessions, one teacher participated in the study. The participating teacher was asked to integrate what she learned in the PD session into her classroom. In studying the participant, I sought to understand her experiences as she made sense of and implemented the models in her 
classroom. A second focus of the study was to explore the use and value of place in curriculum. Place-based education advocates contend that integrating place in curriculum allows students to explore the places they live and love (Sobel, 2004) and provides opportunities for some to take up transformative learning, skills, and action to re-envision their Appalachian place(s) (Wright, 2010). Under this assumption, place-based curricula narrows the gap between the collective valuing of community, noticeable in some rural Appalachian communities, with the oft individualistic valuing of school (Gore, et al., 2011). Therefore, I sought to understand the value of incorporating place in a gifted curriculum.

The research questions that guided this study included:

1) How does one teacher of a small rural Appalachian pull-out gifted programs make sense of the Enrichment Triad Model and how does she use it in her classroom and curricular development?

2) How does a teacher's use of place and the Enrichment Triad influence teaching and student learning in a rural Appalachian gifted classroom?

3) How does place influence a gifted program's structure and enactment in a rural Appalachian school?

Two research questions were adjusted in the analysis phase. First, research question number three, was conceived after analysis revealed themes prevalent about the gifted program in its rural place. These themes did not work to answer the original research questions, but were pertinent findings in understanding the gifted program in context. Thus, the research question, "How does place influence a gifted program's structure and enactment in a rural Appalachian school?" was added post hoc. Secondly, place-based education's and the Enrichment Triad's compatibility (see Table 1), and how the teacher conceptualized the 
models in practice teased out each one's respective influence in data analysis. Therefore, the original research question that began with "How does a teacher's use of place..." was amended to "How does a teacher's use of place and the Enrichment Triad . ." to include the conjoined influence on learning.

The rest of the chapter highlights the theoretical perspective that guided the research, the context of the study in place and time, participant criteria and find processes, data collection methods and analysis, as well as efforts towards trustworthiness.

\section{Theoretical Perspective}

Because this study aimed to explore the stories and experiences of a teacher and her students, a qualitative design was most fitting. As Merriam and Tisdell (2015) note, "qualitative researchers are interested in understanding how people interpret their experiences, how they construct their worlds, and what meaning they attribute to their experiences” (p. 6). I am not only concerned with reporting outcomes such as "what happened," but also in understanding the experiences and perceptions of what happened as recounted in the stories of the participants (Sparkes \& Smith, 2008). In addition, a qualitative design also allowed for an inductive approach to the research (Merriam \& Tisdell, 2015), where theory was built within the confines of the data and emerged in process. Moreover, in using a qualitative design, I assumed that I was not an objective outsider to the research, but that I was the "primary data collection instrument" (Merriam \& Tisdell, 2015; Patton, 1999; Saldaña, 2011, p. 32). Therefore, I could be “immediately responsive and adaptive" (Merriam \& Tisdell, 2015, p. 16) to the shifts and needs of the study that arose during data collection. Lastly, the qualitative approach embraced a multiple truths paradigm influenced by the contexts in which it was situated and the perspectives of the participants. "Knowledge is constructed within the individual, rather than something 
outside of oneself waiting to be discovered" (Saldaña, 2011, p. 23). In other words, I was not trying to unearth an objective, "one truth" (Crotty, 1998), rather, I was interested in truths that were continually constructed, deconstructed and reconstructed and, thus, in flux.

Rejecting a "one truth," I took up a constructionist epistemology in this research. Constructionism, an epistemology in direct opposition to traditional, and often, dominant positivist views, asserts "all knowledge, and therefore all meaningful reality as such, is contingent upon human practices, being constructed in and out of interaction between human beings and their world, and developed and transmitted within an essentially social context" (Crotty, 1998, p. 42). Therefore, truth was determined as the interaction between the person and the object and not something that was already in existence to be discovered (Crotty, 1998). Constructionism does not solely lie in subjectivism or objectivism, instead it relies on "intentionality" or the interaction between the subject and object (Crotty, 1998). Thus, meaning was only constructed in the relations between person and object.

While constructionism provides the epistemological foundation for this study, my theoretical framework was informed by [social] constructivism. A constructionist epistemology influences two dominant paradigms: social constructionism and [social] constructivism. In short, social constructionists believe that knowledge and meaning are created in the discourse of the social interaction (Crotty, 1998). [Social] constructivism, on the other hand, claims that meaning is more subjective and internal. "Constructivism...points up the unique experience of each of us. It suggests that each one's way of making sense of the world is valid and worthy of respect as any other" (Crotty, 1998, p 58). The teacher and students in my study were worthy of having their voices heard. The truth that the teacher and each student constructed "is relative and...is dependent on one's perspective" (Baxter \& Jack, 2008, p. 545). The meaning my participants 
made of their experiences, while culturally and socially influenced, were created based on their own individual subjectivities. In this study, I did not aim to find generalizable truths across populations, cultures, or contexts. Instead, I explored the truths that emerged through the stories my participants told and the narratives they constructed, which were deeply personal and subjective (Elbaz-Luwisch, 2007).

Crotty (1998) claimed there were no "valid" truths but, he did assert that some truths were useful. The stories of my teacher participant were useful because she added to the narratives of teachers of gifted students in rural settings, who navigate gifted frameworks within the contextual nature of their practice. Additionally, understanding students' stories rooted in their own voices, as participants in gifted curriculum focused on place, provided a platform for an often underexplored and undervalued population. Using a narrative constructivist lens, I was able to appreciate the sharing of stories of the teacher, the students, and the students' parents.

While constructivism emphasizes an internal meaning making model, narrative constructivism focuses on the sharing of these internal constructions of knowledge and understandings. It is through these sharings, or storytellings, that further meaning can then be constructed (Sparkes \& Smith, 2008). I asked my participants to tell me their stories of being a teacher or a student within a rural Appalachian gifted program and how they navigated curriculum, teaching, and/or learning in their place. The stories they told were not just a telling of facts of events, but they also encompassed their emotions, feelings, and individual meaning makings. Narrative constructionism gives weight to the social construction of narratives. A narrative constructivist, while not shunning socio-cultural impacts, tends to the "personal experience" as "active engagement of the individual person in the process of self-construction" (Sparkes \& Smith, 2008, p. 297). The meanings the teacher and students constructed were not 
static and representative eternally; instead they were a snapshot into the temporal construct of how they made sense of their experiences and learnings (Webster \& Mertova, 2007).

\section{Methodology: Case Study}

Case study, a "phenomenon of some sort occurring in a bounded context" (Miles \& Huberman, 1994, p.25) was chosen as the methodology for this study. Yin (2003) suggested the following characteristics be considered to determine if case study is appropriate as a design for a specific research study: (a) the type of research questions, (b) the degree of experimental control, and (c) contemporary or historical focus of the study. He goes on to suggest that case study is best suited for research questions that ask "how" and "why," looks at phenomena in context, requires minimal researcher control over events, and focuses on current or contemporary happenings. The phenomena of interest for this study fulfills Yin's (2003) case study criteria because it focused on current happenings like the teacher's attendance at professional development sessions and implementation of the framework in her classroom. Also, there were no variables of systematic control or manipulation. Moreover, research questions in this study were "how" oriented and were concerned with the process and experience of the participants. Yin (2003) claimed that these types of questions lend themselves to case study because they are explanatory and require understanding across time. Lastly, I focused on the teacher's and students' practices and experiences in the present, albeit on a time continuum, meeting Yin's contemporary criteria.

A case study is constituted by the boundaries of the case. By creating boundaries to bind the study, it "indicates what will and will not be studied in the scope of the research project" (Baxter \& Jack, 2008, p. 547). Binding the case prevented the gathering of unnecessary data, thus unnecessary time spent, that will not help answer research questions. There are multiple 
ways to bind a case, but for this study, I chose to bind it by definition and context (Miles \& Huberman, 1994). Therefore, this case was bound by one elementary gifted classroom in one rural Appalachian county. This case study focused on a teacher's, her students', and their parents' stories within one rural Appalachian gifted program. Thus, I explored the experiences of one teacher as she navigated and implemented a gifted framework into her practice. My purpose was not only to identify change in the teacher's practice, but to also understand the changes and how the teacher herself made use and cognized the conceptual and ideological framework in her practice. In parallel, I also considered how students' perceived the use of place as influencing their learning. Thus, I also identified narrative inquiry, "a study of human experience" (Webster \& Mertova, 2007, p.1) as an essential methodological lens through which to view happenings and attain experiences within the case (Lyons \& LaBoskey, 2012).

In the field of qualitative educational research, case study is a prominent, well used methodological approach (Yin, 2003; Saldaña, 2011; Stake, 1995) and welcomes the intermingling of methods. Yin (2003) claimed that a case study can be used alone or in conjunction with other methods of inquiry. A researcher may wish to include another inquiry method within a case study approach to best incorporate their epistemological view and to best actualize and answer their research questions. Therefore, I integrated narrative inquiry within my case study methodology.

The practice of narrative inquiry spans disciplines and fields, limiting the actualization of one single narrative inquiry method; thus, "narrative inquiry approaches are typically combined with other methodological approaches and philosophies which have been influential in that particular field of study" (Webster \& Mertova, 2007, p. 6). In fact, Riessman (2008) suggested 
that "it is a form of case-centered inquiry" (p. 193), which supported my decision to root this narrative inquiry within a case study approach.

When asked "What can you learn by studying just one of anything?" Henry Walcott, an anthropologist and perpetuator of the case study, responded "All you can!" (Saldaña, 2011). For this research, Walcott's words exact the attraction of using a case study. Studying "one thing" in-depth and across time provides insight into how the teacher and students make sense of their contextualized, and personal experience. Stake (1995) appropriately captured this essence by stating:

For the most part, the cases of interest in education and social service are people and programs. Each one is similar to other persons and programs in many ways and unique in many ways. We are interested in them for both their uniqueness and commonality. We seek to understand them. We would like to hear their stories. (p. 1, italics added)

Stories are enacted in all places, across time, and for different purposes, and are grounded in the conviction that stories, both in formal and informal contexts, are "fundamental to communication" (Webster \& Mertova, 2007, p. 16). I aimed to examine the phenomena of student and teacher experiences within the context of their rural Appalachian gifted classrooms. I wanted to understand how they "make sense of [their] worlds by synthesizing new experiences into what [they] have previously understood" (Brooks, 1999, p. 4). Narrative inquiry, thus, was the most appropriate avenue for understanding the phenomena. I needed the stories of my participants to gain a "better understanding of teaching, learning and performance" (Webster \& Mertova, 2007, p. 16). As an observer, I could only reflect on the observable actions or absence of actions. I could not surmise intent and meaning in the action; however, the construction of my 
participants' meanings were heard in their narratives. Furthermore, a narrative inquirer acknowledges that a "story is never "just a story" instead it houses implications of "truth, power, morality and individual agency" (Rymes \& Wortham, 2011, p. 37, 40). As Chapter 2 indicated, the complexities of being a youth with talents and a teacher of the gifted in rural places are not without significant implications. Narrative inquiry allowed me to explore how teachers and students constructed their narratives - as truths, as assertions or as submissions of power or morality, as well as how they asserted their individual agency to make sense of their experiences in the narratives they constructed. By creating a space to understand the experiences of the teacher and how she actualized gifted pedagogy within the case, narrative inquiry "assist[ed] in generating more appropriate teaching tools and techniques" (Webster \& Mertova, 2007, p. 16) for this rural context.

\section{Research Context}

Within West Virginia, gifted and talented child find processes and identification measures are mandated by state policy. West Virginia developed a set of standards and guidelines school districts must follow to identify and service students with gifts and talents. In policy, giftedness was defined as "exceptional intellectual abilities and potential for achievement that requires specially designed instruction and/or services beyond those normally provided in the general classroom instruction" (WVDE Policy 2419, 2017, p.31). The policy outlined three main criteria for identification of a student to receive gifted services: a full scale at or above the 97th percentile rank (referencing a student's psycho-cognitive intelligence quotient), academic achievement at the 90th percentile or higher, and demonstrates the need for specially designed instruction. Moreover, mandates require teachers to be certified if they are responsible for overseeing gifted students' cases and/or providing direct or indirect services. 
Each district must provide personnel as defined in West Virginia Board of Education Policy and set forth by the Every Student Succeeds Act (ESSA) and IDEA (2004) who are appropriately trained for the area(s) of exceptionality in which they have primary responsibility. (WVDE Policy 2419, 2017, p.66)

Because of teacher shortages, the term "appropriately trained" shifted recently. Current policy allows teachers holding a valid teaching certificate to receive an additional endorsement in Gifted via a passing score on the Praxis, a standardized assessment (WVDE Policy 2419, 2017).

\section{Place in Context}

Demographics of the county indicate that of the almost 27,000 residents $94.6 \%$ are White, $2.9 \%$ Black, and $1 \%$ Hispanic. The county experienced a $-4.5 \%$ population growth in the last eight years. Per capita income for 2017 was $\$ 21,888$ and there are 86 people residing within a square mile (U.S. Census Bureau, 2018). Identification of gifted students account for less than $2 \%$ of the county's school population which is comparable to the state's identification rates (Rural County Special Education Department, personal communication, 6.26.2019; Rural County Department of Education, personal communication, 6.26.2019).

Economic. The rural Appalachian county and surrounding area was once the center of an industrial hub. Multiple factories, mills, and active railroads kept residents employed for generations. The economic stability of the place, however, was more recently in flux. During the tenure of this research, one of the last major factories in the area, a paper mill, unexpectedly closed leaving many jobless. As discussed in Chapter 2, places are interdependent and the closing of the factory is one example of this. There were 676 people who lost their jobs completely and another 2000 workers such as loggers, truck drivers, and railroad employees were negatively and economically affected by the closure (Hernández, 2019, June 1). 
Additionally, the mill provided drinking water and sewage for the town in which it resided, a curtesy that no longer existed for town residents. Even county schools were negatively impacted by the closure. The treasurer for the county claimed that the closure impacted schools because the loss of tax revenue and support of school programs that the mill provided were lost (Ridder, May 10, 2019). The mill was part of an identity to the community and employed generations of families, even though at its closing, employed a fraction of the people of times past.

Positively, on the other side of the county a commercial and industrial center employed approximately 1,100 people. The large security firm was slated to expand, thus creating 500 new jobs (Blaisdell, 2019, April 4). While both current employment numbers and potential employment numbers are promising for the county, many employees commute from the bordering state only minutes from the industrial center and are not residents of the county.

Drug Epidemic. While other parts of the state were more grossly enthralled in the opioid struggle, the county in which this study occurred, also had devastating effects. In one year, out of 55 counties, the Appalachian county in the study went from being ranked $31^{\text {st }}$ to $15^{\text {th }}$ in death toll rates associated with the misuse of drugs. The rise in death toll was directly related to also being ranked $9^{\text {th }}$ in the state for abuse of prescription medications (West Virginia Board of Pharmacy \& West Virginia Department of Health and Human Resources, 2017). Residents who were not terminally effected were still entrenched in the battle. In fact, the large security company bringing in over 500 jobs to the area, could not fill the 25 positions they had open for a long time because applicants could not pass drug screenings (Superintendent, personal communication, April 19, 2019). After the mill closed, though, these vacancies were filled by unemployed mill workers. 
Throughout the tenure of the research, the local newspaper often published accounts and statistics on the drug epidemic. Events and expert speakers focused on the opioid epidemic, support, and outreach opportunities frequently occurred over the last year. The narrative of leaving and "getting" talented youth out, is more prevalent now in the face of the drug epidemic, than ever before. While I do not want to characterize the place in deficit terms, the reality of the epidemic needed to be shared for contextual understanding of the temporal shifts in population, economic norms, and mobility.

Education. There are eight elementary schools that feed into two middle schools and two high schools on opposite ends of the county. A composition that is similar to rural counties that have not consolidated small elementary schools. The middle school in which this study takes place is one of two in the county that housed grades 5-8 with approximately 500 students and 33 teachers (NCES, 2018).

In West Virginia there have been two teacher strikes within the last two years. The county within this research participated in both strikes and also enacted a countywide sit-in between the two strikes. Conflicts around teacher pay and rising health care costs were the driving force behind the first strike and the second strike was rooted in those same contentions; teacher pay and health care costs. Although, the second strike largely resulted from legislature bundling resolutions from the first strike within a larger bill. The larger bill provisioned the allowance of charter schools within the state and educational credits for families homeschooling their children. Both provisions were interpreted by teachers as ciphering resources from public schools. After the second strike, the bill was eventually tabled. Positively, a public forum was arranged to include local legislative representatives and teachers within the West Virginian County to productively discuss compromises. 
In providing the contexts of place, I do not contend that I have represented the area holistically or even marginally. I have selected a few key happenings within place that occurred during the tenure of my data collection that I felt pertinent to the story of place. This relevant glimpse into place was foundational for readers interpreting findings and understanding how schooling was enacted within its midst.

\section{The Participants and Their Roles}

Participants in this study included an educator of students with intellectual and academic talents in rural Appalachia, the students within her talent program, and the parents of students. Using Ericskon's (1986) funneling strategy, found in Miles, Huberman, and Saldaña’s (2014) Qualitative Data Analysis: A Methods Sourcebook and applied by Azano (2011), setting and recruitment followed a broad to narrow path. Because this study aimed to explore teacher and student experiences in rural Appalachia, one county was conveniently and purposively sampled (Gay, Mills, \& Airasian, 2012) because it was categorically rural, in Appalachia, had gifted and talented service mandates and because the researcher taught academically gifted students in the area from 2009-2014. A "county" boundary was chosen because low population density in the area replace districts with countywide jurisdictions. Site permission for the county schools was obtained by an in-person meeting with the superintendent on two occasions. In the initial site permission, I only requested permission for "elementary schools;" however, in the county fifthgrade, which is considered elementary (WVDE, 2019), was housed within middle schools. Therefore, the site permission was revised to allow research in any school within the county. I chose to limit the study to elementary because of my experience and interest with this age, and typically elementary gifted programs use enrichment strategies (Callahan et al., 2017) a method compatible with the Enrichment Triad Model and place-based education. 
After Internal Review Board (IRB) approval, I immediately began an active search for participants. The teacher participant was sampled from schools that employed a teacher of the gifted as noted in their staff directory on the school website. Teachers were recruited via email (Appendix A) to their public school email addresses, as found on schools' webpages. The initial interview protocol (Appendix B) and consent form was attached to the email. A follow-up phone call script was created (see Appendix C), but was not used because of responses to emails. Two participants responded favorably, but one gifted teacher only serviced gifted students 30-40 minutes a week. Considering that potential participant(s) would not begin implementation of the place-based Enrichment Triad until mid-February, I decided that limited service time of 30-40 minutes was not sufficient to implement the model. Therefore, I only consented the teacher who had a gifted class for 60-90 minutes per week.

Teachers of the gifted in rural schools are more akin to secondary teachers in that they service different groups of students each class period. Therefore, once the teacher participant was identified, snowball criterion sampling (Gay et al., 2012; Miles, Huberman, \& Saldaña, 2014) was used to recruit students and parents. Student participants were identified as gifted and talented, designated in a current IEP, and attended the participant teacher's pull-out gifted program. However, discussions between myself and the teacher, and ultimately the teacher's discretion (Gay et al., 2012), determined the fifth-grade class would be the most appropriate and convenient class to engage in the Enrichment Triad Model. Once potential student participants were identified, I visited the participant teacher's class. During the visit, I explained the study to potential student participants and read and requested written assent. All students signed the assent form at this visit. Parents of the students' were also recruited as participants. A packet consisting of a cover letter, permission, consent, and interview questions for both student and 
parent participation were given to each student to bring home to their parents/guardians. Within the packet, requests for parents/guardians to call or email with any questions or for further discussion of the study. All students returned signed consents within two days of distribution. Additionally, assent was read and requested from the student prior to each interview.

\section{Teacher Participant}

During the seventeen weeks of the study, the participating teacher engaged in two professional development sessions focused on developing talent by means of the Enrichment Triad. The workshops, which totaled 10 hours, were provided by an assistant professor of gifted education who held a doctorate in Gifted Education and was an expert in the Enrichment Triad Model, both as a practitioner and researcher. In the first PD session, I also shared with participants benefits of using place-based curriculum and how it could be integrated within the Enrichment Triad. The intent for the PD was to provide teachers opportunities to learn and experience a research-based model designed for gifted and talented youth, but to also encourage the use of place in curriculum.

I observed the teacher participant in class both prior and during the Enrichment Triad implementation, for a total of eight visits. During these observations, I recorded curricular happenings and interactions amongst students and teachers. I documented what happened in the classroom, but also noted my in-moment interpretations. My interpretations were segregated by brackets from the observable occurrences. The observations provided triangulation between teacher and student perceptions. Moreover, I interviewed the teacher five times (see Appendix B) spread across seventeen weeks. Also, informal conversations with the teacher participant were a means of data collection. After an observation, the teacher participant and I would often have discussions as we packed up or walked out that provided insight into her understandings of the 
framework and her conceptualization in that moment. These conversations were documented in my field notes. The teacher also agreed to keep a reflective journal to record her journey. This personal reflection was meant to gain access to her sense making and experiences implementing the framework and its influence on her students; however, the teacher did not complete this request.

\section{Student Participants}

The students in this study were asked to share their perceptions of their gifted class through three interviews (see Appendix D). Other data used to access students' stories included observations of students during gifted class time. These additional measures required no more effort or time on the student than what was expected in their gifted curriculum. See Table 2 for demographic information.

Table 2

Student demographics

\begin{tabular}{|c|c|c|c|c|c|c|}
\hline & Grade & $\begin{array}{l}\text { Entrance in } \\
\text { GT }\end{array}$ & Race & Sex & $\begin{array}{l}\text { Perceived Area of } \\
\text { Giftedness }\end{array}$ & $\begin{array}{l}\text { Parent } \\
\text { Participated }\end{array}$ \\
\hline Mae & 5 & $1^{\text {st }}$ & White & Female & $\begin{array}{l}\text { English, Socially, } \\
\text { and Physically } \\
\text { (Dance) }\end{array}$ & Yes \\
\hline Jonathan & 5 & $1^{\text {st }}$ & White & Male & Math & No \\
\hline $\operatorname{Jim}$ & 5 & $3 r d$ & White & Male & $\begin{array}{l}\text { Opted out of } \\
\text { answering question }\end{array}$ & Yes \\
\hline Sam & 5 & $1^{\text {st }}$ & White & Male & Math and Science & Yes \\
\hline Natalie & 5 & $3 r d$ & White & Female & $\begin{array}{l}\text { Math and a "little } \\
\text { bit" in Reading }\end{array}$ & $\begin{array}{l}\text { Yes, but } \\
\text { inaudible }\end{array}$ \\
\hline
\end{tabular}

\section{Parent Participants}

Parents were asked to share their thoughts about their child's learning during the semester and the final project through one interview at the conclusion of the study (See Appendix H). 


\section{Researcher's Role}

During the first session of professional development, I shared with teachers my understanding of place-based education and how it could be woven into the Triad. The presentation lasted approximately 20 minutes, and I delineated how place-based education had been conceptualized thus far in classrooms (i.e., cultural journalism, community problem solving, and natural studies). I used illustrative examples from a nationally applauded placebased school in the neighboring county to contextualize place-based education in their rural Appalachian place. While my presentation was limited in time, providing that part of the PD put me in a position of power. I was positioned as an "expert" in place-based education and thus aligned with the associate professor providing the rest of the PD. This positioning may have limited the collaborative position I had hoped to achieve within the classroom after the PD.

I worked to position myself, however, in a participatory role during PD sessions and subsequently in the classroom. For the completion of the first PD and the second PD session, I integrated myself as a participant. Each activity or discussion that emerged, I participated as if I were an active teacher in the workshop. I also positioned myself as a collaborator, resource, and an "extra-hand" within the gifted classroom during participatory observations. Following Clandinin's study on participatory narrative inquiry, Elbaz-Luwisch (2007) stated that "researchers should have something of value to contribute to the school and to the teacher whose classrooms they enter" (p. 360). I hoped to lessen burdens faced by the gifted teacher because teachers of the gifted in rural areas are compounded with structural complexities that include time constraints, role factotums, and isolation (Azano, 2014; Burton, et al., 2013; Miller \& Brigandi, forthcoming). During participatory observations, I consciously worked to represent myself as support and positioned the teacher as the expert in the context to reduce 
researcher/participant role crystallization (Hayes, 2008). I faithfully kept a reflective journal on the occurrences and interactions and adjusted future encounters as needed; however, and as Chapter 4 delineates, my overcompensation to reduce role crystallization inhibited my intended support and collaboration.

My participation and interactions within the research site, with participants, and with the data were a common positioning in qualitative work. The closeness achieved by these practices negates impartiality that is touted in quantitative research. However, since I am the primary research instrument (Merriam \& Tisdell, 2015; Saldaña, 2011), to add credibility to the study, I explored and made transparent my subjectivities and biases which are outlined in the next section.

\section{Subjectivity Statement}

In qualitative research, the researcher is the primary data collection agent (Merriam \& Tisdell, 2015; Saldaña, 2011). Data “do not speak for themselves," a researcher has to interpret data and data themselves are not a reality, but instead a representation of reality (Becker, 1993 as cited in Merriam \& Tisdell, p. 242, 2015). Given the primary role the researcher plays in qualitative inquiry and analysis, the researcher must not influence data to a degree that affects credibility. However, "neutrality and impartiality are not easy stances to achieve" (Patton, 1999, p. 1204) and most researchers bring their own biases and preconceptions to the research. Patton (1999) asserted that information about researchers needs to be provided to readers so that readers can deduce trustworthiness. Therefore, it is consequential to the credibility of the study that these biases are brought to the fore and acknowledged. The following subjectivity statement outlining my history within the context of the study, my identity as an Appalachian, and my 
predispositions will work to increase both the credibility of myself as a researcher and the credibility of my study.

While I entertained short episodes living outside of Appalachia, the majority of my life has occurred within its borders. Therefore, my "cultural immersion" (Azano, 2010, p. 84) in my rural Mid-Appalachian place was a lifelong endeavor. My position as both an Appalachian in a rural place and a researcher heightened my partialness identity (Bucholtz \& Hall, 2005) and "any given construction of [my] identity [was] in part deliberate and intentional, in part habitual and often less than fully conscious" (p. 606). For example, I was able to code shift (Azano, 2010) between the academic confines and a rural Appalachian or West Virginian to gain access to research sites, both in this study and others (Miller \& Brigandi, forthcoming). My Appalachian identity and previous gifted educator status also helped build rapport with the participant of this study. I taught in the county for six years as a gifted teacher. For two of those years, I was a gifted teacher at the participant teacher's school for two afternoons a week. Even though I never had the pleasure of working directly with the participant teacher, our paths crossed occasionally. Being able to shift from researcher to peer helped me gain access to the site and acceptance once on site.

I identify myself as an Appalachian and have a strong sense of place fostered by family and community connections, as well as a general appreciation for rural ways of life. Both my parents worked on the railroad for many years. When they started a family, my mother assumed a traditional role of a stay-at-home mother and my father continued to work on the railroad for another ten years. When industry in the area began to decline, many railroad jobs were at stake. My father was given a choice to either take severance pay or transfer to Jacksonville, Florida. Not wanting to leave the area for economic opportunity (Howley, 2006), my parents decided to 
take the severance pay and invest in a retail entrepreneurial opportunity, despite their parents' misgivings of the financial risk. My parents were very explicit in their reasons for turning down the transfer and often stated they chose to stay because they "did not want to leave the mountains." They did not want to leave their hometown, the place where their parents grew up, the place where they grew up, and the place where they had their children. They wanted to remain in Appalachia because of their attachment to the place and the people. My sense of place and Appalachian/West Virginia identity was directly influenced by my family's cultural perspectives and commitment to remain.

The pervasive negative stereotypes used to portray rural Appalachia never bothered me growing up because I took up a resistant identity (Satterwhite, 2010) which allowed me to claim ownership and transform the negative stereotypes of the place. I was able to reverse value judgements (Satterwhite, 2010). For example, the term "redneck" possessed a negative connotation, but through a resistance identity, I inverted its social implication and took up the imagery as a positive marker of my identity. In fact, at times in my adolescence I played up my degree of "redneck" because of my positive perceptions of what it meant in my rural place. However, a recent capstone to my academic coursework, Identity, Place, and Literacy in Appalachia, re-framed how I saw my rural Appalachian place, and thus my identity within that place. My perception shifted from culture, and people, as a fixed "product" that generates a characteristic listing or "differing from" that distinctly identifies it, to culture, like people, as a process that is ever-changing and complex (Street, 1993). I no longer had to be a "redneck" to both fit in my place and reject the "othering." I now embraced an Appalachian identity that need not be confined or enabled by self and other imposed labels. 
Additionally, I am cognizant of the discourse of both romanticized and stigmatized versions of Appalachia and the implications of both within its culture and outside. Stigmatized or romanticized versions of Appalachian place or people can be problematic in the discourses of why they are constructed (see Bell \& York, 2010) or perpetuated (see Lewis, 1999 or Shapiro, 1978). This shift in understanding encouraged me to see around a meta-narrative of a place or people and to look for "truths" which occur in individual narratives that both support and complicate current understandings of Appalachia. This realization allowed me to recognize my biases as I engaged in research. I did not aim to validate or replicate my own experiences or to fit the participants into a rural Appalachian gifted mold, but instead I wished to understand others within their temporal and contextual practices. Yet, I cannot and do not claim that my long held understandings and appreciation of place and people are sterilized through this realization. In fact, acknowledgment of my biases and my positioning within the research both as an educator and as an Appalachian, cognized my research production and analysis through transparent processes that at times were aided and constrained by my personal subjectivities.

Moreover, while I felt I had a stake in the research because it was enacted in my home place and in the same county school system my children attended, my intents were not advocacy oriented. Arnold, Newman, Gaddy, and Dean asserted that advocacy research in rural educational places should be discouraged "for fear that advocacy efforts will threaten the neutrality of the data" (Azano, 2010, p. 83). Like Azano (2010), despite my immersion in the situated context in which I was researching, the work of solving the "rural problem" (Theobald $\&$ Wood, 2010) was not the intent of the study. Instead, I hoped to provide support to the teacher in the complexities of her practice, promote reliance of best practices in gifted pedagogy, and engage students in meaningful experiences that complement their home or community lives. 
Overall, I perceived my Appalachian and gifted teacher perspective as an attribute to the study because I had to critically assess my socio-cultural and socio-educational lens. I acknowledged that my knowing of place and people was not "insider" knowledge, but my own subjective truth and engaging my participants in the dialectic process of research was needed to understand their truths (Dwyer \& Buckle, 2009). Additionally, strategic precautionary measures were taken to understand the cultural influences and implications on my thinking and this research. A reflective journal, inductive analysis, member checks, and investigator triangulation worked toward limiting my bias and subjectivity within the research. Hopefully, the transparency of my subjectivity statement will lend to the trustworthiness of the study.

\section{Data Collection}

The best way to approach this study, within a limited timeframe, but to produce the richest data possible, was to use a case study with narrative methods. Considering that this study was designed around one gifted program, it was crucial to root the data in participants' voices and observe them in their natural places of teaching and learning. Therefore, data were collected and triangulated through observations of daily practices, teaching, learning, and interviews that facilitated the construction of the teacher's and students' perspectives, experiences, and feelings.

\section{Interviews}

In qualitative studies, interviews are a prominent data collection tool (Saldaña, 2011) to understand participants' life worlds from the participants' perspectives (Kvale \& Brinkman, 2009). In contrast to other data sources, most notably quantitative measures, interviews provide access to information not available through objective or observational measures. Interviews are effective for “soliciting and documenting, in their own words, an individual's or group's perspectives, feelings, opinions, values, attitudes, and beliefs about their personal experiences 
and social world, in addition to factual information about their lives" (Saldaña, 2011, p. 33). In short, interviews are a structured exchange of conversation with a contextual purpose (Kvale \& Brinkman, 2009).

While there are many ways to enact and engage with interview practices based on epistemological or ontological foundations as well as for various intents or purposes of the interview itself (i.e., reporting events or reproducing knowledge) (Kvale \& Brinkman, 2009), I approached interviewing as a means of understanding people's stories and experiences. An interview for a narrative inquirer is based on the following premise:

[The] stories people tell constitute the empirical material that interviewers need if they are to understand how people create meanings out of events in their lives. To think of an interviewee as a narrator is to make a conceptual shift away from the idea that interviewees have answers to researchers' questions and toward the idea that interviewees are narrators with stories to tell and voices of their own. (Chase, 2005, p. 660)

As a complement to my narrative constructivist epistemology, Seidman (2013) relied on four themes derived from an interpretivist tradition. These themes are foundational to illustrating the importance and complexity of narrators' stories. First, he asserted that experience and meaning are temporal and these meanings are mutable and can shift over time. Therefore, truth is impermanent and is influenced by context and time. Next, he acknowledged that the truth of these experiences are participant's "subjective point of view" (p.17). It is their personal truth of the lived experiences of their past or present. In other words, the participant's truths are influenced by their own subjectivities. Yet, during an interview it is not only the participant who is active in constructing meaning; Kvale and Brinkman (2009) pointed out the researcher's role 
in this meaning making and knowledge construction. They claimed that "the process of knowing through conversations is intersubjective and social, involving interviewer and interviewee as coconstructors of knowledge" (p. 18). Thus, theme three deconstructed the notion of a "lived experience" as the in action moments that people encounter; instead the stories shared by the participants about those experiences are a reconstruction of the in-moment occurrences. Therefore, how a participant choses to recreate and share his/her experiences through language provides insight into their subjective truths (Seidman, 2013). Seidman further contended that stories are not just a recalling of experiences, with sole attention to factual occurrences, but that narratives themselves become a meaning making experience in their reflective retelling.

Embracing temporal "truths," relies on a subjective point of view, is a (re)construction or co-construction (Kvale \& Brinkman, 2009) of lived experiences, and the (re)construction itself is a meaning making process (Seidman, 2013). I used Seidman's three-interview framework to guide the interview process and protocol development. Within this framework, semi-structured narrative interviews were used with all participants. A semi-structure interview was needed in that "the very idea of a particular story is that it cannot be known, predicted, or prepared for in advance" (Chase, 2005, p. 662). To foster a narrative inquiry, Seidman (2013) claimed that most, but not all, questions within this framework should be open ended. The openness of semistructured interviews allowed for probing and follow-up questions as needed.

The use of a series of three interviews with multiple second interviews encouraged the construction of in-depth understandings and fostered the relationship between the researcher and the participant (Seidman, 2013). The first interview required participants (see Table 3 for timeline) to create a life history account related to the context of the study. For example, because I wished to understand the participant's experiences as a classroom teacher, more specifically as 
a gifted education classroom teacher, I focused the first interview on the participant's story "as a teacher" from past to present. To elicit contextual details, the first interview protocol used openended questions framed around a "how" or "what" structure that encouraged a reconstruction of events (Seidman, 2013) such as "Tell me how you came to teaching" (see Appendix B for Teacher Interview Protocol). While I term this as a question, and continue to refer to it as a question in the rest of the paper, it is actually an imperative statement to elucidate a story. This type of questioning was also used for student interviews. For example, I asked students to "Tell me about something you have done in gifted class that was meaningful to you" (see Appendix D).

The second interview in the series "allow[ed] participants to reconstruct the details of their experience within the context in which it occurs" (Seidman, 2013, p. 21). While I only conducted one "second interview" with students (see Appendix D) due to considerations for interviewing young children, I conducted multiple "interview 2's" (see Appendix D) with the teacher.

Implementing a gifted framework is not the same as trying a "lesson" that was time bounded. A framework, and specifically the Enrichment Triad, was multidimensional model and required certain pedagogical and conceptual shifts within the traditional teacher centered classroom. Additionally, the framework itself was meant to be implemented across time with varying degrees of process and product requirements (see Chapter 2). Therefore, soliciting teacher's perceptions, understandings, and uncovering happenings that occurred at multiple benchmarks, approximately every third to fourth week throughout the semester, better facilitated a telling of her experiences. Again, since a second interview was about eliciting details (Seidman, 2013), a question found in both teacher and student interview protocols 2 was "Tell 
me about what happened in class today" (see Appendices B \& D). This prompt encouraged a recalling of the procedural experiences that invited opinion responses as well. If only factual details were provided, I followed with a prompt to solicit their opinion such as "What do you think about that?" or "How do you feel about that?"

Table 3

Data Collection Timeline

\begin{tabular}{ccccc}
\multicolumn{5}{c}{ Type of Data Collection } \\
Professional & In-class & Teacher & Student & Parent \\
Development & Observation & Interviews & Interviews & Interviews
\end{tabular}

2.05.2019

2.22.2019

2.24.2019

2.27.2019

3.19.2019

3.26.2019

4.02.2019

4.12.2019

4.17.2019

4.30.2019

5.07.2019

5.29 .2019

5.30.2019-6.7.2019

5.31 .2019

6.4.2019 $\mathbf{x}$

$\mathbf{x}$

$\begin{array}{ll} & \\ \mathbf{x} & \mathbf{x} \\ \mathbf{x} & \\ \mathbf{x} & \end{array}$

$\mathbf{x}$

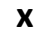

$\mathbf{x}$

$\mathbf{x}$ $\mathbf{x}$

$$
\mathbf{x}
$$

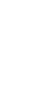

$\mathbf{x}$

$\mathbf{x}$

X

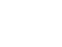


using the Triad in her classroom and if she planned to continue using it. Therefore, a question in the third protocol focused on her future curriculum: "Now that you have gone through the process of implementing the Triad, what value might the Triad have for a small rural pull-out program?"'(see Appendix B). I also engaged students in reflecting on the meaning of place in their classroom and how they understood the value of place in their classroom. For example, I asked them to tell me what they would like their gifted class to look like in the future by asking "Imagine you get to decide what you will learn in gifted class next year, what would you choose to learn about?" (see Appendix D).

The teacher was interviewed a total of five times ranging from 9 to 44 minutes. The first interview occurred prior to implementing the model, three interviews were conducted as the teacher implement the model, and one interview took place at the conclusion of the Type III investigation. Students were interviewed three times, at the beginning, middle, and end of the study, with interviews ranging from 12-33 minutes. Parents were interviewed one time at the conclusion of the study with interview times ranging from 9-14 minutes (see Appendix H). All teacher and student interviews were in person and audio recorded for transcription purposes. Four out of the five parents participated in the interviews with three being conducted over the phone. One phone interview transcript was inaudible therefore was excluded from analysis. Field notes recorded shortly after the non-transcribable interview were included in analysis.

As data were collected, audio recording of the interviews were promptly sent to a consulting firm, REV.com, for transcription services (see Appendix I for confidentiality agreement). Narratives were transcribed sans speech stalls and breaks (i.e. uhhh, umm, or he..he said.. he said that) to better facilitate the reading and interpretation of the stories (Riessman, 2008; Seidman, 2013). To ensure completeness and accuracy, I read over transcripts while listening to 
audio recordings. During this time, any people or place identifiers were replaced with pseudonyms. Participants chose their own pseudonyms. Because of the heuristic nature of narrative inquiry, I used MS Word to organize the data in appropriate files and folders. All data was stored in a password protected computer.

\section{Observations}

Qualitative case study research often employs observations as a data source, in part, because observations provide insights into the space in which the case resides, as well as a firsthand accounts of the case itself (Merriam \& Tisdell, 2015). I engaged in participant observations ten times over the course of the study including the two professional development sessions. When I observed in the classroom, I was there for the duration of the fifth-grade gifted class period in hopes that I was "present to witness the mundane, the typical, and the occasionally extraordinary events" (Saldaña, 2011, p. 46). Observing the teacher and her students in the classroom provided a glimpse into how they interacted with each other and how lessons progressed. Observations gave me the sense of contexts and processes that interviews alone could not provide.

My field notes were extended into a narrative within twenty-four hours of the observational occurrence to create clarity and provide thick description (Emerson, Fretz, \& Shaw, 2011). To ensure descriptive validity (Gay, et al., 2012), I took care to create a narrative that strictly adhered to concrete observable actions, settings, and conversations. My interpretive notes were designated aside from the happenings as memos. For example, in the field notes, any description of my analysis and interpretations of my field notes were bracketed so that in the analysis phase there was a distinction between concrete occurrences, interpretive or analytic notes, and memoing. 


\section{Data Analysis}

Based on the nature of my research questions, I employed socio-cultural narrative analysis and thematic narrative analysis for interview and observation data. Every person has a subjective truth and that truth is influenced by their place and reconstructed in the telling of their stories. A socio-cultural analysis supported participants' individual truths by rooting stories in their voices with a socio-contextual lens. Thematic narrative analysis was chosen to further data understanding by identifying a sharedness or divergence across a participant and amongst all participants.

As Yin (2003) recommended, data collection and data analysis phases overlapped. I simultaneously collected and analyzed because it allowed a deeper understanding of the case and promoted design reflexivity and data manageability (i.e., Saldaña, 2011; Merriam \& Tisdell, 2015). For example, after analysis of one of the teacher interviews, I was able to include a followup question about how she identified herself as a learner in the next interview, which was not in the scripted protocol.

\section{Socio-cultural Narrative Analysis}

I chose a socio-cultural narrative analysis because I was most interested with the content of the participants' stories (Riessman, 2008). It provided opportunities to explore contextual factors that influenced particular narratives while keeping the narrative itself intact. Thus, the participants' micro narratives were situated within broader cultural, ideological, political, or historical macro-narrative contexts.

Grbich (2013) acknowledged that there is no one "right" way to enact a sociocultural narrative analysis and the field often shifts with the emergence of new approaches; however, she provided a process to follow that encouraged a detailed analysis. First, I "identif[ied] the boundaries of the narrative segments." In this study, a narrative referred to specific life episodes 
(Grbich, 2013) or "a bounded stretch of talk [or text] that answer[ed] a single question" (Riessman, 2008, p. 92). The narrative analysis composite, or what Seidman (2013) called a profile, was a way to take bounded segments of text and transform them into a story. I began (see Figure 4) by working within a "single interview at a time, isolating, and ordering relevant episodes into a chronological, biographical account" (Riessman, 2008, p. 57). This work was needed because conversations do not flow seamlessly, chronologically, or with an absolute adherence to a topic. By eliminating irrelevant pieces of conversation, I was able to create texts that closer resembled stories, even if the stories answered interview questions. Seidman (2013) recommended copying what Riessman calls "relevant episodes" into a word document to keep the original text intact. Then, I continued to recreate the narrative rooted in the participant's words with only "transitions or some contextual needs put in" (Seidman, 2013, p. 122); this act of composing a narrative from the full storied accounts of my participants was a form of analysis itself (Seidman, 2013). This work created a narrative that could be analyzed in a reader friendly format. These stories were constructed by the researcher; therefore, I made subjective analytical choices as to what was important to the story and what was not.

A second step in analysis was to "explore the content and context of the story" (Grbich, 2013, p. 222). In this step, I began to look at what and how segments were framed, examining how the narrator made sense of their experiences and the values (i.e. specific emotions) that they highlighted (Grbich, 2013). Since the study only included one program, I then explored the intersections and divergences among the stories my teacher, her students, and the students' parents told. The fourth step in Grbich's (2013) process was what drew me to the sociocultural analysis. In this step, I looked at how the stories were nested in the current cultural or ideological contexts and relevant political structures. While this could prove to be overwhelming because of the many 
contextual factors involved, I structured my analysis within the cultural and political confines of rural Appalachia and current ideologies and practices within gifted education.

\section{Figure 4 \\ Socio-Cultural Narrative Analysis:}

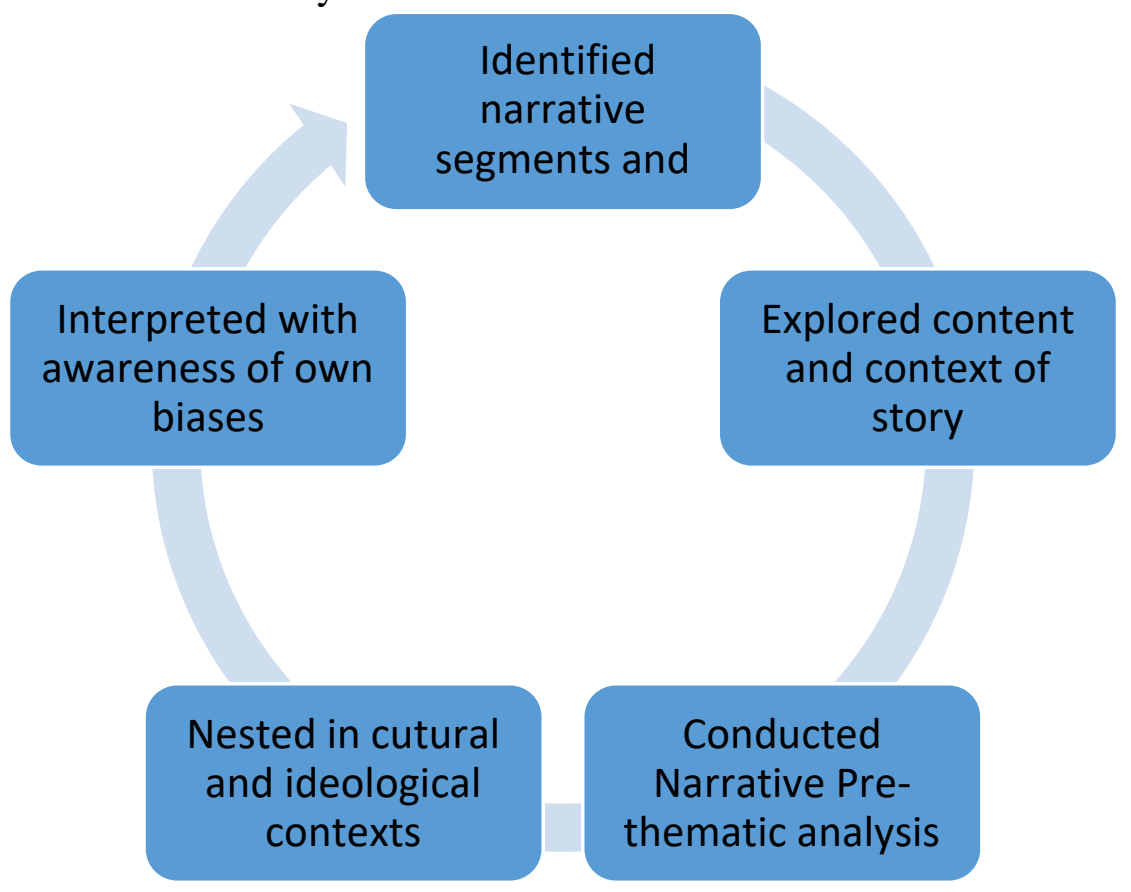

The last step in Grbich's (2013) process was one that put the researcher's subjectivities front and center as I then "interpret[ed] stories being aware of [my] own positions and reactions and how do they shape the final text" (Grbich, 2013, p. 22). Therefore, I called on my reflective journaling and memos I created during data collection, analysis, and writing up my findings in order to illuminate my position within the research's socio-cultural constructs. Journaling and referring back to my notes often helped me to reflect on the possible influences of my positionality on my research.

\section{Narrative Thematic Analysis}

Narrative thematic analysis is derivative of sociocultural analysis. Just as there was no standard method for enacting a sociocultural analysis, there was also no structured approach to narrative analysis. Riessman (2008), however, presented exemplar cases in narrative thematic 
analysis as a guide toward quality standards. My research analysis drew heavily on these exemplar cases and Seidman's (2013) recommendations of analysis for a series of three interviews.

Thematic analysis focuses on the content of the narratives and what the narrators are saying as opposed to how they are saying it (Riessman, 2008, p. 4). Therefore, I did not analyze the language or form of the narratives. I began by coding the narratives of each of my participants. Then, I looked for themes across participants, but within the case. Managerially, I accomplished this by first reading through the profiles (Seidman, 2013) that I created during the socio-cultural analysis in their entirety. As with any first read of data, analytic memos were written as I read the text. Simultaneously, I coded data with words or phrases that summarized what was being said, the feeling, assumption, description, subject or other inductive labels creating a name for each occurrence (Riessman, 2008). For example, when the teacher addressed a question about her curriculum, I noted what she was saying about the curriculum (i.e., differentiated) as well as any emotion or feeling she expressed (i.e. a lot to manage). Emotions were highlighted in yellow in the text to create a visual of the emotional experience as I analyzed. After multiple rounds of reading data, I then placed connected codes in categories (See Figure 5). Once I arranged my codes in categories, I searched for themes across the excerpts within the category and then for themes across categories (Seidman, 2013). Themes were derived from data themselves and theory was kept within the case (Riessman, 2008). In other words, findings and themes did not lead to generalizable theories across all gifted programs, teachers, or students.

While I did not give much attention to the local context such as who the narrator spoke to, I rooted the narratives in the macro-socio-cultural contexts of rural Appalachia and gifted education (Riessman, 2008). 
Figure 5

Example Delineation of Codes to Categories to Theme

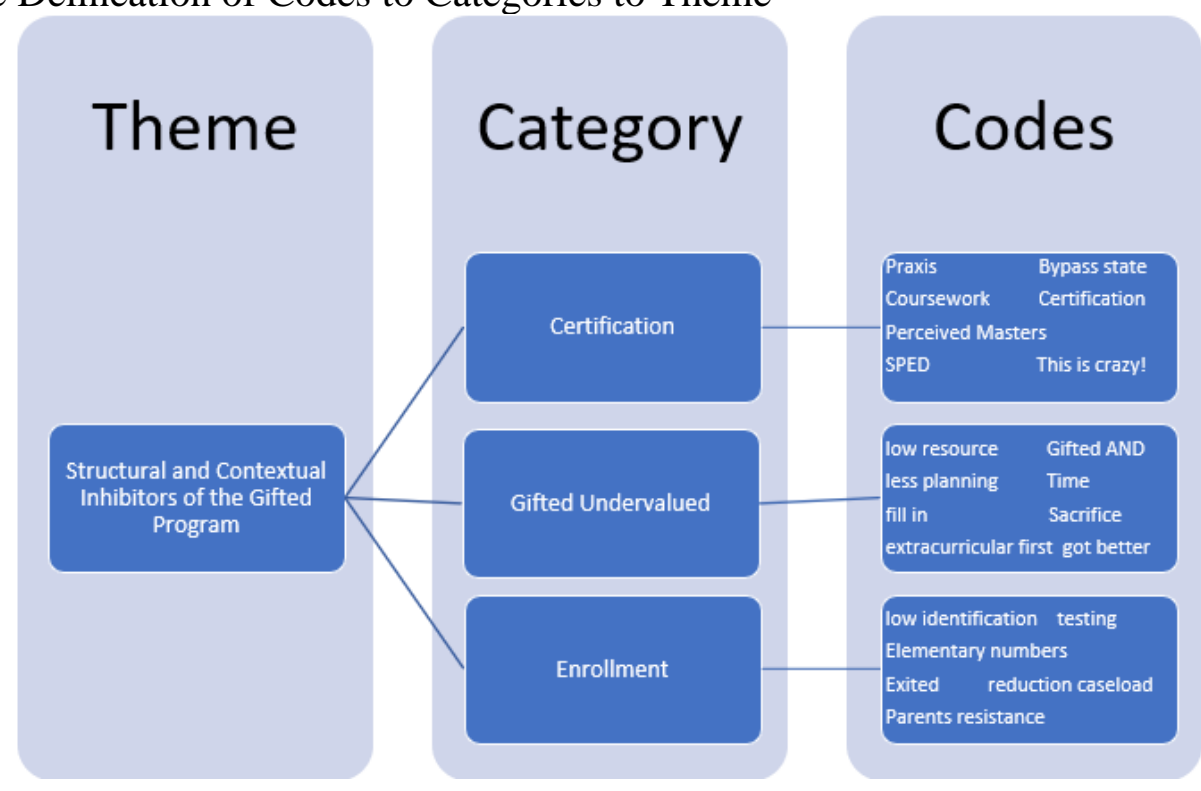

Both the socio-cultural narrative analysis and the thematic narrative analysis were discussed here in clear, separated steps. Yet, in analysis they were at times separate and at times conducted simultaneous. For example, profiles were created individually without influence of other analysis, yet my analysis of the content and context of the story often coincided with analysis of current cultural and ideological perceptions (Gribch, 2013).

\section{Trustworthiness}

Measures were taken during design, data collection, and analysis phases that ensured rigor of design and thus integrity or trustworthiness of the research itself. Employing criteria developed by Guba (1981), Shenton (2004) noted that trustworthiness increases by focusing on four specific constructs: credibility, transferability, dependability, and confirmability. As Shenton (2004) noted, dependability and credibility are closely related, therefore I merged them in my discussion of credibility. Additionally, certain practices are used to support multiple aspects of trustworthiness. Therefore, even though I chose to structure this section under the headings of the three main constructs (credibility, transferability, and confirmability), the 
methods to achieve each are interwoven and multi-purposed. Lastly, because narrative inquiry differs from general qualitative inquiry, verisimilitude, (Loh, 2013), was also addressed.

\section{Credibility}

Shenton (2004) described credibility as an "attempt to demonstrate that a true picture of the phenomenon under scrutiny is being presented" (p. 63). I worked to accomplish this through having familiarity with the culture, using well established methods, triangulation, debriefings, and peer critiquing.

As previously noted, I grew up adjacent to the community in the study, and taught within the same school district. Therefore, coming into this research, I possessed a working knowledge of the rural community and school culture. However, to affirm my understandings of culture, I began attending community and school-sanctioned events both leading up to the beginning of the study as well as during the study. For example, I attended annual community events, a few sporting events, a local educational forum, a public superintendent search and interviews by community leaders. I reviewed community documents such as local newspapers for the region and looked for updates on the board of education's county website. A second step towards credibility was the use of established research methods (Shenton, 2004). The methodology and methods utilized within this study are well established in the field of qualitative research. Similar approaches and researchers' uses and conceptions of the paradigms in the field have been cited earlier in this chapter.

Another strategy employed to ensure trustworthiness was the use of triangulation. I collected data on the same phenomena using various data sources, to ensure trustworthiness and confirmability (Patton, 2002; Shenton, 2004). My collection and analysis of interviews of 
various stakeholders (i.e., teachers, students, and parents) and classroom observations, provided a triangulation of methods (Patton, 2002).

A concern with credibility is questioning to what extent the researcher's "predispositions or biases of the [researcher] may affect data analysis" (Patton, 1999, p. 1204). To reduce this bias in data analysis, investigator triangulation (Merriam \& Tisdell, 2015; Patton, 1999; Patton, 2002) and reflective journaling was incorporated. Emergent findings in interview narratives and related raw data were shared with two academic peers in an open coding session to support findings and establish what Patton (2002) called analyst triangulation.

Most all expert investigators in qualitative methods encourage keeping a reflective journal (Loh, 2013). A reflective journal was a place where I documented my own thoughts, concerns, reactions, preconceptions, and biases (Patton, 1999; Merriam \& Tisdell, 2015; Ortlipp, 2008; Shenton, 2005). Divulging personal reflections and the "values and assumptions" I embraced was not an attempt to "control bias, but to make it visible to the reader" (Ortlipp, 2008, p. 697). By documenting my reflections throughout the research process, the journal writings themselves became a "visible and an acknowledged part of the research design, data generation, analysis, and interpretation process" (Ortlipp, 2008, p. 703). In other words, by disclosing my thoughts, concerns, and decisions I practiced transparency, which was a turn toward trustworthiness in qualitative research.

Credibility was also heightened through member checks (Merriam \& Tisdell, 2015; Shenton, 2005). Members checks occurred throughout the course of my study and were actualized through peer scrutiny and participant validation. Frequent meetings occurred between myself and my research mentors. During the design phase, I met with my dissertation chair weekly via phone. In addition, I also elicited feedback from other members of my committee via 
phone or email. During the data collection and analysis phases, I met with my chair on several occasions to solicit her perceptions, critiques, and expertise. Participant member checks were also utilized. Prompts in interviews were used to reaffirm my understandings of what the participant was expressing as his/her story. In other words, prompts such as "what I hear you saying is..." and "Is this correct..." or asking for follow-up, detail-oriented questions (Loh, 2013) facilitated a clarity of communication between the participants and myself.

\section{Transferability}

In traditional positivist approaches to research, findings should be applicable to similar populations and settings. This case study was not meant to be generalizable, but there were specific steps taken to help ensure transferability. In qualitative research, "the burden of proof lies less with the original investigator than with the person seeking to make an application elsewhere" (Lincoln and Guba, 1985, p. 298 as cited in Merriam \& Tisdell, 2015). However, to support readers of this research in making their decisions, I wrote a thick description of the phenomena and research (Shenton, 2004; Patton, 1999; Lincoln \& Guba, 1985 as referenced in Merriam \& Tisdell, 2015).

\section{Confirmability}

Confirmability is directly related to reflective journaling because reflective journaling makes transparent the researcher's positions and biases. Confirmability looks to make sure that findings are rooted in the narrators' stories and not overly influenced by researcher bias (Shenton, 2004). Throughout this research, I addressed my own predispositions and design choices. My beliefs and assumptions are made transparent in a subjectivity statement (Shenton, 2004). I also transparently and critically evaluated my design choices to include limitations and 
shortcomings. Most importantly though, I created an audit trail (Shenton, 2004). This showed step-by-step actions and decisions throughout the research process.

The following section, while similar to the strategies discussed as a part of the qualitative research paradigm, slightly differs because of the unique lens of narrative inquiry.

\section{Verisimilitude}

Loh (2013) claimed that "since narrative studies look at the interpretations of personal realities, it is important that these studies meet the criterion of verisimilitude" (Loh, 2013 p. 9). Verisimilitude examines the study's findings and stories of the participants to determine if they "ring true" (Loh, 2013; Webster \& Mertova, 2007). In other words, was the study believable? Webster \& Mertova, (2007) best outline verisimilitude when they claim that:

Narrative research...does not strive to produce any conclusions of certainty, but aims for its finding to be "well grounded" and "supportable"...it does not claim to represent the exact "truth", but rather aims for 'verisimilitude'--that the results have the appearance of truth or reality. (p. 4)

To achieve verisimilitude, Loh (2013) offers two trustworthiness strategies, peer validation and audience validation. Peer validation, a type of member checking, was discussed previously. Audience validation (Loh, 2013; Webster \& Mertova, 2007) or reflexive triangulation (Patton, 2002) is a less used technique that is pertinent to narrative inquiry and requires the researcher to share findings with stakeholders. Portions of the teacher participant's story, especially her story of how she came to teaching and her preexisting curricular practices were shared with her. From her feedback, one temporal change was made within the document. Additionally, four persons in the educational field reviewed findings of this study. The four reviewers had experience and expertise in place- 
based education, Appalachian contexts, gifted programming, and/or teacher learning —all constructs studied in this research. Their comments and critique, both in process and in final, provided critical feedback on the verisimilitude and, thus shaped the final text (Loh, 2013).

In conjunction with verisimilitude, narrative inquiry considers utility (Loh, 2013). Because narrative inquiry is focused on the construction of knowledge by individual participants, their stories are not generalizable (Shenton, 2004). A crucial question then is to what use are these stories? My participants' stories are useful within both the research community (Loh, 2013; Riessman, 2008) and the teaching community (Loh, 2013). The process of understanding a rural gifted teacher's experiences as she navigated a new framework, curriculum, and the complexities of her situation, as well as understanding the value of studying place from students' perspectives shed light into a previously ignored situation, thus generating more questions to be explored. Moreover, the stories of the rural gifted teacher and her students highlighted the possibilities and limitations that other teachers may experience as they aim to improve their practice. Establishing utility makes use of the same practices that support verisimilitude: member and audience validation (Loh, 2013).

In conclusion, this qualitative case study using narrative methods was employed to understand a teacher's and her students' experiences and perceptions as they navigated place and the Enrichment Triad in their rural programs. Data were collected through interviews and observations. Using a [social] constructivist lens, data were analyzed using socio-cultural narrative analysis and narrative thematic analysis. Trustworthiness was addressed throughout the study using a variety of methods. 


\section{CHAPTER 4: FINDINGS}

Taking up a [social] constructivist lens using narrative inquiry, I explored my participants' subjective and internal meaning making as they engaged with the place-based Enrichment Triad. The meanings my participants made of their experiences, while culturally and socially influenced, were created based on their own individual subjectivities. Their stories were deeply personal and subjective (Elbaz-Luwisch, 2007). Therefore, these findings are not generalizable, but to be understood within the socio-cultural temporal space in which they happened.

Both a socio-cultural narrative analysis and a thematic narrative analysis were used to facilitate the re-telling of participants' stories and to understand the relational aspects within and amongst their stories. The overarching research questions that guided the study were:

1) How does one teacher of a small rural Appalachian pull-out gifted program make sense of the Enrichment Triad Model and how does she use it in her classroom and curricular development?

2) How does a teacher's use of place and the Enrichment Triad influence teaching and student learning in a rural Appalachian gifted classroom?

3) In what ways does place influence how a gifted program is structured and enacted in a rural Appalachian school?

I organized this chapter in two distinct ways. Because a main component of the research was Jane's attendance at professional development (PD) and the subsequent influence, her narratives before and after the PD were needed to create a totality of her perspective. Therefore, I first worked to retell Jane's educational and teaching story from childhood to present. I began by renarrating her stories of how she came to teaching, her experiences at university, and her return 
home. Then, I continued her story as a gifted teacher in her rural school, noting her pre-existing curricular frames. Lastly, I re-narrated her story as she engaged in PD and began learning and enacting the place-based Enrichment Triad Model. Jane's curricular development from these events are highlighted within the findings.

While the first section of this chapter solely encapsulated Jane's story in her voice and, at times my own, since I was situated as a participant observer, the rest of the chapter was organized into themes that included all participant voices including students and parents, as well as the teacher.

I organized the second part of the chapter through two overarching stories/themes. The first story was Jane's use of place and the Enrichment Triad Model and included a) students' affective growth with new and challenging experiences, b) navigation of interpersonal and collaborative discourse, c) students' perceptions of interpersonal growth, and d) cogency of place in curriculum. The second overarching theme focused on how place influenced the conceptualization of gifted education. This larger theme was then divided into sub themes that included a) certification hurdles for teachers obtaining gifted endorsements, b) diminished student participation and identification, c) undervaluing of gifted education in place, and d) colleagues' perceptions of the gifted position.

Although this chapter was divided into stories and themes, at times they overlap due to the fluid nature of the narratives (Cowger, 2017). I first begin, though, with Jane's story of her educational journey to teaching.

\section{Jane's Educational and Teaching Experiences}

In understanding Jane's journey implementing the place-based Enrichment Triad, her story needed to first be contextualized and understood through her experiences coming to 
teaching, how these experiences influenced her practice, and how she framed and developed her current curriculum. Her story of change and learning was informed by the socio-cultural contexts in which her stories were constructed and exist, both past and present. Therefore, I begin by describing how Jane's story was nested within her rural cultural realities and larger cultural and educational frames.

Jane was a lifelong resident of the rural Appalachian county in which she taught. She had been teaching for six years, five of them were as a mathematics and gifted teacher. When she discussed how she came to teaching, her remembrances were painted with her personal connection to place, the school and community, and her identity within those places. She recalled:

Eighth grade, they say, "Hey, you need to pick a career and that's going to determine your classes in high school." I'm like, "I don't know what I'm going to do." My dad had mentioned to me, he said, "Well, what about teaching? You play school all the time, what about teaching." I' m like, "Yeah." That was what I knew. I liked school. I was a good student. I was the student that if a teacher needed papers graded, "Oh yeah, I like to do that." So I was like, "Yeah, that sounds like something good." (Jane, Interview 1, February $5,2019)$

The decisions Jane was asked to make in early adolescence influenced her journey towards education. The first, described above, occurred as she transitioned from eighth-grade to high school. To prepare students with specific college and career readiness skills, students were required to choose a career track. For example, a student who wished to become a biologist needed to make sure he or she had the pre-requisite classes and skills prior to entering higher education. Although this was a longstanding practice, it was not always an effective one because 
many students are undecided about their major or change their majors during their first years in higher education. In fact, $37 \%$ of students who enroll in higher education and declare education as their major, as Jane did, eventually change their major (NCES Data Point \& Leu, 2017). Yet, for Jane this event solidified her future path in education.

The second event that influenced Jane's career path was a discussion she had with her father, prompted by her need to pick a career at age thirteen. Because she enjoyed and excelled at school and engaged in imaginary play at home focused on school, her father believed choosing a career in education was a logical suggestion. Systemic educational processes and culture dictated middle school students to think critically about their distant future and career aspirations, a selfanalysis that required identity understandings, interest narrowing, and career option literacy. Yet, for Jane, her decision was most influenced by her father's perception of her pre-possessed ability and interest in teaching. In the literature, the myth that people are "born to teach" is denounced. Instead, teachers become teachers and their identities as teachers are never final; they are always under construction (Britzman, 2012). Jane's rationale for becoming a teacher was, in part, influenced by the understanding that she was inherently predisposed to teaching.

It is also valuable to consider how Jane's rural Appalachian place might have influenced her choices. In a place that is heavily dependent on trades work, it was not unusual that Jane and her twin sister were first generation, four-year college graduates. Her father earned an associate degree and her mother did not attend higher education. Jane and her twin sister, who also became a teacher, were not only first generation four-year college graduates in their family, but were in company of only a small group of fellow college graduates within their county of residence. Eighty-nine percent of high school students graduate in West Virginia but, only $55 \%$ enroll in higher education (State of Education Report, 2018). Moreover, less than 13\% of Jane's rural 
county's residents haves four year degrees (United States Census Bureau, 2018), a number that is well below the state's and national average of $19.9 \%$ and $34 \%$ respectively (United States

Census Bureau, 2018; NCES, 2018). This data suggests that jobs in the area do not require skills attained through higher education and those who choose to pursue higher education do not return in great numbers to Jane's rural county.

Moreover, women, in rural places, who pursue higher education often seek out jobs that allow them to return to their homes when they have finished (Corbett, 2007). Teaching and nursing provide opportunities for employment, even in the smallest of communities because people need access to both education and health care. As Jane reflected on the decisions she made that led her to teaching, she acknowledged how considering place inspired her choice_-as a way to return home and provide Jane an acceptable fit for her identities as a daughter, woman, and future mother.

I knew I wanted to stay in this area, so I knew that teaching was something that I could do in this area and also, the idea of raising a family played into that idea verses something which nursing, I'm squeamish around blood, so that would've never worked for me,... [or] verses something that I would've had to have worked nights and days and weekends and holidays and all of that. I knew that teaching would allow me something that would work with my family and I felt that that could be a balance.

Jane, like many rural youth, had strong ties and connections to her place (Corbett, 2007; Howley, et al., 1997; Jones, 1994; Staunton \& Jaffee, 2014; Richards \& Stambaugh, 2015). The importance of family and place was heard in her decision to pursue a career in education that was compatible with her maternal vision and allow her to return "home" after college. For Jane, her home was her place of birth. Jones (1994) claimed that no matter how long rural youth are 
removed from their rural places, they are still likely to refer to the places where they grew up as their "home" (Jones, 1994). Returning "home" for Jane meant pursuing a degree that would allow her to come back to her place of birth with economic and familial stability.

When Jane began her journey in higher education, she decided to attended a local community college for one year and then transfer to a larger university. The community college was in the county in which Jane lived, a subsidiary to the larger in-state university, and was a short commute across the county. Her decision to attend the community college for her first year allowed Jane to live at home. "I went to the community college and then I went to [in-state university]" (Jane, Interview 1, February 5, 2019). Again, her connections to place were evidenced, at least partially, in her resolve to remain in her rural place for the first year of her higher educational journey before transferring an hour and a half away to the larger in-state institution.

To be successful at the university, Jane needed to locate her place within the larger setting, a niche that was characteristic of her understandings and connections with her rural place (Heinisch, 2018). In the "big city" she aligned herself with a "neighborhood and little school" she described as "homey."

... it was something that I loved. It was something that I would volunteer extra time rather than what was just required, because it was ... the neighborhood, you're in this big city compared to here [small rural town], but the neighborhood and the little school that I was in was just ... it was so homey. It just was something that I was like, "Yeah, this is absolutely what I want to do.” (Jane, Interview 1; February 5, 2019)

When rural students attend large universities and seek out experiences or opportunities that resemble the values and sense of community of their rural places, they more likely perceive 
the large university as an "extension" of their small town (Heinisch, 2018). Jane affiliated and immersed herself within her teacher education host school and the surrounding neighborhood because they aligned with her sense and understanding of place, which she developed growing up in a rural setting. Moreover, success for Jane depended on her ability to create a bond with people and the place (Heinisch, 2018). Jane created this connection with her new place when she volunteered and donated her personal time for various activities and collaborations within the small community and the little school despite being foreign to the "big city" experience. Her active and immersed involvement increased her sense of community connection and her place in the neighborhood (Staunton \& Jaffee, 2014). Additionally, Jane's perception of the large university's size and scale positively influenced her sense of belonging. Jane was able to "break down the large environment into smaller, more comprehensible pieces" (Heinisch, 2018, p.205) to increase her sense of belonging and self-efficacy. "We had a house and it just really became a part of the community" (Jane, Interview 1, February 5, 2019). Jane personalized and localized her experiences in a "big city" and aligned herself with the "neighborhood" and "little school" instead of the university at large.

Jane's ability to focus on the micro community, engage in opportunities that were similar to her rural values and sense of community, and connect and bond with the people (Heinisch, 2018) supported Jane's sense of belonging and success in the "big city.

\section{Finding Her Fit}

While her endeavors to become a teacher were purposive, Jane claimed she "fell into" teaching the gifted. Jane substituted in her home county after graduation and then took her first job as a special educator for students with autism. After her first year as a full-time teacher, she 
applied for and was offered a mathematics job in the middle school that she attended as a child and where her twin sister also taught.

Jane's duties and title of "Mathematics and Gifted Teacher," included teaching advanced mathematics courses and managing the gifted program at the school. She taught gifted students in a pull-out model two times a week for fifth graders and three times a week for sixth through eighth graders, each session lasting 30 minutes. Being the only gifted teacher permanently in the building, Jane was the students' gifted and advanced math teacher from fifth grade through eighth grade.

I get to meet them when they come in as fifth graders and they're still very elementary and they're still very childlike, and have that excitement for school and have that willing to please ... I get to move with them through the middle school. . .it's just really awesome to get to see that transition from they're fifth graders where they are, again, very elementary, to where they're eighth graders and they're talking seriously about graduation plans ... these students are so intense about, they're so serious about their studies. (Jane, Interview 1, February 5, 2019)

Often in small rural schools gifted students are serviced by the same gifted teacher for multiple years (Azano, et al. 2014; Miller \& Brigandi, forthcoming), and this structure is perceived as a positive from Jane. She was able to track students' growth, academically and socially, across multiple years and to really "get to know" her students academically. In her recollection of a conversation with a gifted student, the depth of understanding her students as learners was noticeable.

I' ve seen them since they were fifth graders. By the time that they got to eighth grade and they are choosing a career and they are choosing a career path, and they're choosing classes, 
I know them well enough to say, "You need to be in the honors course," or a student that says, "Well I don't think I want to do the honors course." I know them well enough to know their abilities. I know them well enough to know their limits... (Jane, Interview 2, March $19,2019)$

In her rural school, Jane's classroom was a place for academically advanced students, those identified as mathematically advanced or gifted. It was also a place of familiarity because students were able to have Jane as their teacher for four years. Jane claimed that she "fell into" a position teaching academically talented students, but it was also where she carved her own niche and found her "fit."

I just felt like I fell into it, but I truly feel like it's where I ... I truly feel like I've found my fit. I fell into it, but I really feel like I found my fit with them [gifted students]. I just feel like I can relate with the students. I just feel like what I do here, I feel like it matters and I feel like I can see gains, and I can see where I' m making a difference with them... Jane's degree of "fit" could be attributed to her own talents. Although Jane was not identified gifted in school herself, she performed well as a student throughout her tenure. During her grade school years, she recalled being a "good student" and a "teacher's helper." In her postsecondary pursuits, she earned Bachelor's and Master's degrees, and multiple certifications. During the study, she pursued a technology integration specialist certification and the prestigious National Board Certification — ventures spawned by her own interests and desires for continued learning. She noted that when working with gifted students, she "can relate with the students," (Jane, Interview 1, February 5, 2019) which may be due to the fact that she understood her gifted students as being invested in their learning, as she was her own. However, despite her propensity 
for advanced learning in educational institutions and her identification with her students, she was reluctant to identify herself as "gifted" in the academic context.

So would I consider myself to be gifted? I don't know. That's a tough one. I see in myself a lot of the characteristics that our gifted students hold. The hard working and extremely dedicated to activities, or anything that I pursue. Academically though, I don $\mathrm{t}$ think things come as easy to me as they do to some of our gifted students, so I don't know. (Jane, Interview 4, May 07, 2019).

In this narrative, Jane teeters between the traditional "schoolhouse" view of giftedness (Renzulli \& Reis, 1997, 2014) and broader conceptions of giftedness. "Schoolhouse" abilities refer to "test-taking, lesson-learning, or academic giftedness or talents" (Renzulli \& Reis, n.d.) as static conceptions related to achievements and intelligence quotients (Renzulli, 1982). When it came to using "gifted" as a label for herself, she was reluctant, and stated that "academically" things did not "come as easy," which indicated her understanding of giftedness as an innate attribute with pre-embedded skills and knowledge. In contrast, she conceptualized a broader sense of giftedness and discussed her gifted "characteristics" as behaviors such as her task commitment (Renzulli \& Reis, 1997, 2014) and being “extremely dedicated to activities." In her self-identification, Jane confounds both her rural place's general academic and static conceptions of giftedness with the broader understandings of what giftedness might entail.

Beyond her capacity as a learner, Jane's abilities as a teacher of the gifted were noted by her students' affection towards her (in class and in interviews), her students' achievements which included county, regional, and state successes, and her Teacher of the Year nomination. Although she did not win Teacher of the Year, her nomination speaks to her excellence as a teacher. Jane was also active in the school, participating and chairing many committees. She 
chaperoned a weeklong camp and an out of state band trip during the tenure of this research.

Jane's degree of "fit" teaching gifted students seemed to align with her achievement as a teacher. When she refocused the ideal of herself not as a "gifted" learner but as a "talented" teacher, she was more comfortable identifying with the term "talented" and acknowledged that she does have a degree of talent as a teacher:

My students are achieving high, and I feel like some of that has to come back to what I'm doing with them. And the opportunities I'm providing to them. And those sorts of things. So without sounding conceited about it, yes, I would consider myself [talented] in that area of teaching. (Jane, Interview 4, May 07, 2019).

While Jane did not acknowledge her "giftedness" as a learner in academic contexts, she reluctantly identified herself as a "talented teacher" because of her ability to facilitate achievement in her gifted students. How she perceived giftedness for herself, as innate and static, contrasted with how she perceived giftedness for her students — as being malleable and supported by her influence. Additionally, Jane did not want to concede her giftedness until I pushed back against her denouncement, and only then would she confer with the term "talented," but not “gifted." She also prefaced her admission with "without sounding conceited," indicating potential socio-cultural implications of her acknowledgement of her gifts in her small rural place. In this rural Appalachian place very few people are identified as gifted and talented; therefore talking about being "gifted" or having "giftedness" could be perceived as a purposeful endeavor to socially or academically distinguish oneself from the greater population.

Jane disclosed that she was not referred for gifted testing when she was in school and her parents did not want her tested for the program. Pervasive gifted under-identification in Jane's rural county (Gifted Trend Data, WVDE 2014), a common failing in rural places and places with 
large pockets of low SES students (Azano, et al., 2017; Abell \& Lenox, 1999; Corbett, 2010), left Jane unidentified as gifted despite her capacity to demonstrate gifted behaviors. This was consequential because students who are identified as possessing gifts or talents have greater selfconcepts than high achievers, like Jane, who are not labeled (Bain \& Bell, 2004). Clearly, Jane's academic self-concept was lower than her actual achievements. She internalized her non-labeled, therefore non-existent giftedness in her identity as a learner; however, through reflection and renarrating she acknowledged her current talent and ability to foster giftedness in others, as an educator.

\section{Jane's Sense of Place Influencing Her Creation of Place in the Classroom}

Jane possessed a deep sense of family and connection to her rural place. Wakeman (2015) suggests that a sense of place is "both a social and personal construction of meaning, values, memories and experiences around a geographic location that ideally promotes stewardship within and love of place, as well as action" (p. 6). These notions are not only heard in Jane's narratives, but also observed in the décor of her classroom.

Hanging on the door as you enter her classroom was a wreath embroidered with the initials and colors of her in-state alma mater, and the name and colors of the school in which she taught; a blend of her macro and micro place affiliations, both discussed positively in her previous narratives. The logo and school colors of Jane's in-state alma mater was socioculturally commodified as a representation of the state. For example, in-state residents and outmigrants often purchase the state namesake university's merchandise or sport the university's colors as a positive affirmation of home or connection to place, not necessarily as a support or tie to the university itself. Therefore, when Jane visually displayed these logos and colors, it was not 
just as a commemoration of her preparatory years, but also as a representation of her positive relationship with and interconnectedness to place: her state, her county, her town, and her school.

Moreover, upon entering her room, her place attachment was further noted in the university logo of her clock, the large bi-colored flag hanging behind her desk, bulletin board borders, as well as miniature state cutouts with students' names written on them displayed on bulletin boards. Her school satchel and her clothes often proudly displayed her in-state alma mater's logo or colors. Aligning with Wakeman's (2015) definition of sense of place, Jane's personal experiences within her Appalachian place (e.g., choosing to attend a local college for the first year, returning home after college, and teaching at the school she once attended) and her remembrances of her Appalachian place (immersion in the "neighborhood" and "little school" in the "big city") were positive affirmations in her narrative and illustrated her "stewardship within and love of place" (Wakeman, 2015, p. 6). Jane's connection to family and place was heard throughout her narratives, but it was also visible in her daily life.

If I re-lensed Jane's commitment to place using a critical pedagogy of place (Gruenewald, 2003), her sense of place was essentially nested in her familial commitments. Jane's understandings of the socio-political, socio-historical, socio-environmental, or even socio-cultural understandings of her rural place did not emerge within the contexts of this study. Therefore, with a critical pedagogy of place lens, it is more accurate to claim that Jane possessed a deep sense of family and a nested or personal understanding of place as opposed to a deep sense of place.

\section{Pre-existing Curricular Frames}

Jane, like many rural gifted teachers (Miller \& Brigandi, forthcoming; Callahan, Moon, \& Oh, 2017; Azano, 2014) used her own ingenuities, connections, and interests to create her curriculum. Therefore, her commitment to and experiences as a math teacher and a technology 
integration specialist student influenced how she framed her gifted curriculum. Jane's gifted curriculum was largely focused on STEM learning and her curricular processes and products were often guided by competitive opportunities such as entrance into academic competitions.

\section{STEM.}

Jane's curriculum was largely focused on STEM opportunities for her rural gifted students. In fact, at one point she even referred to a portion of her sixth, seventh, and eighth grade gifted class as "STEM time." Her renaming "gifted class" as "STEM time" highlighted the emphasis STEM played in her gifted curriculum. Even in Jane's recollection of her curriculum, her narratives were saturated with STEM activities. For example, in discussing beneficial or meaningful activities she recalled an activity where her gifted students created "STEM stations" for general education students to use.

They' ve set up stations for the fifth grade. We rotated the entire fifth grade through STEM stations a couple of days before Christmas ... we spent most of December planning stations and then implementing the stations with the fifth graders." Another time Jane highlighted STEM's presence in her curriculum was when she recalled an activity she perceived as being influential for her gifted students.

It started in my eighth grade math class where they're talking about slope, $\ldots$ and they're using the Sphero and they're using other materials to build a ramp ... they were trying to decide how fast would it go, was what they were trying to decide. But then, from that activity, those students came over to gifted then, ... .they knew they wanted to take that Sphero and drive it into the locker. They wanted to build a ramp to drive it into the locker. Well, my eighth grade students then took those ideas that we had done and said, "Well, hey, we can do that. We can tweak that. Instead of going downhill, we just need it 
to go up hill and then move from that." I think that may have been the best lesson that wasn't even planned to be a lesson. (Interview 1)

Although Jane herself clearly had interest and expertise in STEM, she contended that her students also had a propensity toward the field. "A large percentage of those students are interested in careers around STEM careers, engineering careers or we have some that are interested in the sciences and .. a couple that are interested in coding or computer science careers" (Jane, Interview 1, February 5, 2019). The importance of Jane understanding her rural students' interests in STEM was consequential because the field is broad and generic and certain STEM opportunities may not be as useful to rural talented youth.

[Y]oung people's interests in mathematics and science may be diverse. Some may be very specific and do not match the school curriculum but could possibly lead to a STEM career. One example might be in computer science. Fostering such an interest can only be done if educators know about it. (Roberts, 2011, p.11)

Furthermore, students in Jane's state are failing to meet STEM academic success predictor benchmarks (ACT, 2017). In fact, only $11 \%$ of the 12,000 graduating students passed STEM benchmarks last year (ACT, 2017). While place does not correlate to ability, it does "shape the interests and opportunities that a child may have" (Roberts, 2010, p. 11).

Jane held certifications in mathematics and in gifted education, but she felt her students' interests in STEM required more than her, at the time, current repertoire of strategies could provide. The needs and specific interests of her students influenced her decision to pursue a technology integration specialist certification. "STEM fields and those kind of activities were things that our students were interested in, and those were things that our students excelled at. So, I went back and got my TIS certification ...” (Jane, Interview 1, February 5, 2019). 
While Jane's curricular frames were situated in her and her students' realm of experiences and interests, it was also influenced by larger national trends for both females and talented students. In recent years, there have been well-documented calls to engage underrepresented groups, such as females and rural students, in STEM learning experiences to ultimately increase their future participation in the field. In fact, some scholars have indicated a need for STEM to be place-based for rural talented youth (Morris, Slater, Fitzgerald, Lummis, \& van Etten, 2019) to contextualize and localize STEM understandings and opportunities.

Moreover, the National Association for Gifted Children, the foremost voice for gifted education, devoted a page on their website to "Gifted and STEM" and new books such as STEM Education for High Ability Learners edited by Bronwyn MacFarlane, Ph.D. emerged amongst the gifted literature. Even locally, there were recent notes of encouragement for quality STEM teachers. A recent bill brought to the West Virginia's senate floor proposed to provide teachers in certain STEM areas extra compensation for assuming these traditionally "hard to fill" roles (WV S. 451, 2019).

With these socio-educational influences, Jane positioned herself as a STEM educator through her TIS certification and her extra-curricular pursuits. For example, Jane volunteered to manage a coding demonstration booth at a local STEM Festival, and she chaperoned local students to a national space camp. Influenced by dominate socio-educational narratives and Jane's own interest in the field, she consistently used STEM in her curriculum.

\section{Competitions and contests.}

Jane's personal interests, expertise, and cultural persuasions influenced her propensity toward her curricular STEM focus. However, the processes and products within her curriculum were often guided by a competition, more aligned with traditional aspects of American schooling 
and gifted education. "We're big into the competitions, just because my students are big into competing. They're competitive and they like those activities" (Jane, Interview 1, February 5, 2019). Competitions have long been widely used in gifted programs (Cambell \& Walberg, 2011; Cropper, 1998; Ozturk \& Debelak, 2008) and while the literature is conflicted in its value, competitive engagements were a constant in Jane's classroom.

Jane outlined various competitions in her narratives which included a "Coding competition," "Minecraft competition," "Robotics competition," "Math Field Day," "Pumpkin Drop," and an "Essay competition" (Interview 1) many of which were regional and state competitions. Her students competed well at these events, earning first place ribbons in the coding competition and Mindcraft competition, both statewide honors. Many of her students also placed at county and regional Math Field Day competitions. On par with current national educational trends, Jane chose competitions focused on STEM topics (Coxen, 2012; Riley \& Karnes, 1998). For Jane, competitions worked to fill the void of differentiated curriculum and lack of resources (Cambell \& Wallberg, 2011), but little research exists on the value for a rural gifted demographic.

On the county's main website, there were often pictures of Jane's students who earned achievements at recent competitions or contests. Two displayed during the tenure of data collection for this research were Math Field Day winners and six of her students who won a state Mindcraft competition. Even though typical funding for gifted programs are minimal (Kettler et al., 2015), Jane noted that she received county financial support to attend these competitive events. 
Our county has been pretty good about funding things... They're like. .."Yeah, we'll take care of funding if you have the students that are prepared and ready to go to it." So, they're great funding wise. . (Jane, Interview 1; February 5, 2019)

As with any competitive endeavor, Jane's goal was not just for her students to attend these events, but for them to do well and earn honors. Her competitive mindset was evident in a portion of her narrative as she discussed her "frustration" with her fifth graders' repeatedly poor performance at Math Field day and how she planned to scaffold their future success.

Our gifted students usually do pretty well with Math Field Day. When we go to Math Field Day, our fifth grade, it's been a little bit of a frustration because I'm like, "I just don't know why these kids aren't doing well. They get to sixth, seventh, and eighth, and they sweep it, but in fifth grade, we're not getting there. We're like, "Maybe it is when they're starting the program," So, we're working on getting a program set up with some of our top math students in third and fourth grade, fourth grade specifically right now. We're looking at the top tier of 10 or 12 of their math students to bring them here at the end of the day and start those activities (Jane, Interview 2, March 19, 2019).

Student engagement and success in competitions were important parts of Jane's curriculum, as illustrated in the previous quote. She learned of these competitions through the connections her TIS certification afforded her. "I'd made connections with people at Apple and people at Sphero ... through that TIS certification. . . [and] it's opened me up to a lot of other experiences for our students" (Jane, Interview 1, February 5, 2019). Her connections at Apple and Sphero, both technology companies, notified her regularly of upcoming competitions. Some competitions were annual events, but other opportunities were intermittent. "They're not well 
planned in advance, but they just, when something presents itself, we take it and run with it" (Jane, Interview 1, February 5, 2019).

Jane's curriculum was not scripted or pre-planned. "We don't have a set curriculum and here's what you're going to do." Instead Jane grounded her curriculum in the competitions and between those events she often asked herself, "Okay, what do I want to do with these kids this week?" She claimed that "curriculum-wise, there isn't a curriculum. I'm just trying to pull things, and I'm pulling things that I've used in the past with the gifted students that have been really enjoyed." (Jane, Interview 1, February 5, 2019; Interview 2, March 19, 2019) The unscripted nature of Jane's curriculum, a practice common to small pull-out gifted programs (Borland, 2012; Miller \& Brigandi, forthcoming), had no predetermined scope or sequence (Borland, 2012). Much of that could be attributed to her having to design her own curriculum without support.

. . I've done research on my own. I'm finding activities on my own. . . So, while at the school level and community level, I don't feel like there's a ton of resources, I've gone seeking those resources. . I spent a lot of time working on finding opportunities for the students. (Jane, interview 1, February 5, 2019, emphasis added)

In fact, Jane wrote multiple grants to gain access to STEM materials. One of her funded grants, allowed her to supply Spheros, robotic balls, to her gifted class so they could learn and practice coding techniques. Evidenced here by her admission in spending a "lot of time" supplying resources and accessing curriculum, Jane was taxed with satisfying her gifted students and her own interests and needs in the curriculum.

Like many other gifted teachers, Jane did not rely on a particular set of instructional materials or gifted programming standards (Callahan et al., 2017). Instead, she used her connections and 
her STEM field knowledge to engage her students in opportunities such as contests and competitions, that she felt interested and engaged her students. Without formal in-service learning opportunities specific to gifted education, Jane engaged in "independent teacher learning" to find resources and capitalize on opportunities (Croft, 2015, p. 350).

In closure, Jane's pre-curricular frames aligned with metropolitan ideals of success which included socio-educational status and monetary capital (Jones, 1994; Richards \& Stambaugh, 2015). She perceived her role as a gifted teacher was to first create academic opportunities that positioned her students for notoriety within the school and community and second as a step toward career success within a global and mobile capacity. Understanding the nuances of Jane's gifted curricular pre-perceptions, allowed for in-depth understandings of her processes as she began implementing the place-based Enrichment Triad Model.

\section{Implementing the Place-based Enrichment Triad Model}

One of the purposes of this research was to explore how Jane, a teacher in a small, rural Appalachian pull-out gifted program made sense of the Enrichment Triad Model and used it to support her curricular development and teaching. Therefore, this section presents narrative vignettes of how Jane learned about and then enacted the model in her classroom, amongst her own ideologies and contextual features. Her stories were organized in three themes which included (a) learning the place-based enrichment triad (b) enacting the place-based enrichment triad, and (c) support and collaboration during implementation.

\section{Learning the Place-based Enrichment Triad}

Jane attended two professional developments focused on the Enrichment Triad and PlaceBased Education on February $27^{\text {th }}$ and April $17^{\text {th }}$. All gifted educators in the county were required to attend and, for Jane, it was the first PD focused on gifted education she had ever 
attended. "This is my sixth year in the county, that's the first time I've ever received gifted training" (Jane, Interview 5, June 4, 2019). Unfortunately, Jane's lack of ongoing learning in gifted education was not uncommon. The majority of teachers do not receive any (Farkas \& Duffett, 2008) or receive insignificant amounts (Callahan et al., 2017) for continued learning specific to gifted education.

Over two sessions, Jane engaged in 10 hours of professional development specific to gifted education. The PD was designed as an all-day session and a second half-day workshop in which gifted teachers in Jane's county were introduced to the Enrichment Triad, specifically Type III's (see Chapter 2) and strategies to incorporate place-based education with the Enrichment Triad.

Jane actively engaged in all discussions and activities during the PD sessions. The intention setting portion of the PD, where participants shared how they hoped participation in the PD would benefit them, Jane asserted that she wanted to gather strategies to "motivate and engage" her students (Field notes, 2-27-2019). She went on to share that she was pretty sure she "engages her students in activities that are of interest to them-except a few that she does not" (Field notes, 2-27-2019). She did not elaborate on how she knew that she was meeting students' interests or even what she did for the few she felt she was not.

Overall, Jane seemed pleased with the PD and claimed that she "really enjoyed the last one with the creativity" (Jane, Interview 3, April 30, 2019). She perceived what she had learned during the PD as being directly applicable to her fifth graders engaged in the place-based Enrichment Triad, and specifically with their composure and enactment of their presentation:

I'm really excited to pull in some of the creativity and storytelling pieces. I liked the creative story where we chose the pieces and then we were told which ones we were going to use 
then come up with a story. I think especially with the creative story it makes them work together, or a leader emerges and that person is the one that really takes the lead on that story ... I think it will help them come out of their shells a little bit, I am hoping, so maybe that would be something that would help us. . I'm excited. (Jane, Interview 3, April 30, 2019)

As part of the requirements for participating in the study, Jane was to implement what she learned about the Triad and place-based education in her classroom. She decided she wanted to pilot the Enrichment Triad with her fifth grade students whom she served in a pull-out model twice a week. Of the multiple ways place-based education could be envisioned with the Enrichment Triad, Jane decided to pursue community issues, a problem-solving approach.

Best practices in professional learning claim that successful integration must be a derivative of the teacher's work, require active learning opportunities, extensive amounts of time spent learning and implementing the model, collective participation including job embedded assistance, a focus on content or pedagogy, and the use of a bottom-up design (DarlingHammond \& McLaughlin, 1995, 2011; Desimone, Porter, Garet, Yoon, \& Birman, 2002; Guskey \& Yoon, 2009; Pitsoe \& Maila, 2012; Porter, Garet, Desimone, Yoon, \& Birman, 2000). The professional development that Jane attended met many of these best practice markers, but not all. I knew that structural and contextual realities restricted the PD to reach certain standards (i.e., extended hours of learning and guided implementation) to maximize Jane's learning. Therefore, I chose to frame myself as a support to Jane during her implementation process. By doing this, I hoped to provide the job embedded assistance that the PD and county administrators were incapable of providing due to structural and resource constraints. 
With most research-based models, adhering to the structure and process of the model is most crucial to obtain the best results, such as high student achievement. This adherence is called fidelity of implementation. Fidelity of implementation is the "the extent to which delivery of an intervention adheres to the protocol or program model" as it was originally intended, designed, or scripted (Azano et al., 2011, p. 695). Mitigating factors in fidelity of implementation for this study included contextual features specific to rurality and the amount of time provided to Jane to learn and apply the new model. Jane serviced her students twice a week for 30 minutes each session, roughly equating to five percent of the instructional school week. Moreover, implementation of the place-based Enrichment Triad did not begin until March and school ended in early June. Jane's time constraints and her emerging understandings of the model restricted this woman ability to adhere faithfully to it.

Additionally, conjoining fidelity of implementation and place-based education is an oxymoron, because of the "in moment" authentic opportunities and hearings required in placebased education. However, in efforts to contextual how Jane utilized place-based education, it needed discussed in relative terms here. Within the PD, she was provided with a place-based discussion guide, to jumpstart students' noticing and sharing about their place. I developed this guide because of the assumed novice of teachers' using place practices in their programs. Yet, Jane did not use the place-based discussion guide to scaffold her hearing her students' understandings, wonderings, concerns, and knowledges about their place. Because of Jane's emergent understandings of placed practices and her personally nested sense of place, she proceeded to studying place with a cautious and acute scope. 
Her understandings and modified enactment was similar to other rural teachers (Azano, et al., 2011, 2014) and those implementing the Enrichment Triad model for the first time (Brigandi, Gilson, \& Miller, 2019).

Due to the minimum time Jane engaged in PD, limitations within her rural place, and the ideological shift required she could not be expected to implement the model precisely as it was designed and intended. Degrees of error and lack of understanding were typical given her novice involvement in the process. Therefore, the degree of fidelity of implementation, although discussed here for transparency and contextual purposes was not foregrounded in the analysis. Yet, in understanding Jane's experiences, her actions and inactions during the implementation were included to create a picture of her conceptualization and use of the place-based model.

\section{Enacting the Place-Based Enrichment Triad}

During implementation of the place-based Enrichment Triad, Jane did not rely on many of the forms associated with the Enrichment Triad Model. Instead, she modified the process. For example, she did not use the Interest-A-lyzer (Appendix E), an embedded form in the Enrichment Triad Model, or the Guide for Place-Based Discussions and Topics (Appendix F), an elementary place specific interest guide I created and shared at the PD. Both were designed to gather interest data on students and aid in the initiation of appropriate Type III investigations. Instead, Jane decided to gather this information informally. She sat at a pod of six desks with the students and used chart paper to record the problems students identified in their community and in their school. However, the modification to the model did not produce the results she intended.

It "was rocky," Jane admitted. "Really, they didn't give a whole lot of ideas" (Jane, Interview 2, March 19, 2019). This intake activity spanned two class sessions and on the second day, Jane disclosed: 
I was truly dreading coming down here and doing the activity today. I was getting ready to leave the cafeteria, and I said, "I'm going to do this place-based activity with these fifth graders. I don't know what to do. I can't get them to come to something. I just am not sure how to approach it. I think maybe we just need to start over. I don't know what to do. (Jane, Interview 2, March 19, 2019)

When she came in the room, Jane invited me into the discussion and asked if I had any suggestions because it was not going well. Since place-based education is more about problem posing as opposed to problem solving, I helped her reframe the questionsInstead of asking, "What is a problem in your school or community," we asked, "What would you like to see changed or happening in your school or community?" When Jane expressed that she wanted the question to be applicable to their school, the students brainstormed two changes they wanted for their school. At this moment in Jane's understanding of the place-based Enrichment Triad, she hesitated to allow the focus of the Type III to be expanded and explored through students' places and knowledges outside of school. As noted earlier, Jane's nested sense of place attributed her conservative enaction of a place-based Type III at this moment in her development.

Yet, Jane believed this small shift in the nature of the question allowed students to think more personally and productively about the topic.

We were much more successful, I think, in that route. We were looking at very large-scale issues [before]. I think taking it to, "What is something you want to see changed in your school?" brought it down to more of a fifth grade, more of a personal level for them. So, I think that definitely helped. We were trying to go too big. (Jane, Interview 2, March 19, 2019) 
Jane perceived her initial problem discussion as being "too big” for fifth graders. However, students' inability to productively discuss local "problems" was less attributed to their age, but an evidence of their novice in place-based thinking. If students had more Type I experiences focused on exploring, discussing, and understanding their place, they would be much more aware of their surroundings and able to think critically about them (Comber, 2001).

I was not in the classroom when Jane decided not to include the interest inventory or place-based discussion guide, but I was there on the second day to make the suggestion that she utilize a decision-making matrix to help students narrow the topic. In the first PD session, the presenter asked Jane and the other participants to brainstorm things that "bugged" them about their educational place and then created a matrix to democratically determine a topic for exploration. Jane admitted that "I had kind of forgotten about that grid, so just having the support in the classroom has been fantastic" (Jane, Interview 2, March 19, 2019), after which Jane implemented the Decision-Making Matrix just as she had engaged with it in the PD.

The matrix was used to evaluate the investigative topics based on criteria the students deemed important (i.e., affect the most people). Jane allowed the student to take an active role in creating the decision grid and evaluating criteria.

We did finally start to see them get on the same page. We just saw them having a discussion, like we saw them really putting out those ideas and... talking, and having a discussion. A lot of times, neither one of us had to facilitate that discussion. Once they got going on "this is the idea," they were back and forth on, "Oh yeah," and just discussing it on their own. (Jane, Interview 2, March 19, 2019) 
As noted in her narratives, when Jane relied on supports provided by the Enrichment Triad and introduced in her PD, such as the decision grid, she perceived the learning process for her students as smoother and decidedly more productive.

The literature is replete with best practice research and standards in professional development (i.e., Darling-Hammond \& McLaughlin, 1995, 2011; Desimone et al., 2000; Guskey \& Yoon, 2009; Pitsoe \& Maila, 2012; Porter, 2002), but contextual considerations, such as what works in isolated rural pull-out gifted programs like Jane's, is less explored (Davis, 2019; Croft, 2015). While it did not mitigate all hiccups, Jane's development was fostered by inthe-moment, live-time professional development that was responsive to her resources, contexts, and personal understandings (Howley \& Howley, 2005).

\section{Support and Collaboration During Implementation}

Jane's disregard of Enrichment Triad's specific resources provided in the PD was not interpreted as a blatant attempt to disregard the model. Instead, it was representative of the contextual factors that often inhibit teacher change in the classroom. For example, after the decision-making class, I suggested she use the Management Plan (see Appendix G) in her next class to help focus the project. I showed Jane the management plan on my computer and asked her if she wanted me to modify the complexity for her fifth graders. I assumed that the form was too advanced; however, Jane felt that it was at an appropriate level for them. Jane then asked if I could email it to her, and I remembered she was given a copy in her take-home folder from the PD. Asking her if she had the folder with her, "she shook her head but then almost immediately said "Wait" and went to her bag" (Field Notes, 3-19-2019). In our conversation that followed, she revealed that the folder was still in her bag from the day of the PD. "She had not pulled it out 
or looked at it in the three [two and a half] weeks since she attended the PD" (Field Notes, 3-192019) or began implementation of the Type III.

Jane's inadvertent shelving of her PD packet was similar to other teachers who attend workshops and professional development. Inconsequential to teachers' intents to implement what they learned or resources they gathered, when they return to their classrooms they do not have the time, support, or the know-how to translate what they have learned into their current practice and curricular structures, thus limiting teacher change (Brigandi, Gilson, \& Miller, 2019; Brigandi \& Miller, 2018; Porter, Garet, Desimone, Yoon, \& Birman, 2000; 2002). Moreover, in top-down PD models, teachers are not always as invested in the learning and implementation as if they participated in grassroots models that centered their voices, needs, and ideologies (i.e., Darling-Hammond \& McLaughlin, 2011). The top-down model that Jane experienced restricted Jane's development and desire to invest in place-based practices because it essentially ran counter to her own current understandings of her role as a gifted educator, her expectations of her gifted students, and her understandings of place. She understood place from a personal perspective and established a curricular focus that aligned with larger achievement and success oriented narratives of academically gifted students. Additionally, Jane was notably preoccupied with other responsibilities, such as chairing committees within the school, submitting her narrative and curricula vitae for County Teacher of the Year, and compiling the extensive packet required for her National Board Certification. Jane prioritized her educational responsibilities, which resulted in the PD materials unexamined.

Jane demonstrated why classroom and continued support is crucial for teachers who attempt to change their practice. Although I sought to frame myself as a support for Jane as she implemented the place-based Enrichment Triad, the degree of my support ebbed and flowed. 
I really only try to "jump in" where there has been a clear invite of the day-as I do not want to overstep my bounds. After all, it is her classroom and her experiences through this that I am interested in and not necessarily how well it is being implemented. (Field Notes, 4-30-2019)

Because I did not want to "overstep" my welcome in her classroom and hinder her experience, I refrained from providing guidance unless Jane directly asked for my input and participation during an observation session or after.

The ebb and flow of my support for Jane was noticed in her narratives and reflection on a need for consistent in-process guidance during the implementation of new curricula. For example, after my assistance with problem finding and problem narrowing, as discussed previously, Jane positively reflected on the support she received:

Having you come in today was excellent. I mean, the professional development was great. That was, how many weeks ago? Yeah, maybe three weeks ago. I had kind of forgotten about that grid, so just having the support in the classroom has been fantastic. . . . I think that it was really awesome having you. Like seriously, honestly. I mean, sometimes I'm not communicating the idea clearly, so then just for them to hear that from another person has been great. So yeah, I think it's been a really good thing for them and for me. I think the support that I feel like I needed I think has already been provided. (Jane, Interview 2, March 19, 2019).

Jane reflected positively on her experience in the PD claiming that "the training has been great," but as her implementation of the Triad Model continued, she began to experience uncertainties in her understanding and yearned for collaborative support. The support Jane required went beyond strategic assistance provided during the problem finding session. In the 
following narrative, a few weeks later, Jane illustrated her need for reinforced foundational and operational understandings of the Enrichment Triad model during implementation.

I [also] have a hard time... Are we in a level [Type] III on the Triad? Or we're still in a II? Do you know what I mean? I guess I still have a little bit of... Sometimes I'm not sure where on the Triad we fit. I guess from the teacher aspect of it, it's something that I do try to keep in the back of my mind and then I'm like, "Oh, wait a minute, I'm not sure if we're hitting this." So yeah, definitely would be something that would be better, could be better supported. (Jane, Interview 3, April 30, 2019)

In her narrative, Jane illustrated how both her conceptual understanding of the Enrichment Triad and her in-process understanding were still forming. After this comment, Jane and I discussed how the Types were not hierarchal but that they were, at times, interwoven. Students might be engaged with both a Type II and a Type III throughout the semester. For example, interpersonal and communicative skill acquisition, a Type II, occurred because the students decided to present their product as an oral presentation in their Type III. The face to face authentic product presented to the principals was the culminating point of their Type III, but the practice and attaining the skill of composing a persuasive presentation was a Type II.

Throughout Jane's narratives she often spoke of how she felt she knew her older students, who they were, and what their interests were. However, the relationship and understandings of her fifth-graders were still forming. Because of this, she felt that implementing a place-based Type III required stakeholder input to understand who the students were:

I see these kids twice a week, so I don't see them in their everyday setting, I just see them with the five of them. Even like their classroom teachers saying, "Oh well, this is how their interactions occur in the classroom." So I think knowing maybe a little bit better with the 
students or someone knowing them a little bit better might be a way that we could overcome those issues in the presentation that we're having. (Jane, Interview 3, April 30, 2019) As delineated above, Jane did not use many of the "getting started" forms of the place-based Enrichment Triad. The Interest-A-Lyzer, in particular, designed to gather data on students' interests, experiences, and strengths, would have potentially mitigated Jane's uncertainties about her students and the need for general education teachers to "tell" her who her students were. In her narrative, she felt she needed other stakeholders to inform her. While stakeholder perceptions are valuable, the students themselves are most valuable and reliable in providing self-interest data. Her non-use of arguably the most important student data gathering form in the Enrichment Triad, illustrated Jane's underdeveloped conceptual understanding and in-practice vision for the Enrichment Triad. If Jane had comprehensive live-support during implementation, she might have recognized the role of the Interest-A-Lyzer to "knowing them a little bit better."

Jane's narratives also provided evidence of the need for collaborative support given the isolation she experienced being a rural gifted teacher (Azano et al., 2014; Burton, et al., 2013; Floyd, McGinnis, Grantham, 2011; Miller \& Brigandi, forthcoming). All gifted teachers in the county received the same training on place-based education and the Enrichment Triad, but Jane reflected on her contextual isolation and the difficulties of engaging in a collaborative learning process with other gifted teachers.

Being in this small area, makes that [implementing the Enrichment Triad] more difficult. . . In this area, sometimes even within the school you don't have that collaboration, but you definitely don't have it across the 30 minutes to get to [other middle school in county]. (Jane, Interview 4, May 07, 2019) 
To combat this cultural reality, Jane envisioned a partnership between the state university where students and professors engaged with the Enrichment Triad act as supports to teachers in rural areas attempting to implement the model.

Just the vast amount of knowledge that the professors have. The students at the university. . They're learning about them and the way that they should take place in the context. . . You guys are the experts in those. . the idea of finding, okay, how does this work, and what should this look like? And okay, now I've hit a roadblock, I've hit a wall, I don't know where to go from here. And just having that person that you can go back to, and bounce the ideas off of. . .I think, too, thinking about getting creative about how to interact with those supports like Skype, email, those sorts of thing. But just having someone that has that knowledge of what is the Triad, what does it look like in a classroom context, I think is really the supports that are needed to make that work. . . (Jane, Interview 4, May 07, 2019) As stated above, contextual features constrained the ways in which Jane was able to take up the practices she learned during the PD sessions; consequently, Jane's fidelity to the framework varied. Her degree of fidelity to the model, discussed to contextualize her processes, was not a matter of importance as a finding in and of itself. Instead, her narrative understandings and experiences with implementing the place-based Enrichment Triad, amongst the need to modify the model, were of most relevance. At multiple junctures in Jane's narratives, she reinforced her need for both collaborative and in-process supports to assist her as she went through the process of learning and implementing the place-based Enrichment Triad. Her narrative aligns with literature on current practices for professional learning that call for sustained learning opportunities, in-practice support, and collaborative opportunities (DarlingHammond \& McLaughlin, 1995, 2011; Desimone et al., 2002). 


\section{Jane's Classroom and Curricular Development}

Even though Jane's conceptualization of the place-based Enrichment Triad was in process throughout the semester, developments were evident in her classroom and curricular practices. Jane's curriculum began to have scope and sequence which included long-term goals and objectives that were co-created with students. Additionally, through her learning about and engagement with the place-based Enrichment Triad, Jane re-visioned her understandings of gifted curriculum and the ways in which she engaged and developed it.

\section{Developing Curricular Scope and Sequence}

Implementing the Enrichment Triad focused on place shifted Jane's curriculum from a "hodge podge" compilation towards one with scope and sequence and "address[ed] identified educational needs in a logical sequence" (Borland, 2012, p. 71).

Prior to the Enrichment Triad's implementation, Jane claimed:

We don't have a set curriculum and here's what you're going to do. I sat down at the beginning of this school year, and I thought, "I'm going to get this all laid out," and it doesn't happen. It just doesn't happen. . . The curriculum is ever-changing and the planning is happening from day to day. It's not happening ahead, which I hate, but it's changing based on getting to know the students and finding their interests. It doesn't look great on paper when they say, when it's Tuesday to say, "What are you going to do with your gifted kids on Thursday?" "Oh I don't really know yet. "We'll see how today goes and then we'll get to it." (Jane, Interview 1, February 5, 2019)

Jane's moment to moment programming aligned with results from the exploratory case study that piloted this dissertation. Gifted teachers in this rural Appalachian area did not ground curricula in gifted programming standards, frameworks or models, and curricula were often short 
sighted with no cohesive purpose. Instead teachers built their curricula from various resources and chose lessons at random that would be "fun" or "enjoyable" for their academically capable students (Miller \& Brigandi, forthcoming).

Jane also discussed her struggle in identifying appropriate activities and projects that interested her fifth graders. Typically, she chose activities from her repertoire that the older gifted students were interested in or engaged with, but she felt that her efforts were often in vain.

I've tried to pull activities and competitions because that's what has worked for us in the past in gifted activities, and they've really enjoyed. I've tried to say, "Well okay, we've got this poetry contest going on," or, "We have this robotics competition going on." They [5 $5^{\text {th }}$ graders] don't like to write and they don't like to do robotics. (Jane, Interview Final, June 04, 2019).

After an observation in mid-March, Jane and I discussed next steps in her place-based Type III implementation. The students had just finalized the topic for their study, and we decided to that using the Management Plan would be beneficial. The Management Plan (See Appendix G), with headings such as "Intended Products" and "Methodological Resources and Activities" served as a curricular guide for the project and facilitated a linear, progressive gifted enrichment curriculum - a curriculum in which student voices were valued and Jane was no longer straining to "find" activities.

While Jane did not directly speak to the management plan as a resource, she did describe how the Type III investigation was the totality of her curriculum during the semester.

Recently and today we've been working on getting that presentation together. They've collected, they've researched, they have different websites and that sort of thing that they've researched. They collected the data. Last week they made graphs of the data that 
they collected and then they've been just really working on getting that presentation together, the poster and then the idea of who's going to present what. So with it right now this project is the only thing that I'm facilitating with them ...(Jane, Interview 3, April $30,2019)$.

By utilizing the place-based Enrichment Triad, Jane's curriculum now had "scope and sequence" (Borland, 2012). She was able to relate each activity the students engaged in to a big picture. Moreover, the skills taught were interrelated, built upon each other and were applicable to the activities and goals within the Type III. For example, the students' goal was to create a persuasive argument to present to their principals in hopes of changing school policy (big picture). It was decided that reviewing literature research would help their cause (goal). Yet, researching from credible sources was not a skill they previously mastered. Therefore, Jane facilitated discussions and practiced finding reputable or valid information (skill). Jane noted this interconnectedness of the project itself and the learning within the project.

I think there's a lot of skills within this project that are coming out. First of all the idea of researching, when we started that they had no idea, like they just type in or Google something about water and then all of these sites pop up and they're, "Oh, Wikipedia, let me go here this is something I've heard of before." And then we had to talk about, "Well, what do you think are more valid or more credible sources?" So the idea of researching was something that we've been looking at. . So the whole idea of researching and then taking it together to put it into a presentation is kind of where we're heading now. (Jane, Interview 3, April 30, 2019)

Jane discussed the various activities completed, skills learned, and goals met. While seemingly divergent (i.e., learning how to analyze data and practicing eye contact), they were integral to the 
big picture of their place-based Type III. In Jane's curriculum prior to the PD, and typical for rural gifted teachers (Miller \& Brigandi, forthcoming), she engaged students in activities and skills that, at times, were sporadic and piecemeal. In a place-based Type III, her curricular activities coalesced for an identified and transparent purpose to change school water bottle policy. Jane reflected on how the semester's curriculum was different from her previous curriculum:

It really kind of was my entire curriculum for fifth grade... So, it was kind of nice to have and know, "Hey, we're going to work on this project today," and have a set curriculum rather than each week, like, "Okay, what do I want to do with these kids this week?" And it kind of gave us a long-term project to focus on rather than something that we looked at for two or three days and then moved on to something different. So, it really gave us a focus for the curriculum ... (Jane, Interview 3, April 30, 2019)

Her narrative illustrated her development towards a curricular plan, which diverged from her preplace-based Enrichment Triad curricular structure where she claimed "the planning is happening from day to day. It's not happening ahead" (Jane, interview 1, February 5, 2019). The importance of Jane's newfound "scope and sequence" is best illustrated by the following science curriculum analogy.

Most of us who are scientists have enjoyed climbing this ladder as part of our education. We revel in the lofty view from the top. Unfortunately, many students do not see the connection between the successive rungs. They are not told and do not discover why or where they are climbing. Before long they develop vertigo. Often they jump or fall off the ladder before they reach the top. (Schwartz, 2006, p. 981) 
In Jane's curricular development with a place-based Type III, the connectedness and purpose of the "ladder rungs" and where the students' "climb" led were transparent for both Jane and her students. Students engaged in various activities, such as conducting a survey or researching reputable sites (ladder rungs), which provided support for their argument to change school policy (where the "climb" led).

\section{Re-visioning Curriculum}

As Jane continued to develop her gifted curriculum, she grappled with a) the ways in which power was shared in a Type III and disrupted her role as a teacher and b) her evolving and flexible role as facilitator. Highlighted in the following stories of Jane's developing practice are evidence of her resistance to and then adoption of student autonomous practices and her conceptualization of a facilitator within the Enrichment Triad.

\section{Sharing of power.}

Implementing the Enrichment Triad Model and place-based practices required ideological and pedagogical shifts from traditional teacher led, directive, didactic classroom structures. Within a Type III especially, Jane attempted to assume the role of facilitator and moderated students' completion towards their goals. She did not prescribe the topics of study, how students engaged with the topic, or how students created their products. Instead, these learning topics and processes were co-created among students and teacher. Yet, when the Enrichment Triad's pedagogy is oppositional to current teacher practices, the transition becomes precarious. Jane discussed her trepidation with the new pedagogy and her resistance to "giving up control" related to curricular content, process, and product.

Traditionally, a teacher and a textbook determine the specific content of study within a course. Content is "what the student needs to learn or how the student will get access to the 
information" (Tomlinson, 2000, p. 2). For example, a teacher will develop his/her lesson plans based on a topic or theme (i.e., volcanic eruptions) and then determine what materials will be utilized to study this topic (i.e. Will It Blow?: Become a Volcano Detective at Mount St. Helens by Elizabeth Rusch). Jane's pre-existing curricular frames illustrated her authoritative role over the content in her curriculum, often centered on STEM fields. For example, Jane shared her decision to have students "code" or compete in the "pumpkin drop" that she replicates every year.

We've got the activity that I do with the seventh and eighth grade students for the pumpkin drop, so I know that's something that we've done, that's something that's been pretty beneficial for my students, so that's something that we put into our curriculum for usually the month of October, it takes.(Jane, Interview 1, February 5, 2019)

Even though she constantly attempted to find activities that interested her students, ultimately, she exercised a decisive role over content. However, the Enrichment Triad focused on place freed her from dictating "what is to be studied" and refocused that responsibility on the student (Renzulli, 1997, 2004).

Jane admitted that she struggled to change her teaching stance from one of control and transmission toward a student-centered approach, despite her conceptual understanding of its advantage. "I've always understood that the teacher needs to facilitate the learning, but it's hard to give up that control. It's always been very hard for me to give up that control." (Jane, Final Interview, June 04, 2019). In recanting a session where students were narrowing and determining their topic of investigation, she discussed her struggle:

Giving up that control of I want... like they came up with their ideas and I'm like, "Oh, I really, really want them to do this idea." Well it's not going to happen. I mean, they're going 
to decide on something else and giving up that control is hard." (Jane, Interview 2, March 19, 2019)

Jane shared that the "idea" or the topic of study she really wanted them to choose already had funding allotted for it and it would most likely get approved by those who had the power to approve it. While it did seem as though she favored this agenda during the discussion, she ultimately released control and her students made autonomous decisions.

Each student got to make their own claim to what they thought an issue was and they chose to stay within the school, but each of the five students got to make their own. I think we ended up with six because I think one student couldn't decide between two, but each student got their voice in that. (Jane, Final interview, June 04, 2019)

In the end, Jane acknowledged that this process "broadened my thinking of activities that could be done. Like the water bottle activity with the fifth graders, I would have never come up with that activity" (Jane, Final Interview, June 04, 2019).

Jane also discussed giving up control in the curricular process, in making decisions about the "activities in which the student engages in order to make sense of or master the content" (Tomlinson, 2000, p.2). Jane was able to relinquish control as she encouraged her students to be responsible for deciding how they were going to proceed with their investigation. For example, her students decided they wanted to survey the student body to access local data on water drinking habits. In a discussion on "how" they were going to conduct the survey, students decided that they wanted to face-to-face poll the students instead of sending a short questionnaire to each class. Jane reflected on the students' decisions and her reaction to them in a conversation with me after the students were dismissed: 
While the kids were leaving, she [Jane] turned to me and said that she wanted the kids to do the survey on pieces of paper instead of how they decided; by going into the lunch room with clipboards and polling them. We talked about it a bit and I questioned her on whether this would need to be addressed with the group and she said, "Like I told you before, it is hard for me to let go of control, but I feel that this is something that I can just let them do." (Field notes, 3-26-2019)

Autonomous expectations within a Type III were not representative of traditional student roles. Students were afforded responsibilities as curriculum co-creators instead of receivers. Jane recognized the shift in power as a new experience for her students that at times "frustrated" them.

If I said, "Hey, you need to write me this paper," they're not necessarily happy about it but they know how to write a paper. They know what the final product is supposed to look like. I don't know that they've always been given a lot of choices in doing that, so I think that's a struggle for them. I think they're a little bit frustrated with "why isn't she just telling me what she wants me to do? (Jane, Interview 2, March 19, 2019) Although her students experienced some discomfort with the autonomy, Jane did not waiver from asking her students to take more responsibility for what and how they might learn. Eventually, even Jane came to value students' control over curricular processes. The following narrative illustrates how she applied the Enrichment Triad's ideology with another student in an older gifted class.

[B]efore the place-based triad with the fifth grade and seeing them go through their project and letting them choose their product and seeing their outcome, I may not have been as open to just letting him [another student in another class engaging in a project] go 
on his way. So, I think it's allowed me to stop and think before I necessarily give them a whole lot of feedback on how to do something. Because they do have creative ideas and they do have ideas that I don't come up with and they're great ideas. So, I think that's changed my thinking. (Jane, Final Interview, June 04, 2019)

Thus, Jane began to expect more autonomous decision making from her students in all her gifted classes, for those engaged in the place-based Enrichment Triad and for those not engaged in the process. Interestingly though, she perceived this aspect of the place-based Enrichment Triad as generating "ideas" as opposed to understanding students' interests central to the Enrichment Triad or hearing FoK important in place-based practices. The generic nature of how she frames "ideas" reflects the limiting way in how she conceived students' personal understandings and experiences within place, despite her strides in sharing curricular power.

Positively, though Jane also began to value the learning that occurred within nonscripted, student-centered processes, as opposed to teacher controlled processes, and began implementing "discovery" activities in her general education math courses.

Seeing the fifth grade project come together has really emphasized that, hey, it needs to happen this way. So, I think like I've started planning a lot more discovery type activities in math, and if we spend the first 20 minutes and there really isn't a right answer coming out of it, that's fine because we're still getting those discussions that lead us to, "Okay, how do we do this or what's the importance of doing this?" (Jane, Interview 5, June 04, 2019)

Just as Jane made adjustments related to curricular content and processes, she also began to shift her conception of appropriate student products or the "culminating projects [tasks or activities] that ask the student to rehearse, apply, and extend what he or she has learned ...(Tomlinson, 
2000, p.2). Prior to engaging in the Enrichment Triad focused on place, Jane claimed that she was "pretty product" oriented:

[B]efore I was always focused on "I want a pretty product at the end." And again, this is my issues, my things, but if somebody comes into the classroom and says, "Hey, what are you doing?" I want them to be able to present something that's like, "Oh wow," like they really are doing something. (Jane, Interview )5, June 04, 2019)

Her engagement in the Enrichment Triad allowed her to shift this focus and Just step back and let them go ahead and do that product, even if it's not what exactly I would have envisioned would be the product of that, but just giving the students the choice and the chance to find their way through that of really giving the students the control and deciding how they want to do something. (Jane, Interview 5, June 04, 2019) It was new territory for Jane to ask her students to conceptualize their own products. As noted in her narrative above, she began to shift the importance from "pretty product[s]" as most crucial towards a processual value, even though it possibly sacrificed external validation for her, as the teacher. Neoliberal influences in schooling, such as value-added evaluation models, directly correlate teacher ability and effectiveness to student achievement. Achievement is the product of student learning and Jane grappled with the competing narratives of systematic neoliberal conceptions of teacher efficacy and authentic processes and products in a place-based Enrichment Triad.

Jane may have also felt a socio-cultural pressure to ensure her students' products were exemplary because she taught students who were categorically expected to perform with proficiency, gifted students. She illustrated her sensitivity towards such ideology in a discussion that occurred during the first PD session. After viewing some examples of Type III's that were 
not topographically content based, Jane spoke up and said it would be "hard sell" to others to do that with their gifted class. She then went on to share how recently she had to defend her curricular decision and students' products by requesting a retraction in the school's newspaper. Below is an excerpt from my field notes:

Students had to research something in Appalachian State's history [to] create scale replicas in Minecraft, cite sources appropriately, record a presentation, etc. but in the school newspaper it was written that "the gifted were playing on Minecraft"playing, that is the word that bothered her most. She did not specify what she did exactly, but she did say that they retracted/erased it. (Field notes, 2-27-2019) Although she did not specify to whom or why she had to justify her curricular decision to use Mindcraft, I believe she was referring to other teachers in the building. Jane's belief that she needed to provide a rationale for her decisions may illustrate the pressure to produce “excellent" and socio-educationally recognized "quality" products with her gifted students. Additionally, the notion of "play" illustrates the discourse of teaching gifted students and being gifted in this rural place. It is well-established that for young children "play" is a productive vehicle for learning. For school age children, the benefits of play through video games, like Minecraft, are also well explored (i.e., Ekaputra, Lim, \& Eng, 2013 ). Play is a process, but seemingly not the right process for gifted students in this rural place. These notions align with conceptions of the brain drain and determinates of tracked "paths" leading gifted students out of their place.

Despite these socio-cultural pressures, Jane re-visioned what constituted exemplary products. She relinquished control and asked her students to envision the products they felt were 
most interesting and effective. As she renounced her product authority, she began to find value in this process.

[E]ven if the finished product isn't that beautiful piece, there's a lot of important steps to getting to that." So what focusing on the process has definitely taken a focus rather than taken priority over just getting to a pretty end product.

Across all three domains, content, process, and product, Jane discussed her difficulty in sharing power with her students and asking them to decide their curricular paths. Despite her discomfort, she embraced the ideology of the Enrichment Triad and supported student agency by relinquishing her teacher-controlled curriculum. She even conceded, "giving up control is getting easier" (Jane, Interview 5, June 04, 2019) as she continued to design and enact studentcentered curriculum.

\section{Becoming a facilitator.}

While Jane made strides in sharing power in the design of curricular content, processes, and products, her understandings of her role as facilitator proved more challenging to develop. At times she seemed to embrace her facilitator role and use open ended questions to guide stalled discussions and facilitate the process.

[I would] throw out suggestions like, "Well, how do you think that we can do this?" Rather than saying, "Hey, let's introduce it this way. How do you think we should introduce it? Do you think it's important that we introduce to them what we're talking about?" Just kind of in those manners. (Jane, Interview 3, April 30, 2019)

However, at other times, when her facilitation was required to advance students' understanding, she teetered on her what her role entailed. As illustrated in the following excerpts, students had not previously engaged in persuasive presentations in which they collaborated with other 
students to create visual and oral arguments--all with autonomous responsibility. Because these were new experiences for her students, it could not be assumed that students had pre-possessed abilities to engage with and navigate these processes. This is something Jane noticed as she observed her students engaged in creating their poster.

Sometimes with the five in a group, as with every group project, it feels that some of them were carrying more of the load than others. Because at times there was like when two students who were working on the poster and the presentation or the speeches were written, it was kind of like, "Okay, what did the other students do?" (Jane, Final Interview, June 04, 2019)

Here Jane acknowledged the imperfect process, but her inaction to address her students' needs in the moment illustrated she was still constructing an understanding of her role of a facilitator for place-based Type III's. For example, Jane could have prompted the unengaged students to evaluate their goals and determine if their processes were aligned with their goals. She could have simply asked them to reflect on what their current role was and how they were meeting that role's descriptors. Due to her naïve understanding, it limited the ways in which she asked her students to reflect on place. For example, Jane could have engaged her students to think of larger implications of the local water issue. For example, reports during this time highlighted the extremely poor water quality with West Virginia (Spencer, September 28, 2019). Because of students' interests in creating a healthy school community through increased water consumption, Jane could have facilitated an environmental exploration of their place that sought to understand the history and power inequities that led to the pollution. However, it seemed, in these instances, her trepidation to position herself as a facilitator, rather than a teacher who tells 
her students what to do, as well as her limited understanding of place overpowered her capacity to act in that way.

Jane recognized her in-process development and stated, "so that's still kind of trying to find that balance of guiding them in a direction that's going to make their presentation meaningful . . and just telling them how to do their presentation" (Jane, Interview 3, April 30, 2019). In fact, Jane's development as a facilitator was most constrained during her students' compilation of their authentic product — an oral presentation accompanied by a poster visual (Figure 6) presented to their principals. While Jane described her students' engagement and excitement throughout the project up to this point, she also claimed that

The actual presentation is a little bit of a struggle right now. They can't agree on who is going to do what, nobody wants to be the one that talks, no one's emerging as a leader in that group to kind of take charge and say, "Okay, let's do it, this, this and this." And kind of give people roles. So, that part's a little bit of a struggle. (Jane, Interview 3, April 30, 2019)

Once again, I was able to support Jane as she discovered how she might make use of the Triad to design her curriculum and teaching. After students practiced their oral presentations for the first time, Jane and I discussed how the session was nonproductive. The students were not willing to focus on practicing their presentations; instead they engaged in excessive social banter. 


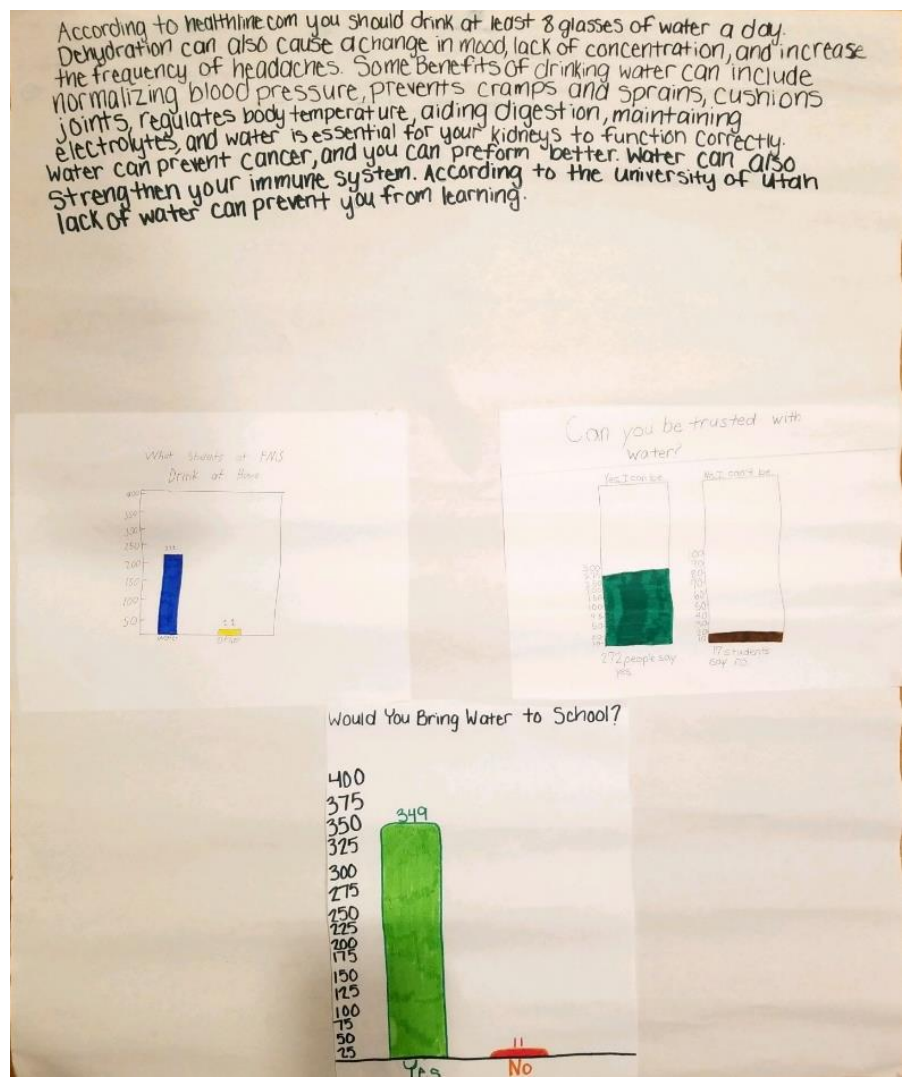

Figure 6: Student Poster Presentation

To refocus students on the process of creating a presentation, I suggested she find some YouTube videos of exemplar presentations and non-exemplar presentations and engage students in a discussion of the characteristics of each. Then, have students compare the exemplar presentation to their own. Until this point, Jane facilitated the creation of the presentation but had not asked students to analyze characteristics of an exemplar presentation. She had not exposed them to exemplar posters or reinforced how they might use persuasive argument techniques they had learned. In other words, Jane could not, at the time, conceptualize how Type II skills could be taught in her role as a facilitator of a Type III. She interpreted her role as a facilitator as largely "hands off."

During a subsequent observation, Jane shared with the class they were going to watch a few videos and identify characteristics of effective and noneffective presentations. She located 
YouTube videos after school hours at home, but when she attempted to share the videos at school they were blocked through the county's technology access/permissions. After a couple minutes of trying alternate routes, she decided to engage students in a group discussion on characteristics of a good presentation. Although the videos would have given them concrete examples, the discussion promoted student communicative and interpersonal learning. Suggestions in the discussion such as "looking up" away from notes (Figure 7) during the presentation led to eye contact during the final presentation. In Jane's reflection on what the students learned, she reflected on student's gains in understanding a good presentation.

I think presenting, and even one of the students said, "I learned how to actually present a project," which was really cool to hear because like I had seen that outcome, but for the students to realize, "Hey, maybe before we did this, I didn't. I've presented a lot of things, but I really wasn't sure what made a good presentation," that was just really cool to hear. (Jane, Final interview, June 04, 2019)

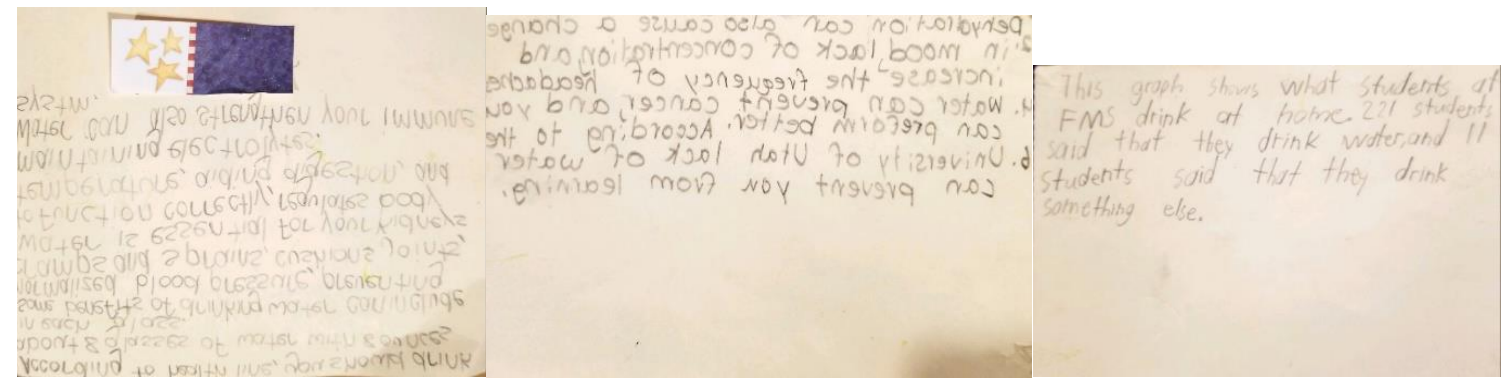

Figure 7: Student Note Cards for Presentation

\section{Incorporating the place-based Enrichment Triad in future curriculum.}

As Jane considered her future teaching, she foresaw herself using the place-based Enrichment Triad as a framework for curriculum, albeit modified across grades. During the study, she implemented a place-based Type III with her fifth grade students; in her future 
curriculum she perceived her implementation as being tailored, using a Type III without a place focus for her fifth, sixth, and seventh graders.

I would like each grade level to go through, create the decision making matrix, a small group coming up with a project ... thinking this would be a fifth, sixth and seventh, then we would just do some type of activity to get a chance to go through the process. And then by the time they got to eighth grade then they would be really good with the process. So, it's something I'd like to implement as part of the curriculum next year.

Although Jane wanted to continue to use Type IIIs, she foresaw the place-based focus to be reserved for her oldest students, the eighth graders.

Ideally, I would like for the eighth graders to go through this process and continue sticking with place-based, and I've kind of gone back and forth with that. Because I feel like not that the fifth graders didn't do a great job with it, but I feel like the eighth graders are a little bit more mature and they're getting closer to that age of being out in the world and trying to make changes and able to see different aspects and different viewpoints that sort of thing. (Jane, Final Interview, June 04, 2019)

Jane perceived her eighth grade students as being "mature" and thus more appropriate for conducting place-based Type III's.

Her desire to engage only eighth-graders in place-based activities seemed to be rooted in two elements. First, she conceptualized place-based education as being exclusively based in problem-solving. Although there are other forms of place-based education such as natural studies or cultural journalism (Smith, 2007) that can be paired with the Enrichment Triad, Jane embraced the transformative strand and focused her future curriculum on positioning students to create "change." As noted above, Jane believed the eighth graders were poised to conduct place- 
based Type III's that were relevant and transformative. She rooted her reasoning in characterizing them as more "mature" and able to "see different aspects." In her narrative, she provided a current cultural example of how she perceived student maturity mattering in problem solving place-based Type III's.

Like it was funny when we were talking with the fifth graders and said, "Okay, what are issues that could be with the water bottles?" And they were like saying, "Oh, people might bring something other than the water." And it's like, yeah. And then they got off into this, "Well, let's do clear because then we see what's in it and it's clear and it's okay." And then one of them started and like he went off on 10 or 15 minutes about, "Oh, it could be sprite," you know what I mean? And I'm just sitting there thinking, "Yes, and I'm going to let you think that," but I think the eighth graders in the sprite issue wouldn't be a big deal, but I think the eighth graders might see the whole picture, you know what I mean? And from the administrative aspect I think too, like they're probably not as worried about sprite being in that bottle as another clear liquid. I'm meaning alcohol. So, I know the eighth graders would see that aspect of it, and I think just that they can see and they can understand too more from the administrative aspect of the trash, the spills, as to the fifth graders who were like, "Well, I don't really think that will be that big of a deal. (Jane, interview 3, April 30, 2019).

Jane discussed concerns of misusing water bottles for illegal substances, and her concerns were not unfounded because approximately $19 \%$ of students under the age of 13 reportedly have consumed alcohol in West Virginia (Centers for Disease Control and Prevention, 2018). Jane supposed the eighth graders were more perceptive about administrative regulations of clear 
liquids and thus able to aptly address the issue because they were in the socio-demographic for this concern.

Secondly, Jane's thoughts of using a place-based Type III with her older students were, in part informed by her desire for student success and notoriety, as evidenced in her previous curricular products rooted in competitions. During the last interview with Jane and six days after students presented their persuasive arguments to the principals, no answer had been given to students on whether school policy would be amended to allow students access to water bottles. They did not get an answer [from the principals]. I was very afraid that it would be a negative feeling if they didn't get the response they wanted and then they really didn't get a response at all. I guess that idea is always out there that they say, "Hey, we did this and we went about this the right way and it didn't make a difference anyway." So like I really hope it doesn't make that negative effect. I hate that for them ... (Jane, Final Interview, June 04, 2019)

The "non-answer" from the principals impacted how Jane envisioned engaging in a place-based Type III in the future. Her belief that the fifth-graders' campaign to alter school policy did not result in change influenced her thinking about place-based practices. She interpreted "place" in the curriculum as change and most appropriate for her eldest and more "mature" students because of their greater likelihood of their success.

Essentially, of the two constructs, the Enrichment Triad Model and place-based education, it was easier for Jane to conceptualize a Type III in her practice. Taking up the social context piece required in place-based education proved to be a barrier because of both the ideological shift it required (i.e., towards FoK and dark FoK), but also because of Jane's own need to stretch her perceptions and recognitions of place beyond her personal experiences. 
Jane had a deep sense of family and personal connection to place. She took pride in her place, both the local and the state, and had long developed familial, community, and professional relationships. Yet, her place consciousness did not act in support of an "interdependent relationship" (Budge, 2006, p.7) between her students and the community and culture in which they live. In other words, Jane's own sense of place and belonging was inconsequential to position and support her students in developing the same relationship. The disassociation between educational stakeholders' sense of place and their ability to foster that same connection was evidenced in Budge's (2006) study in which educational leaders, who possessed strong attachments to place, could not identify how schooling fostered or supported their students to "live well in the local community should they decide to do so" (p. 6). Jane's own sense of place was not enough to override socio-cultural success perceptions of gifted education or idealize the relevance of place-based Type III's in promoting the development of her students' own deep connections to their rural place.

In conclusion, Jane engaged in learning and implementing the place-based Enrichment Triad. Her previous narratives illustrate how Jane navigated competing discourses, such as implementing a research-based model within the complexities of a rural pull-out program, addressing her own pedagogical resistance and limitations to her learning, and impediments between her own sense of place and supporting the same commitment in her students.

\section{A Teacher's Use of Place and the Enrichment Triad Model}

Up to this point, I have delineated Jane's story and her narration based on my sociocultural narrative analysis and the themes that emerged were rooted within her narrative(s) alone. The following sections share a thematic representation of the data and includes all participant voices: teachers, students, and parents. The stories that follow provide evidence of how Jane 
made use of place and the Enrichment Triad model, how it influenced her teaching, curriculum development and the learning of her students. The themes that emerged from analysis include: (a) students' affective growth while encountering new and challenging experiences, (b) students' navigation of the interpersonal and collaborative discourse required within a Type III, (c) students' perception of interpersonal growth and d) cogency of place in curriculum.

\section{Students' Affective Growth in New and Challenging Experiences}

Gifted students in this study were confronted with expectations and experiences they had never encountered. In an educational culture where typical comportment is for the teacher to dictate procedural and processual expectations, students are given little opportunities to grapple with those decisions. The Enrichment Triad, specifically a Type III, required Jane's fifth-grade students to become autonomous in their learning processes, and take charge of their interpersonal experiences rather than be passive receivers within the process. The shift the place-based Enrichment Triad required put "the students in that position to really drive the learning or to choose the topics" (Jane, Final Interview, June 04, 2019). These new expectations and experiences engaged students in positive educational and interpersonal discourse.

At times, the fifth-grade gifted students were nervous and hesitant as they engaged with elements in the Enrichment Triad that disrupted their typical experiences as learners, such as surveying older students and presenting their findings to authentic audiences. For instance, students created a three-question survey to poll the student body on their drinking habits (e.g., "What do you drink at home? Do you want to be able to bring your own water bottle from home? Could you be trusted to have your own water bottle?" [Field Notes, 3.26]). However, students expressed hesitance about conducting it because the survey was a face-to-face poll with the older student body. "[I was] a little nervous, because they're older" (Jim, Interview 2, April 10, 2019). 
A mother recalls a conversation she had with her daughter about the experience. "I think it's a big deal 'cause they surveyed kids who are older than them. 'Cause she told me one day she was like, "I had to talk to eight graders. I had to do a survey with eight graders." She was like, "It was kinda scary.'"(Mae's Mother, June 4, 2019). Yet, by engaging in a practice that unnerved them, students' emotional responses began to change. “At first, I was like really scared 'cause I didn't really want to talk to a big group of people. But then, once we did the first table, we kinda warmed up to it" (Natalie, Interview 2, April 10, 2019). One student even termed the experience as being “fun.”(Sam, Interview 2, April 10, 2019).

Students also expressed nervous emotions about another task in the project. In the Enrichment Triad, a Type III requires students' products be presented to an authentic audience. Since students in this study attempted to change local school policy, an authentic audience for their project were those who had the authority to amend such policies. Thus, students decided to present their persuasive argument to the principal and vice principal of the school. Again, a new experience for all of the students.

Typically the only experiences students have with administration, especially nested in a middle school, are negative and revolve around behavioral consequences or academic insufficiencies. Jane noted the non-relationship between her gifted students and the principals by claiming, "They don't have interaction with them because unfortunately it seems that at this level you don't have interaction with the principals unless it's something in a negative connotation, and these students haven't had that interaction with them" (Jane, Interview 3, April 30, 2019). Studies have found that positive, focused, one-on-one interactions between student and principal have been shown to have positive implications on student cognitive achievements (Silva, White, 
\& Yoshida, 2011). Jane's students met with their principals on a small scale, within a positive context, bound by a focused topic — changing policy.

The teacher and parents also perceived shifts in student positioning and implications on students' affective processes. Jane considered the social significance of this shift for her fifth graders and claimed, "I think that's not going super well for them, the idea of overcoming that fear ... I think they are a bit intimidated knowing that it's going to be [presented to] the principals. .." (Interview, 3). In fact, the emotional significance of engaging in such a task was evident in the query of one parent who had to verify during her interview that her son actually had a speaking role in the presentation because "my son does not like to get up in front of people and talk" (Jim's mother, May 30, 2019). She was particularly confounded that he was willing to do so for authority figures such as the principals.

The students verified their parents' and teacher's perceptions and expressed mildly negative emotions related to these experiences, including embarrassment and nervousness. Sam, a shy and quiet boy, claimed that he was "embarrassed" in rehearsals because "I didn't really present right, and I kind of got embarrassed. I just looked at the board and didn't really look back where the people [principals] would be" (Interview 3). All other students expressed feelings of nervousness related to their presentations for the principals. "[I am] A little nervous, kind of. I mean, they run the school" (Jim, Interview 2). However, after conducting the survey and completing the presentation all students considered these emotion evoking experiences not as negative but instead as an "accomplishment" (Jonathan, Interview 3, May 31, 2019), one which generated feelings of pride. One student stated that it made her feel good about herself and that she felt "powerful" after presenting: 
I just felt like kind of powerful. I don't know. It just felt really good to get it done ... For like your first year of middle school doing that, it just made me feel like good about myself for doing that already even though it's only my first year of middle school and getting that done (Mae, Interview 3, May 31, 2019).

The following summary of Natalie's evolution of emotions is representative of the affective responses of all students as they engaged with these new experiences: surveying older students and presenting to the principals:

I was proud when we did the survey because we don't really talk that much. I mean, we talk to each other. We goof around and stuff like that sometimes, but talking to the eighth graders and the seventh graders, just having them be three to five years older than us, was kind of ... it was a little bit scary. It was. It made me proud because I felt like getting to socialize with those people, that it was kind of a new experience. (Natalie, Interview 3 , May 31, 2019)

The challenge and growth students experienced was illustrated in Mae's mother's ideology that any experience "out of your comfort zone in a supportive environment is always very enriching" (Mae's mother, June 4, 2019). Her notion is evidenced in other studies focused on the Enrichment Triad. Brigandi et al, (2018) found that "students perceived engagement in Type III Enrichment as cognitively challenging. Perhaps unexpectedly, however, successfully navigating this challenge positively affected students' perceptions of enjoyment after project completion" (p. 298). Similarly, the fifth-grade students in this study, who participated in a place-based Type III, reported feelings of embarrassment, nervousness, and being scared. After successful completion of their Type III, they shifted their mildly negative emotions and positively perceived their experiences, reporting they now felt "powerful" and "proud." 


\section{Students' Navigation of Interpersonal and Collaborative Discourse}

Students' narratives depicted various opportunities and degrees of collaboration within their schooling. Stories noted: (a) the lack of opportunities to collaborate with their peers in their general education classes, (b) students' preferences for collaborative learning and (c) students' experiences in collaborative discourse within a Type III. Research literature claims gifted students benefit from collaborating with other gifted students (Diezmann \& Watters, 2001; Kaplan, 2014; Rogers, 2007) and when tasks are challenging, gifted students typically preferred to work collaboratively (Diezmann \& Watters, 2001). The themes found in this study support the literature, but also provide depth or nuanced understandings of this notion. Students' shared stories of their predominant interests in collaborating aligned with what the literature suggests, but they also illustrated challenge with collaborative processes, especially within a Type III. Interestingly, the discourse of collaboration was evidenced in how students framed their collaborative discussions within a Type III as a challenge, but ultimately as the most rewarding.

Collaboration was not a learning strategy students in this study experienced fully or often in their general classrooms. Mae's narrative illustrated the differences between her general education class and her collaborative experiences in her gifted class. She began by outlining the lack of collaborative problem solving in her general classroom:

If we have any problems we can only talk to the teacher, and we can't really work it out with a partner, which would probably give us more knowledge, instead of just going to the teacher and her telling us. It would be better if we could just work it out with somebody. (Mae, Interview 2, April 10, 2019)

Sam also asserted that in gifted class: 
"[W]e can talk more often sometimes...We can talk quietly. While there's more people in the classroom that are done, they're going to be louder talkers, so that means the teacher wouldn't let us talk more often... I mean you can talk to your friends more without getting in trouble [in gifted class] because usually in regular class there's more people and usually teacher yells at everyone versus a couple people. (Interview $1 \& 2$; February 22, 2019; April 12, 2019)

Mae goes on to discuss the social acceptability of disagreeing with your peers and the development of personal autonomy within a Type III as compared to her general classes.

Like, you get to talk a lot more and use teamwork a lot more and say what you're feeling about the project instead of just saying, "Okay, we can do that." You get to be like, "No, we shouldn't do that. We should do this." Then, the group that's kind of like some people say, "Oh, yeah, we should do that. Yeah, we should do that," instead of in other classes you just come... the teacher tells you what to do. (Mae, Interview 3; May 31, 2019) Just as Mae recalled, traditionally "the teacher tells you what to do" and typically processes are standard. "I research it, I do a PowerPoint, I present it. I research it, I write a paper, I turn it in. I don't even present it" (Jane, Interview 2, March 19, 2019). However, by engaging in a Type III focused on place, students found themselves collaboratively detailing decisions and processes for a larger purpose than to just "present it" or "turn it in."

From the beginning of the study, students voiced their enjoyment of collaborative experiences that encouraged them to work together. For example, Jim remembered an activity from fourth grade in which he collaboratively "built boats and you had to put them on water... and just see who's stayed up the longest and stuff" (Interview 1). He claimed this activity was meaningful because "we did it on teams so it kind of be like a teammate and stuff like that, like 
work together." At the outset of the study, most of the other students expressed a similar preference for collaborative opportunities.

The relationship between collaboration and gifted and talented students is often assumed to be an easy and successful learning experience (Kaplan, 2014), but with newfound student autonomy in a Type III, students in this study experienced collaborative challenges, despite their propensity towards engaging in collaborative experiences. The gap between students' desires to work collaboratively and their knowing how within a Type III was illustrated in both Jane's and the students' narratives.

Jane attributed the variableness of the collaborative process in a Type III to being "out of the normal of what they've done" (Jane, Interview 3, April 30, 2019) and specifically talked about students' struggles in the process.

I think they're a little bit frustrated with "why isn't she just telling me what she wants me to do?" It's a struggle for them when every detail isn't outlined ... They can't agree on who is going to do what, nobody wants to be the one that talks, no one's emerging as a leader in that group to kind of take charge and say, "Okay, let's do it, this, this and this." And kind of give people roles. So, that part's a little bit of a struggle ... they're not working together all that well... (Jane, Interview 2 and 3, March 19, 2019; April 30, 2019)

Jane was not the only one to recognize this struggle; the students also voiced challenges within the collaborative process. "Probably whenever we were figuring out how we wanted to present it ... I think that was probably the most stressful time because nobody knew what we were doing and we were kind of just mixed together" (Mae, Interview 3, May 31, 2019). 
While some students expressed frustration with the collaborative discourse, they all perceived a value in it. For example, Natalie became frustrated "when we were trying to decide what project to do. We kept disagreeing, and we weren't coming to the conclusion... we could not get it straight on what we were going to do." (Natalie, Interview 3, May 31, 2019). Despite this frustration, Natalie repeatedly discussed her enjoyment working together as a group and her desire for more opportunities to engage in the collaborative processes.

I enjoy that. Working with everyone, instead of by myself . . I like to socialize ... I enjoy working in groups of people more. I just think it's better to talk with other people about their ideas, too. . I I would probably just make us work together on everything. That's my favorite thing. Just working with everyone. That's probably one of the only things I would change. (Natalie, Interview 2, April 10, 2019)

Similarly, Sam discussed his disapproval of how group members made decisions when choosing a topic. The students utilized a decision-making grid to narrow the topic of the project based on criteria students identified, such as "cost" or "likely to get approved." Sam felt certain criteria should have been ranked higher than others.

I don't really think it should have won with all the other ones. Like someone had Fortnite [club] and that turned out to be the least popular. Well, it's also it's probably going to be the most popular because most people like Fortnite. One of the lowest, it got like a two. It should have got like a five. (Sam, Interview 2, April 10, 2019)

Yet, in the end he was content with the topic chosen citing personal relevance for his acceptance of it and a need for current policy to change. "I am really thirsty when I come in and usually I can't get a drink until like five minutes after so, and you get no time at the water fountain. So it's just kind of bad" (Sam, Interview 3, May 31, 2019). 
Both examples, Natalie's and Sam's, illustrated that students engaged in authentic collaborative discourse throughout the place-based Type III. Despite having to negotiate decisions as a group through discourse, students positively reflected on the experiences, as all of them stated they would like to continue to conduct Type III's, or "projects," in the future. For example, Sam claimed if he was in charge of the gifted program he would definitely keep [t]he projects. Because they're fun most of the time. The water bottle one is pretty fun so that one's the only one we've done, I'm pretty sure. [I would change] how often we have the projects. Maybe once a month or I think we might have them once every two months. I would want them once a month because I like the projects that we do. Because sometimes you get to go around the school and do some fun stuff. (Sam, Interview 2, April 10, 2019)

Jim juxtaposed his collaborative experiences with his typical school experiences and stated he would like to "do more projects. I mean, they're fun. And you get to interact with others. It's better, it's just kind of better than just doing schoolwork" (Jim, Interview 2, April 10, 2019). He did not perceive his engagement in collaboration as a norm for "schoolwork." Natalie concurred, stating that if she had the power to guide curriculum she would "definitely [keep] what we're doing right now [place-based Type III].” Even Jane claimed she would implement a place-based Type III with her eighth-graders next year.

Student engagement in a Type III focused on place allowed challenging and collaborative learning opportunities throughout the semester. The collaborative processes were facilitated by the teacher, but largely left for students to decide. Unlike traditional group work in which roles are assigned and processes are scripted, the students navigated social complexities of 
collaborative work (Kaplan, 2014) and made collective decisions based on topic, content, process, and product — areas which are traditionally dictated by teachers and textbooks.

\section{Students' Perceptions of Interpersonal Growth}

As students reflected on what they learned in the place-based Type III, their responses provided evidence for interpersonal development (Renzulli \& Reis, 1997; 2004). In fact, events that engaged students in collaborative discourse and activities and sparked students' emotional responses, detailed in previous sections, were perceived by students and teacher to be the most valuable learning experiences both now, and for their futures.

Students reflected on their collaborative processes and how those experiences supported their learning. Natalie claimed her learning was espoused through "teamwork. Working with the boys and the girls in a small group was kind of hard because they have way different opinions than us" (Interview 3). Mae claimed what she learned in the place-based Type III was "to get what you want you need a lot of hard work and teamwork if you can get it" (Mae, Interview 3, May 31, 2019).

In a similar vein, other learning was also derivative of affective growth. Presenting to the principals conjured mildly negative emotions in almost all the students. Yet, students recounted the experience as pivotal in their learning. Sam claimed that "I learned how to present properly" (Sam, Interview 3, May 31, 2019) and Jonathan concurred and claimed his most influential learning was "probably how to present better. I've presented things in the past but never like to principals and like stuff that run the school, so just to present to like higher authority people probably" (Jonathan, Interview 3, May 31, 2019). Natalie echoed her peers sentiments and recalled: 
Well, I learned a lot about the presentation and eye contact. . . I learned that you have to get a point through no matter what, and you have to have details to support that, or else what's the point of having it? (Natalie, Interview 3, May 31, 2019).

Jane also felt that her students gleaned the most learning from their experiences presenting. ... I think presenting, and even one of the students said, "I learned how to actually present a project," which was really cool to hear and from that specific kid, yeah, because he is not one that puts a lot out there. So, it was really cool for him to be the first one to kind of chime in and to chime in with that because I had seen that outcome, but for the students to realize, "Hey, maybe before we did this, I didn't. I've presented a lot of things, but I really wasn't sure what made a good presentation," that was just really cool to hear. (Jane, Final Interview, June 04, 2019)

Perceived learning for students were related to the processes they engaged in as opposed to the content they learned from enacting original research or conducting a literature review on the topic. The participants discussed interpersonal skills such as "presenting" and "working together" as achievements within the place-based Type III. This supports Brigandi's (2015) claim that although typical methods encompass advanced content acquisition for gifted students, non-cognitive processes are equally essential:

When students find learning interesting, meaningful, and enjoyable, and when they are personally interested in the topic, their identity is tied to the task, they view the task as something that is immediately useful, or they view the task as useful in the future, they are more likely to engage and achieve. In essence, if we want students to achieve academically, we must appeal to the non cognitive before the cognitive. (p. 118) 
Not only was the Type III meaningful for students, many perceived their newfound presenting skills to be the most applicable to their future endeavors:

It would kind of help with a job interview or something like that because you get more comfortable presenting in front of people that are in charge of you and stuff like that. So that would probably be very helpful to be able to talk to people without being shy about it. If you ever have to put together like a presentation for your work or maybe learn how to work with different people that you don't know super well. (Mae, Interview 3, May 31, 2019)

Jonathan also perceived his newly crafted presenting skills, despite the fraught affective process to achieve them, as important to his future. "Probably for presenting in the future. Since I've already done it before I'll know how to do it in the future." (Johnathan, Interview 3, May 31, 2019).

By engaging in the discourse of the place-based Enrichment Triad, students saw value in their interpersonal learning experiences and increased their social self-concept (Bain \& Bell, 2004), especially with regard to peer collaboration and interaction with older peers and those in power. The themes threaded with affective conflict, such as negative emotions and collaborative discourse, were most prevalent in the teacher's and students' narratives as the most prevalent perceived learning that resulted from their engagement with a place-based Type III.

\section{Cogency of Place in Curriculum}

As evidenced in Jane's pre-existing curricular frames, place-based education was largely absent from the curriculum. Implementing the place-based Enrichment Triad was Jane's first conscious attempt to connect her gifted curriculum to the place in which her schooling was enacted. I term it "conscious attempt" because in some of her narratives she discusses activities 
that had threads of place-based education, but were housed in her more dominant influences of STEM and competitions. Therefore, the "place" potential was largely undeveloped. Despite Jane's inexperience with incorporating place in the curriculum, clear themes emerged in the narratives that showed the impact of studying place on student learning and teacher growth. Engagement in a Type III focused on place shifted curricular focus towards: (a) tangible alignment to students as individuals in place, (b) positioned students as change agents within their small rural place, and (c) fostered a teacher's growth toward acknowledging students' rural identities in curriculum.

\section{Tangible curriculum.}

Notable shifts in curricular points of view were evidenced in many of the participants' narratives. Parents and students both noted that the particular activities and projects students had experienced previously were less challenging and more abstract and nonpersonal. In contrast, the place-based Type III engaged students in projects that were holistic and meaningful.

For example, Natalie's mother pointed out that the skills required in the Type III focused on place may have not been new skills. Students were previously given opportunities to research, present their products, and engage in certain collaborative experiences. However, as she emphasized, typically these skills were taught and practiced in isolation. Rarely were students engaged in projects that required the totality of these skills. Similarly, Jim's mother noted the expectations for learning this semester differed from other projects.

They do projects in a reading class and they have to present in front of the class. But there's only one time it was a group and there was no compromising or research needed. Just had to read a book and make like an art project on it. Because I think that's [Type III focused on place] a totally different level. And to give opinions and to fight for 
something. No, I want to say this is his first opportunity for this type of research and project. (Jim's mom, May 30, 2019).

Her narrative illustrates the influences of the Enrichment Triad Model (i.e., "totally different level") and a focus on place (i.e., "give opinions and to fight for something"). The students were advocating, on behalf of the whole student body, to change policy within their school.

Another theme emerged that illustrated a perceived curricular shift from extraneous purposes to relevant matters. Jane noted that engagement in a place-based Type III:

Helps to give students value and meaning and ownership over what they're doing. If it's a project that they can see the direct effects of in their community or in their school, they're going to be a lot more excited about it than if it's something that is just, "Oh look, like these students might want to implement this program of having water bottles in their school. What are they going to have to do?" Versus, "Hey, if you want to have water bottles in school, which is what the students decided, what do you have to do? Who are the people that you have to talk to? Let's go find those people in our building and talk to them." [Italics and underline added; Jane, Final interview, June 04, 2019]

In this quote, Jane used literary third person to describe traditional learning experiences. Third person learning experiences (i.e., they, their) are hypothetical and decontextualized to students' identities, the places they live, and the current contexts of their daily lives (Theobald \& Wood, 2010). In contrast, first person learning experiences (i.e., we, our) facilitated by the place-based Enrichment Triad, foregrounded students' interests, realities, and lives in authentic placed contexts and actions (Ayers Paul \& Seward, 2016; Comber, 2016; Comber, Thomson, \& Wells, 2001; Graham, 2007; Greenwood, 2011; Sobel, 2004; Woodhouse \& Knapp, 2000). Jane’s 
comparison encapsulated the compelling place-based curricular shift that a focus on place had to offer.

Students and parents also recognized and highlighted the meaningfulness of the placebased curriculum Jane designed:

It's basically only in this class, I feel like [we] talk about stuff that's important like the water bottle project and that kind of stuff, we get to decide for ourself what we want to do with that kind of stuff, and work together ... I really like projects, but not the projects like I just said, where you just learn about one person, and never really think about them again, because unless that person's really important to you and that kind of stuff, I don't know. I just think there's really not a ton of importance to doing that. [Our current project], will make a difference in the school, and make a difference in probably student's lives, and maybe teacher's lives too. (Mae, Interview 2, April 10, 2019)

Her mother echoed her statement on the relevance of the place-based Type III:

I think that was of course the big difference this year is that it was a learning experience where ... I think it incorporated a lot of different things that could be applicable to everyday life as opposed to doing a project that is just simply creative as far as literature goes or creative as far as dropping a pumpkin or things like that ... (Mae's Mother, June $4,2019)$

In sum, while the gifted students had previous experience with certain skills (e.g., using the internet to find facts or creating a visual display), engagement in a place-based Type III increased expectations and the relevance/meaningfulness of their curriculum. Students engaged in a project of their choice. The topic of study, processes to study the topic, and products to persuade the authentic audience were not only decided by the students, they were controlled and 
enacted by them. While this process was standard in a Type III, in a place-based Type III the focus was within the context of their local, school place-where change could be immediately conceptualized, visualized, and enacted.

\section{Students' evolving identities as learners.}

A theme that emerged within and amongst the narratives was the significance of student action in the local place. The rural county's vision aimed "to inspire students to become ... productive, caring, responsible, American citizens" (Rural County Board of Education, 2019). America is a democratic society and when "power is vested in the people and exercised by them directly" (Britanica, democracy) democracy occurs. Greenwood (2011) claimed "paying attention to places, and inviting learners and citizens to play a direct role in describing what they are and what they become, place-based educators are practicing democracy" (p. 635). Therefore, in the place-based Type III, students were actively engaged in a democratic process where they were positioned for affirmative action meeting the county's vision of students being "productive, caring, responsible American citizens" (Rural County Board of Education, 2019).

The students perceived their democratic action (e.g., advocating on behalf of the student body) as an exceptional opportunity towards change in their learning environment. "I think that's pretty awesome that we can even try to do that. It was a great experience for us, trying to change something" (Natalie, Interview 3, May 31, 2019). Even though they did not perceive it as an easy task. "I thought it [change] was going to be hard to do just because it's been in the policy for such a long time but I thought if we devoted just to try ..." (Jonathan, Interview 3, May 31, 2019). Because this project would benefit the entire student body, Mae perceived their potential success as being comparable to a "hero" 
Sometimes you just have to work really hard to get something, even if it's not just for you._It's going to be for like everybody and everybody's going to get something out of it and you're going to do like a hero. I'm not positive that we got it yet, but if we did, I think a lot of people would be happy that we got water bottles allowed and I just think that would be really cool. (Mae, Interview 3, May 31, 2019)

Traditionally, what and how rural students learn and the products that they create are superfluous to the contexts of their current lives (Theobald \& Wood, 2010). In fact, they often do not get the opportunity in school to learn anything about their own socio-cultural realities (Anyon, 1981). Moreover, the benefits of what students learn and how they engage in their learning is generally self-contained with only self-gaining effects. In contrast, in the place-based curriculum learning opportunities were relevant and meaningful to students' lived realities and identities. Mae acknowledged this influential shift the place-based project offered and noted that if successful, their work could potentially effect "everybody." Jane, too, noted the power of transformative action and its extensive outreach. I think this place-based activity will be really great for that [meaningful] because it's something they can see happen. It's something that they can see that they've made a change to. Yeah, and it's something that when their friends are like, "Oh man, I'm really glad that we do this," they can say, "Well I implemented that. That change came about because of me ... from this project, I want them to see that if there is something that they see as an issue in their school or in their community, that there's things that can be done about it ... (Jane, Interview 2 and 3; March 19, 2019; April 30, 2019) Although the students' and teacher's narratives illustrated the power of studying place, each parent interviewed indicated that students had not participated in place transformative 
action prior to engaging in a place-based Type III. A few parents stated their children had observed transformative pursuits via siblings and listening to speakers on affirmative action, but had never engaged themselves. Despite students' inexperience with transformative action in place through a Type III project, parents perceived the transformative purpose as beneficial. "It was beneficial because he was thinking about something, a real problem in this school ... So, to tackle something like that, and to have that in their court, to be able to make a change I think is a very good thing" (Sam's mother). Mae's mother shared, "[S]he feels like she can make an actual difference in her learning environment, and in her educational experience whereas in the past... you're doing more projects but it's not really leading to a change that could affect other people (Mae's Mother, June 4, 2019). Jim's mother further supports this notion claiming:

It probably opened his eyes into you can fight for local issues, you can make changes in your community if you want to. And that's what, I don't think middle school kids have an idea of. So I think that's a young age to start it, but a good thing." (Jim's mom, May 30, 2019)

Using the Enrichment Triad focused on place rooted curriculum in a research based gifted model (Renzulli, 1977; Renzulli \& Reis, 1997; 2014) and facilitated student learning relevant to the gifted students' lives and identities (Gruenewald 2003; Theobald \& Wood, 2010) . Moreover, students were positioned in democratic action as change agents and worked towards transformative action within their local school place (Smith, 2002). Fifth-grade gifted students worked to rectify an unpopular policy and through this endeavor were given power over their learning environment. 


\section{Jane's evolving understandings of student identity.}

The cogency of place was evident in Jane's evolution from acknowledging the importance of students' interests and extrinsic motivators towards embracing students' identity constructs through intrinsic motivation supports. While both motivations, intrinsic and extrinsic, play an important role in student achievement; intrinsic motivations are tied to students' identities and devout interests. Through Jane's evolution, she came to regard her students as not just learners in her classroom, but unique beings with differing learning interests and identities.

For the duration of this study, Jane understood that her gifted students often were extrinsically motivated. Extrinsic motivation is defined simply as rewards or punishments and “encourages short-term goals" (Cropper, 1998, p. 28)

[T]hey're motivated learners already, they're motivated in the sense that they want the grade, they want the A, or they want to please their teacher or they want to finish a task. . . I think sometimes they get caught up on they want to so badly meet that expectation. (Jane, $2^{\text {nd }}$ Interview, Final interview)

Jane perceived the reward of an " $A$ " or social reward of being praised as a motivator for her students to engage and succeed in their gifted class.

Jane's narrative affirmed how her curriculum encouraged the extrinsic motivation her students expected. Jane regularly incorporated competitions into her curriculum, and Sam's enthusiasm within a portion of his narrative illustrated how Jane's use of competitions supported his extrinsic motivation. "[Y]ou can mail it in, and then if you win [you get] $\$ 500$ towards your college. I want to be a mechanical engineer, and I wrote some stuff about that. Yeah. I really want it!" (Sam, Interview 1, February 22, 2019). Sam also noted that he completed the 
assignment well before the due date and expressed his desire to win the competition. He was extrinsically motivated by the competition and the monetary reward.

Another student, Jonathan also espoused his extrinsic motivation when he discussed why competing at Math Field Day was significant for him. "Because I was the first in my family to go to it before. So it was kind of just cool to do it for the first time" (Jonathan, Interview 1, February $22,2019)$. Jonathan described how it was an honor to attend the event because no one in his family had earned the privilege to do so. He wanted to attend because of how it positioned him within his family. Jonathan also experienced another extrinsic motivator while competing, that acted as an extrinsic motivator for future competition. His performance earned him academic and social notoriety "because in the fifth grade in just this school, I got the highest score for field day" (Jonathan, Interview 1, February 22, 2019).

Intrinsic motivation can be defined as "doing an activity voluntarily for the inherent pleasure of the activity itself and the satisfaction derived from performing the activity" without external rewards or consequences (Vallarand, Gagné, Senécal, \& Pelletier et al., 1994, pg. 172). Intrinsic motivation "occurs when an individual develops a long-term interest in an activity or project" (Cropper, 1998, p. 28). At the beginning of her school year, Jane asked her students what they would like to "do" in her class:

We sat down at the beginning of the school year. I said, "I'm going to see you three days a week now instead of the one day a week that I saw you last year. What kind of things do you want to do?" (Jane, Interview 1, February 5, 2019

Her use of informal interest inventories evidenced her conceptualization that student interests influenced their motivation and learning. While her intents were positive, her use of the strategy was static, generic, and did not elicit students' long-term interests (Cropper, 1998; Brigandi, 
2015; Brigandi et al., 2016), which left her "searching" for activities and opportunities for her students (Jane, Interview $1 \&$ 2, February 5, 2019; March 19, 2019). At this point in her narrative, she had not recognized that the focus of an interest-based curriculum arises authentically from the intersection of students' identities and interests. Identifying interests is pivotal for students who are not extrinsically motivated because interest as an internal construct is tied to motivation. In general, gifted students are intrinsically motivated, even more so than their non-gifted peers (Clinkenbeard, 2012; Vallerand et al., 1994). While some gifted students have high academic intrinsic motivation (Gottfried, Cook, Gottfried, \& Morris 2005), for others the academic curriculum requires revision to include students' interests and spark motivation. In fact, motivation contributes to achievement and incorporating students' interests and personal relevance into the gifted curriculum capitalizes on the phenomena and supports intrinsic academic motivation (Siegle \& McCoach, 2005).

For example, students engaged in the place-based Type III were studying a topic they chose and were interested in thereby supporting their intrinsic motivation (Delcourt, 1988). Jane appreciated how students' interests and their motivation were interrelated:

My older kids are super into it, like they're coming in here in the mornings early and working on it [robotics competition] and that kind of thing, so I thought, "Oh, the fifth graders might really like this." It fell flat on its face. I mean, they're great kids. They oblige anything that you ask them, but they didn't have a passion for it. They didn't have a true interest in it ... (Jane, Interview 2, March 19, 2019)

In this narrative, the effect of intrinsic motivation was demonstrated for her middle school students; they came to class early to work on the project and were "super into it." Yet, her fifth grade students were not intrinsically motivated to build robots which indicated developing 
intrinsic motivation cannot be prescriptive or generalized across all students. While academic intrinsic motivation is higher in younger students (Lepper, Henderlong, \& Iyengar, 2005), the fifth grade rural gifted students did not appear to have high academic intrinsic motivation related to their gifted curriculum. Creative, productive students are internally motivated to engage in self-selected, interest-based activities, like Type III's, but externally motivated in traditional school-based activities (Delcourt, 1988). Understanding this notion, Jane demonstrated reflexivity towards her fifth graders' needs by continuing to try and search for activities of interest that would motivate them.

Like I've tried to pull activities and competitions because that's what has worked for us in the past in gifted activities, and they've really enjoyed. I've tried to say, "Well okay, we've got this poetry contest going on," or, "We have this robotics competition going on." They don't like to write and they don't like to do robotics (Jane, Interview 2, March 19, 2019).

Jane discussed the difficulties she had motivating her fifth grade students, and she recognized that "the motivation that's lacking is true excitement for what they're doing" (Final Interview). She understood students who are motivated, engage or complete tasks more readily than those who are not motivated.

As the implementation of the place-based model proceeded, Jane began to accept students' intrinsic motivators as pertinent to their overall degree of motivation. Jane's perceptive reorientation expanded her curricular focus beyond content acquisition in STEM toward mining students' interests through an understanding of her students' identities. She expressed that next year she did not want to continue to "hit the ground running" in her curriculum and instruction as 
she had in the past; instead she planned to incorporate more in-depth interest gathering activities and time for problem finding:

It's made me a lot more aware that I need to be focused on who they are as individuals and not just their learning. Like, if we're going to focus on something place-based, or if we're going to focus on something that's of interest to them, I have to know what their interests are. And two, I get with them and I'm like, "Oh, I only see them 30 minutes, two days a week, we've got to hit the ground running." Well, and I think that has changed my mindset as to how I'll interact with my students starting next year ... I think next year I'm not going to be as concerned about starting right into whatever we're doing as I am to finding what their interests are and where ... like if we're going to do a place-based activity, well, what is it in your environment that really interests you? What is it that really bothers you? What activities do you enjoy? So, I think that's kind of the impact that's had (Jane, Final Interview, June 04, 2019).

Next year, before envisioning her curricular map, Jane foresees herself asking the questions of her students "What interests you? What bothers you? What activities do you like?" rather than just "What do you want to do?" By creating this open dialogue with her students, Jane may gain access to her students' various identities including academic, cultural, familial, or community and how their identities could potentially interact with and inform curriculum design and the creation of the their learning environment. Engaging in the cogency of place in curriculum shifted Jane's curricular ideology from content "learning focused" and "what do you want to do" toward differentiated "identity focused" and "who are you?"

The place-based Enrichment Triad positively impacted students' affective growth as they engaged in new and challenging experiences. Additionally, there was evidence of powerful 
impacts to the learning process and student positionings when a curriculum was focused on place. Jane's curriculum was no longer abstract and extraneous; instead, it became relevant and meaningful, and positioned students as change makers within their learning environment. Moreover, although Jane always understood the importance of student interests, she began to embrace students' identities as applicable to her curricular decisions.

\section{A Place's Influence on the Conceptualization of Gifted Education}

Giftedness and gifted programs are conceptualized differently across places and across cultures. The inability to universally define giftedness, lack of federal programming policy, state policy variances (NAGC \& CSDPG, 2015) and funding and resources disparities (Kettler et al., 2015; Hammer et al., 2005; Plucker, 2013) all contribute to variances across programs and practice. This section highlights the themes that emerged related to a place's influence on gifted education in a small rural Appalachian school. Various structural and contextual inhibitors to gifted education were noted and prominent themes that emerged include a) certification hurdles

for teachers obtaining gifted endorsements b) diminished participation and identification for rural gifted programs c) undervaluing of gifted education in place and d) colleagues' perceptions of the gifted position. These barriers were noted not only in the local or micro structures but also in the larger or macro structures as well.

\section{Certification Hurdles for Teachers Obtaining Gifted Endorsements}

In West Virginia, additional endorsements such as gifted could be obtained by taking the Praxis, a standardized assessment. However, this was a recent change in policy and during the time when Jane went through certification she was required to complete a substantial amount of coursework. "If I had stayed in West Virginia and certified, I would've needed 36 hours to have 
done it" (Jane, Interview 1, February 5, 2019). Of the hours required for gifted certification at her in-state institution at the time, only four classes directly related to gifted education. The other courses were categorically special education courses and had no direct application to gifted identification or education. In addition, the substantial coursework hours required for certification was comparable to hours required for a Master's degree. With similar requirements between gifted certification and a Master's Degree in gifted, Jane perceived gifted certification as getting a second Master's degree. “Already having a Master's degree, having to go back and get another Master's degree to add on that certification" (Jane, Interview 1, February 5, 2019) was not a task Jane was willing to undertake. The conflation of gifted and special education certification preparation and the extensive amount of coursework, led Jane to pursue another certification route:

My first job was severe, profound in autism room, so I had multi CAT, which to me I felt like a lot of the courses ... I was taking there, I'd already done to get that degree in special ed. So, then it didn't count towards the Masters for gifted there, and I was like, "This is crazy." So, I started looking at other certifications. . I f found Tennessee and they would accept my classes that I'd already taken at [Big City University] and the degrees that I already had ... I was able to certify ... versus if I had stayed in West Virginia and certified, I would've needed 36 hours to have done it. (Jane, Interview 1, February 5 , 2019)

Typically, and as Jane shared in her own experience, teachers pursued gifted credentials while serving as the gifted educator in this rural area. Not many teachers enter the gifted classroom credentialed in gifted education; instead they earned credentials while in-service (Miller \& Brigandi, forthcoming). Pragmatically, though, the logistics of being a new teacher and 
unreasonable amounts of advanced coursework created a significant barrier for Jane. Essentially, Jane circumvented the barrier and attained her gifted credentials externally, out of her state.

The barriers that Jane and other teachers seeking certification experienced influences the quality of gifted programs. If teachers are not provided rigorous and relevant learning opportunities specific to gifted education, they are less likely to enact quality gifted programming standards such as the use of evidenced-based instructional strategies for gifted students' cognitive and affective growth (NAGC, 2010). West Virginia's certification requirements first confounded gifted education with broader special education, then changed criteria for certification to a passing score on the Praxis, a practice of minimal standards - $\mathrm{a}$ practice that reaffirmed Brigandi \& Miller's (2018) claim that "gifted education is one of the only areas where teachers are expected to learn on their feet" (p. 27).

\section{Diminished Participation and Identification for Gifted Programs}

As noted in Chapter 2, Jane's Appalachian state is one of the very few states that service gifted education under the special education umbrella, thus requiring an individualized education plan (I.E.P) for identified gifted students (NAGC, 2015). While this process does work to ensure mandated services, services are capped in the eighth grade. At the end of the eighth grade year, students are "exited" from I.E.P. services, unless they have twice exceptionalities (a.k.a gifted and attention deficit disorder). When Jane discussed parents' resistance to beginning the process of identification in the middle school, she believed this resistance was due to the limited amount of time a student would be in the program before they were exited their eighth grade year.

... It is concerning because. . . I know that there's still those students there that we would label, but...by the time I'm really seeing most of them, it's not a process the parents want to go through because they know they're going to be out in eighth grade, so it's not a 
process at the middle school that really gets started really often. (Jane, Interview 2, March 19, 2019)

Research findings are consistent and students from low SES backgrounds and schools with high concentrations of low SES students are less likely to be identified as gifted (Bromberg \& Theokas, 2013; Olszewski Kubilius \& Clarenbach, 2012; Plucker et al., 2010). Ten of the fourteen schools in Jane's rural county either qualified or were "near eligible" for Community Eligibility Provision, a program that provided free school breakfast and lunch to all students in the school due to high number of need (Food Research and Action Center, 2018). While Jane's school was not on the list, the three elementary schools that fed into her middle school were suggesting an increased risk for under-identification.

In recent years the opioid epidemic has notably affected this area. Over the course of this study, there were multiple articles in the local paper focused on the drug epidemic and its effects on the community. One headline read "Fentanyl deaths up 122 percent in West Virginia." (Appalachian County Daily Newspaper, April, 16, 2019). In an open educational forum in the county during the time of data collection, the superintendent of the county stated that "Fortythree percent of the babies born in this area were addicted to drugs" (Field notes, March 26, 2019) and in the state there were over fourteen thousand households where grandparents assumed the role of parents (spotlightonpoverty.com, 2019). These statistics are indicative to the shifting cultural realities and current educational concerns.

A discussion emerged within a professional development session that addressed these concerns. The gifted teachers who participated in the PD shared their observations of population shifts over the last few years. Jane herself noted this shift and decline in gifted identification and discussed her thoughts in both in the PD session and in her narrative stating: 
... Now, the numbers are quite smaller at the primary schools . . .So it is a concern I don't know if the population is changing or if the way we're identifying students is changing, or just that some of the teachers that were identifying students at the primary at the first/second grade level have retired and now our new teachers, that's not a process they're following. It is concerning . . .(Jane, Interview 2, March 19, 2019)

Jane and her peers' perceptions of reduced enrollment in gifted programs were not unfounded. Within the last five years, gifted enrollment in the county was reduced by almost 50\%, an alarming amount (Rural County Special Education Department, personal communication, 6.26.2019). Over four-thousand students were enrolled in the rural Appalachian county school system in which Jane teaches, but only a disappointing 72 students were identified for gifted education services (Rural County Department of Education, personal communication, 6-26-2019).

Many students also felt their cohort was thin in numbers. In their responses to what they would change about their gifted class, Mae, Jonathan and Jim expressed wanting increased number of gifted students in their class. Mae's comments below are a representative example.

[If I was in charge though] I would change how many kids [are] going to gifted. I would make it a little bit more ... Not like a full classroom, but maybe just like five more kids, like the top 10, or something, because I feel like only five, that's not a lot of kids. . A lot of my friends are just as smart as me, I think, and they put the exact same effort into their work as I do, and that kind of stuff, but they're not in gifted class. . .they are probably in the top 10 , for testing scores. . I just think they deserve to get in too. (Mae, Interview 2, April 10, 2019) 
In light of under-enrollment and perceived structural barriers, Jane felt she must "market" her program to recruit students to not only attend, but also remain in the gifted program. Natalie's mother noted that some students who were identified decided to withdraw from the gifted program during the transition from the intermediate school to the middle school "students who were in the gifted program decided to not participate any more. [Did not give specifics on why the students left, but this does speak to the confliction that Jane was discussing in her narrative]" (Field Notes, June 4, 2019). Jane also described structural inhibitors that caused student withdraw: "Some of them are coming out of social studies, some of them are coming out of science, and some of them have their related arts even changed so that they can come to the gifted program" (Interview 2). Students who were scheduled to attend gifted class instead of their core classes were often required to make up the work they missed; therefore they did not see value in their gifted classes, which led Jane to believe she must "market" her gifted program. "I mean that sounds bad to say, "Hey, we're marketing our gifted program" But I think we're kind of trying to change the mindset of "well it's just more work. . . I want them to feel that they're not missing out on something, but they're getting to do really cool activities" (Jane, Interview 2, March 19, 2019).

Jane's desire to frame her gifted program as enjoyable and an opportunity for new experiences for her students, was also evidenced in her students' narratives. Natalie's narrative was representative of the students' perceptions of Jane's class.

I personally like gifted class in fifth grade better than all the rest. I like it more, because first of all, I like the teacher more. I just feel like it challenges more than the years before, because some of the stuff like we're new to, and things like that . . I like the projects that 
we do in this gifted class more than the projects that we did in the former gifted classes

(Natalie, Interview 1, February 22, 2019).

Jane's STEM curricular frame and engagement in competitions, shifted the "more work" perception of her gifted program because the activities were often student-centered, engaging, provided a chance for "new experiences and different things" (Jane, Interview 2, March 19, 2019)

\section{Undervaluing of Gifted Education in Place}

As the pilot study to this dissertation found, rural gifted teachers experienced "role factotums" (Miller \& Brigandi, forthcoming). No longer were teachers of academically talented students solely a gifted teacher; now and especially in small rural schools, they are Gifted AND teachers (Azano et al., 2014; Croft, 2015; Hammer et al., 2005; Miller \& Brigandi, forthcoming).

Efforts to reduce costs and plummeting gifted identification rates (Personal Communication, Special Education Department Appalachian County, June 26, 2019) have pushed this rural Appalachian county to combine traditionally separate job roles. For example, of the eight elementary schools in Jane's rural county, seven require special education teachers to provide services to all students in special education (Appalachian County school website; personal knowledge). In other words, gifted teachers are also responsible for all other students with exceptionalities in their school, sans services such as speech or occupational therapy. In the era of accountability and efforts to reduce achievement gaps, the need for a gifted teacher and gifted programs was written in policy (WVDE, 2017), but in practice it was perceived as nonessential (Azano, et al., 2014). Thus, teachers were taxed with providing quality curriculum and instruction for students with diverse needs, ranging across the continuum from those with gifts 
and talents to students with autism or students with learning disabilities. This lumping of diverse roles undermined the need for teachers specialized in gifted pedagogy and overwhelmed them with the vast differences amongst the needs of their students.

Jane also experienced the Gifted AND ___ phenomena. She was a math teacher as well as a gifted teacher in her middle school. Her school nametag reflected her two positions of math and gifted teacher. In addition to her dual roles, the hierarchal listing of her two duties with math first and gifted subsumed, illustrated how the rural county prioritized traditional school subjects over gifted education.

County level structural conceptions of gifted teachers' roles also undermined gifted education and positioned programs as non-priority. Jane's curricular focus and time divided between her two commissions, math teacher and gifted teacher. Additionally, her time was under-valued at the school level when her planning blocks were insufficiently prioritized and often misused. At times, she received less planning than her peers and during her planning time she was often utilized as a "filler" for other teachers.

[In the previous years] I had one planning, which was a planning less than everyone else. I had four different preps ... two more than anyone else teaching math in the building. . . It's gotten more manageable. I do have the two plannings most days of the week now ... On Tuesday and Thursday when I pull the gifted fifth grade students, that comes out of my planning. Generally, unless I get pulled to cover something else, then that time gets made up on Wednesdays and Fridays. But sometimes, the band director will be out, so I'll get pulled to cover that advisory or just something, somebody will have an IEP meeting, so I'll get pulled to do that advisory. So, generally, I get the two a week. 
In addition to her planning time being undermined within her middle school, Jane discussed a continued, and possibly, inadvertent demotion of gifted education when certain extracurricular activities at the school trumped students' gifted education time.

Well, okay, so, probably I should add. . . if they're [gifted students] involved in some other activity, if they're involved in jazz band, if they're involved in chorus, year book, STOP, the tech staff, announcements, the list just keeps going. Then, those students only see me two days a week. And then, sometimes a lot of ... the sixth and seventh with band and chorus, but other than that, I see them three days a week.

In sum, macro structural limitations at the state and county level and micro structural and socio-cultural contexts at the school level illustrated gifted education's undervalued existence within this rural Appalachian place.

\section{Colleagues' Perceptions of the Gifted Position}

While structural frames and administrative decisions portrayed gifted education as subsidiary to content specific courses, special education, and even other extra-curricular activities, amongst the staff, Jane's position as a gifted teacher, was perceived as privileged. She illustrated this in her re-narrating why there may have been "snarky comments" and hard feelings towards her when she obtained the mathematics and gifted position as a fairly novice teacher.

I think it was the teacher that. . . retired she had been in teaching longer than any other person in the math department. . [and] she'd been in this building longer than anybody . . . I think they saw that as, "Well, she's the oldest person. She should have the top classes," and they were okay with that. Then when I came in, I was the youngest person in the building, the youngest person on the math team. I had one year of teaching experience, and that was just, I mean everybody thinks that it happens on seniority and, "Well I put 
my time in, then it should be mine." It wasn't that way. . . (Jane, Interview 2, March 19, 2019)

The totem pole inversion that Jane's peers felt she enacted was associated with the perceived degree of ease in educating gifted and talented students.

That [gifted position] becomes coveted ... for teachers that don't teach the gifted group of students are like, "Oh yeah, well, you have the smart kids all day. You don't have any problems," And I'm like, "Well no, there are. Like maybe my issues aren't that my students are failing but there are issues. And in order to take those students from where they are and to take them to the next level, it's tough . . . (Jane, Interview 2, March 19, 2019)

The literature on teacher perception indicated a large degree of variance between positive and negative attitudes towards gifted programs (McCoach \& Siegle, 2007) highlighting the personal and cultural implications of particular perceptions. Thus, gifted positions in this small rural place, were perceived as prestigious in part because of stereotypical notions of student demographics. While Jane noted the tensions apparent amongst her peers she considered it unjustified. "I'm very blunt, so I just finally said, "Well, did you apply for the job?" "No, but I don't see what that has to do with it." Well, I applied for the job and then I've dedicated time ... (Jane, Interview 1, February 5, 2019).

Jane's experience as a new teacher in a "coveted" position runs counter to the high turnover rate in gifted education in the area. For example, in the exploratory case study that was designed as a pilot to this dissertation, all three teachers who participated have transferred to educational positions outside of gifted education (Miller \& Brigandi, forthcoming). Jane also eluded to high gifted teacher turnover when she discussed administrative decisions to train her in 
special education paperwork amidst the gifted teacher turnovers. "They knew that I was a consistent person here and that I didn't have intentions of leaving, so they trained me and not have to train the other person in how to do that paperwork" (Jane, Interview 2, March 19, 2019).

The high turnover is due in part to large amounts of paperwork associated with Individualized Educational Plans, role factotums (i.e., Gifted and____), and job insecurity (decreasing identification of gifted students) (Hammer et al., 2005; Monk, 2007). All three risk factors were heard in Jane's narratives, despite her degree of "fit." Specifically, Jane was a math teacher and a gifted teacher, at times overwhelmed with maintenance of I.E.P's of her gifted students and transition plans for her eighth graders, and she noted how student identification was decreasing.

In conclusion, the micro and macro structures in the school, county, and state inhibited and facilitated the production of Jane's gifted program. The conceptualization of her gifted program was envisioned in light of certification hurdles for teachers obtaining gifted endorsements, diminished participation and identification for rural gifted programs, a general undervaluing of gifted education in place, and colleagues' perceptions of the gifted position.

\section{Conclusion}

This case study employed narrative inquiry, and data were analyzed using both sociocultural narrative analysis and thematic narrative analysis. Findings indicate that implementing the place-based enrichment Triad challenged and facilitated Jane's curricular understandings and practice. Jane took up a new perspective of curricular origins and her students' positioning within it. Curricular "power" was shared between teacher and student and students were repositioned as change agents, rather than passive recipients of knowledge within their learning environment. Students benefited from both cognitive and noncognitive opportunities and growth. 
Lastly, findings also indicated that micro and macro structures influenced the construction and production of the gifted program in Jane's rural place, which subsequently left it largely undervalued. 


\section{CHAPTER 5: DISCUSSION}

In this case study, I explored how one gifted education teacher made sense of Renzulli's (1977) Enrichment Triad Model, how she used it to design curriculum informed by place, and how place and the Enrichment Triad Model influenced student learning. In Chapter 4, I presented socio-cultural narrative analysis and thematic narrative analysis findings. In this chapter, the discussion section, I conducted another level of analysis. The salient themes from the findings in Chapter 4 were theorized here using the guiding question, "What do my findings mean?" In answering this question, theories that emerged focused on: (a) the lack of interdependence between the teacher's rural sense of place and place-sensitive curricular experiences for her rural talented students, (b) the Enrichment Triad Model's efficacy for a small pull-out gifted program, (c) the use of place in the curriculum to re-position students as agents of change, (d) the value in merging the Enrichment Triad Model and place-based practices, and (e) how the written and unwritten policies of place shape the conceptualization and enactment of rural gifted programs. Questions for future research are woven into the discussion of each theorized point. The chapter concludes with implications of the findings specific to future supports for rural gifted teachers and rural talented youth, limitations to the research, and my final thoughts.

A teacher's sense of place influences how a place sensitive curriculum is enacted. Jane, the teacher in this study, demonstrated her connection to place through her narratives and in the creation of her physical classroom. Her sense of place influenced her higher education pathway both in geographic location and career paths. She attended a local community college for a year, then transferred to an in-state institution. Even while at the large university, Jane sought out experiences and opportunities that resembled the values and sense of community of her rural 
place (Heinisch, 2018). "You're in this big city compared to here [small rural town], but the neighborhood and the little school that I was in was just ... it was so homey" (Jane, Interview 1, February 5, 2019). Jane decided to major in education because it was a career that allowed her to return to her hometown after graduation. "I knew I wanted to stay in this area, so I knew that teaching was something that I could do in this area" (Jane, Interview 1, February 5, 2019).

Rural high achievers, such as Jane, tend to have strong attachments to place, but they are the most likely to leave and the least likely to return to their hometowns (Carr \& Kalafas, 2009). Yet, Jane, an exceptional case, did return home. Her boomerang back to place was attributed to her positive perceptions that she could obtain a job after college (Howley et al., 1997; Petrin et al., 2014). Jane purposely sought out a degree that would be applicable within the economic conditions of her place, teaching.

The meaning Jane attributed to her place was personal and bound by her experiences. It was deeply rooted with positive perceptions of her past and future possibilities within place (i.e., family and potential mother).Yet, global and accountable socio-educational discourses did not position Jane to enact a place sensitive curriculum. Instead, her curricular frames were guided by larger macro narratives that valued global citizenry, academic competition, and STEM fields. For example, Jane often utilized academic competitions as part of her curriculum (Campbell \& Walberg, 2011; Cropper, 1998; Ozturk \& Debelak, 2008). "We've been working on the Minecraft competition. . . the coding competition. . . a bridge design and build competition. . . we have this robotics competition going on" (Jane, Interview 1, February 22, 2019).

While some of the competitions described by Jane, especially statewide competitions, included a place focus, it was only through her participation in this study that she purposely and consciously engaged in place-based practices. After receiving PD on the place-based Enrichment 
Triad, Jane implemented it with her fifth-grade gifted students. She focused the topic of study on student perceived problems within their place, their school. As Jane made this change to her curriculum, she noted its various advantages, such as how it "helps to give students value and meaning and ownership over what they're doing. If it's a project that they can see the direct effects of in their community or in their school, they're going to be a lot more excited about it" (Final Interview). Even though she enacted emergent placed practices throughout the semester and positively reflected on its inclusion, her conceptions of its value and its capacity remained unimagined. For example, her fifth-graders successfully completed a problem-solving, placebased project however, Jane was hesitant to engage them in place practices in the future. Ideally, I would like for the eighth graders to go through this process and continue sticking with place-based. . not that the fifth graders didn't do a great job with it, but I feel like the eighth graders are a little bit more mature . . so, I'd like to do it with the eighth grade (Jane, Final interview, June 04, 2019).

Jane perceived her older students as the most suited for critical work. The literature, however, suggests that even young gifted elementary students are capable of critical thinking (Kettler, 2014) and using a critical lens within their place (Comber 2001; Comber 2016). If Jane had taken a more critical direction with her place-based practices, as critical place-based scholars suggest, she could have engaged her fifth graders in questioning and discussions, using students' Fok and dark Fok, to explore the disparities and inequities within place that impact their currency (i.e., no water bottle policy). These discussions, or place-based Type I's and II's, would have encouraged a broader perspective of the issue while building the skills needed to engage in critical place-based practices. If Jane had encouraged a more progressive perspective and engagement of 
place and allowed her students time to build these skills, her perceptions of the abilities to engage in such tasks would likely shift away from age or maturity, but toward opportunities to do so.

While Jane possessed a strong sense of family and connection to place, she struggled to use place as a way to connect her students to learning and potentially connect them to their place. This finding can be analogously compared to the pervasive myth that "teachers are born" (Britzman, 2012). Similarly, teachers with deep senses of place are not "born" with a conceptual understanding of place or how to enact place-pedagogy; instead they must engage in practices that allow them to foresee its value with their students. This theory aligns with Budge's (2006) study that found educational leaders' sense of place was paradoxical to the education they provided.

Leaders participating in this study clearly articulated their own attachment to place. .. Descriptions of long-time ties to family and friends, an appreciation of rural lifeways, and a personal identification with place provided strong evidence that leaders were influenced by a sense of place... Paradoxically... leaders could describe very few ways in which schooling provided experiences to help students live well in the local community should they decide to do so. (Budge, 2006, pp. 6-7).

Similar to Budge's (2006) study, Jane cultivated a strong commitment to family and place for herself in her small rural town, but she did not conceptualize the same positive interdependence and experiences of place for her students.

There have been recent calls to incorporate place-sensitive curricula and pedagogy in teacher education (Azano \& Stewart, 2015; Azano \& Stewart, 2016; Howley \& Howley, 2005; Hudson \& Hudson, 2008; White \& Reid, 2008). While much of the literature centers on 
preparing teachers without a rural sense of place to teach in rural places, the finding of this study contends that all future teachers require such learning opportunities to support and cultivate their students' sense of place — even those who are already deeply rooted in connections and commitments to the communities in which they teach.

Additionally, I suggest that rural teachers' cultural identities may not always be connected to their professional or teacher practices. Much of the place-based literature focuses on how rural students are implicated in the insular practice of schooling through inconsideration of students' cultural experiences and realities in schools. This study explores that teachers also navigate the segregated ideals between educational institutions and cultural or community identities (Azano, 2011). In Jane's case, she possessed strong attachments and relations with place. Her identity as a daughter, educator, and future mother were influenced by her immersion and commitment to place. Yet, beyond the décor of her classroom, school was not a place to demonstrate her rural sense of place or share it with others. This finding provides another layer to the discussion of school's insularity with regard to rural places because it suggests that teachers, not just students, are affected in the cultural segregation between educational institutions and the places in which they are situated.

Place-based education is a pathway for rural talented youth to envision themselves as participants and leaders within their place. Two salient place-based themes emerged from the findings. First, place-based education contextualized student learning and shifted content study from extraneous purposes to relevant, placed matters. Mae, a student, captured this finding when she stated: "It's basically only in this class, I feel like [we] talk about stuff that's important like the water bottle project... [it] will make a difference in the school, and make a difference in probably student's lives, and maybe teacher's lives, too" (Mae, Interview 2, April 10, 2019). A 
second place-based theme, indicated that using place in the gifted curriculum as a means of transformative action, disrupted the power structures found in the systematic enaction of schooling, albeit minimally. Students within this study challenged current policy established by those in power, the principals, and constructed an understanding that students could potentially be positioned beyond passive and involuntary actors within their placed learning environment. One student's mother illustrated this shift in power when she stated, "It probably opened his eyes into you can fight for local issues, you can make changes in your community if you want to" (Jim's mother). Another mother discussed the implications of the power shifts and claimed that her daughter "feels like she can make an actual difference in her learning environment" (Mae's mother, June 4, 2019). Again, the shift in power was minimal considering the principals still held directive authority; yet students' knowledge of the capacity to challenge those in power in their local place, enabled them to act as leaders and change agents within their learning environment. As one student felicitously claimed, because they advocated for the whole student body, the place-based project positioned those engaged in the project comparable to "like a hero" (Mae, interview 3, May 31, 2019) amongst her peers.

In short, the findings of this study indicate that when rural gifted students' schooling provided learning frames that supported students' voice, opinions and concerns with relevant matters, students were positioned as leaders and transformative agents through autonomous, placed practices.

As there are few empirical studies that assessed place-based education's influence on rural talented youth in Appalachia, future research is needed. As a starting point, it would be interesting to explore what types of place-based education impact learning, non-cognitive or affective growth, and place attachments for rural talented students. For example, do rural talented 
students who engage in community problem solving have similar perceived impacts to those conducting cultural journalism, or natural studies, all three are types of place-based education conceptualized in the literature (Smith, 2002)? Additional narrative work is also needed for understanding talented students' rural identity constructs, such as how they perceive success. Traditional rural ideals of success, such as the goodness of a person and their reinvestment in their community, are being replaced with cosmopolitan ideals of success that center on monetary accumulation and social capital (Jones, 1994; Richards \& Stambaugh, 2015). How a talented youth engages with these ideals of success, may influence their perception and acceptance of place-based education. This is just one example, as there are many constructs of identity that should be explored alongside place in the curriculum.

Another theme noted in the findings was that the Enrichment Triad had value for a rural Appalachian pull-out gifted program. Although not conceived for rural gifted programs, the Enrichment Triad's flexible design encouraged its use in a contextually adapted manner (Lewis, 2015). Jane modified the Enrichment Triad to fit her practice and her understandings of the model. For example, she gathered student interest data and narrowed the topic of study through group discussions instead of using the model's Interest-A-Lyzer (Appendix E). "We started with just kind of making a group list." Where she asked students "Okay, tell me about problems that you see in our community,". . "Let's brainstorm a list or a way that we could maybe change some of these problems, or maybe have a positive impact on some of these problems" (Jane, Interview 2, March 19, 2019). Although Jane modified the model to fit her programmatic realities and understandings, the use of the Enrichment Triad Model in her small pull-out program improved her practice and facilitated student learning. 
Jane's practice improved in various ways. First, Jane shifted from a teacher-controlled curriculum to one that provided student autonomy. For example, Jane's prior considerations "always focused on I want a pretty product at the end" but through using the Enrichment Triad she allowed them to "do that product, even if it's not what exactly I would have envisioned would be the product of that, but just giving the students the choice and the chance to find their way through" (Jane, Final Interview, June 04, 2019). Within the Enrichment Triad, Jane shared curricular power with her students and together they co-created content, delineated processes, and imagined the project's product.

Secondly, her curriculum now had "scope and sequence" (Borland, 2012, p. 71), supported student interests, with an overall improved practice. Prior to implementing the Enrichment Triad, Jane claimed that "we don't have a set curriculum and here's what you're going to do" (Interview 1); thus, the curriculum often varied from week to week. Within the Enrichment Triad, she was able root curriculum in student interests and relate each activity the students engaged in to the big ideas of the project. Moreover, the skills required (i.e., communication and collaboration skills) were interrelated, built upon each other and were applicable to the activities and goals within the Type III. While a teacher's practice is always in process and improving, Jane's gifted curriculum notably improved through her use of the Enrichment Triad Model.

Additionally, students indicated growth within the Enrichment Triad Model. They touted interpersonal skills, such as collaboration and presentation efficiency, and newfound selfefficacy (Burns, 1990; Schack, 1989; Starko, 1986, 1989). Illustratively, one student claimed "I learned a lot about the presentation and eye contact (Natalie, Interview 3, May 31, 2019). 
Another shared, “After we presented, I just felt like kind of powerful. I don't know. It just felt really good" (Mae, Interview 3, May 31, 2019).

Jane's curricular developments and student learning were not attained by strict adherence to the model, though. For example Jane designed and utilized Type II's and a Type III that worked within her rural contexts, barriers, and her emergent understandings of the model (Azano et al., 2014; Brigandi \& Miller, 2018; Brigandi et al., in press; Miller \& Brigandi, forthcoming) which often left pieces of the Enrichment Triad unexamined (i.e., Interest-A-Lyzer). While the literature indicates that the totality of the model best supports maximum student growth (Burns, 1990; Delcourt, 1988; Gubbins, 1982; Newman, 1991; Stedtnitz, 1985, 1986), its use in a contextualized and modified manner in a rural pull-out program also produced positive outcomes and growth for both teacher and students. Therefore, I theorize that although empirical evidence supports fidelity of implementation of the Enrichment Triad Model, rural gifted programs may still benefit from modified versions.

As of yet there are very few empirically tested frameworks or models specific for rural talented youth in rural talented programs. Therefore, models designed for gifted programs generically, need flexibility within them to be applicable to the contexts of various programs. The use of the model, even with low fidelity of implementation, positively impacted the teacher's gifted pedagogical and curricular growth as well as student learning.

Suggestions for future research include a continued look into how the Enrichment Triad Model supports curriculum in rural places. This study employed narrative inquiry as its frame; however future research conducted using various types of methods and lenses may produce multiple and more nuanced pictures of its value. Additionally, future research should illuminate features of the Enrichment Triad Model that are crucial in its delivery for student success and 
those that, if needed because of time or resources, could potentially be excluded or modified. The Enrichment Triad model can be overwhelming in its ideology and framework for teachers who have little background in gifted pedagogy or the model itself. The biggest restraint in rural pullout programs is time (Azano et al., 2014), so how can Enrichment Triad Model be utilized, and to what extent, to best support teachers' curriculum and rural youth's education?

Results of the study also indicate the unification of place-based education and the Enrichment Triad supported the teacher's practice and rural talented youths' contextual and educational needs. The marrying of place-based education with the Enrichment Triad was conceived from pilot study findings that indicated rural gifted teachers' curricula lacked "scope and sequence" (Borland, 2012, p.71), a common criticism of pull-out enrichment programs. One teacher in the pilot study claimed, "there is no curriculum so there's some days I'm flying by the seat of my pants and just figuring something out" (Teacher 2, Interview 1, Miller and Brigandi, forthcoming).

Positively though, the teachers in the pilot study reported they wanted professional development (PD) specific to gifted curriculum to improve their practice. Therefore, as part of the design of this study, PD on the Enrichment Triad model was provided. I chose the Enrichment Triad Model given its potential in the rural setting (Lewis, 2015) and its well established value in the field of gifted education (i.e., Brigandi, et al., 2018; Burns, 1990; Schack, 1989; Delcourt, 1988, 1993; Hébert, 1993; Westburg, 2010).

Additionally, the pervasive narratives of "rurality" as a problem (Burton, et al., 2005; Theobald \& Wood, 2010), stereotypical ideals of Appalachia (Lewis, 2000; Shapiro, 1978), and rural youth outmigration (Budge, 2006; Carr \& Kalafas, 2009; Corbett, 2007; Petrin, Schafft, \& Meese, 2014; Staunton \& Jaffee, 2014; Theobald \& Wood, 2010) initiated the use of place-based 
education to support rural talented youth. Essentially, I coalesced the Enrichment Triad Model (Renzulli, 1977), a student-centered gifted model with forty-years of research attesting its value (Brigandi et al., 2016) with place-based education, conceived in a rural landscape, to support student identity and development within place (Smith, 2002). The compatibility between the two frameworks (see Chapter 2), supported the integration, and essentially the Enrichment Triad Model became bound within a place frame. For example, a typical Type I consists of general exploratory experiences to broaden students exposure to various experiences and spark interests (Renzulli, 1977; Renzulli \& Reis, 1997; 2014). Although the place-based focus was not enacted in Jane's practice to the degree that the field of place-based educators would recognize, it was a first step in that direction. As noted in Chapter 4, there were missed opportunities to engage students in authentic place-based practices, but it was a small turn towards such practices. In a full turn towards place-based practices, the merged framework, would be contained within and focused on the various aspects, histories, currencies, and perspectives of place. In sum, the conception of the place-based Enrichment Triad emerged to support both rural gifted teachers and rural talented youths.

This study indicates that the blend of ideological practices simultaneously strengthened a gifted teacher's curricular practice and facilitated student learning. This finding is consequential because it supports rural gifted teachers' establishment of "defensible programs" (Renzulli, 1977) and positioned rural talented youth as potential leaders and change agents within their communities through the endeavor of schooling. Students engaged in transformative action within their school, assessed their situation and sought to improve it. They considered the larger implications of their endeavor (i.e., improving health of a perceived unhealthy population in their community and state). They advocated and provided voice for an often overlooked group of 
people - themselves and their peers, as students. For those who want to remain, this model reenvisions students' opportunities to do so and to become leaders in their rural Appalachian place(s).

This study adds to the discussion of gifted curricula intermixed with place pedagogy (Azano, et al., 2011; Azano, et al., 2017; Howley et al., 2009; Seward Ayers \& Paul, 2016) and provides empirical support to theoretical claims in the literature (Howley et al., 2009; Seward Ayers \& Paul, 2016) by conceptualizing a curricular framework that embraces the unique needs of being a) a student with gifts and talents and b) a student in a rural Appalachian place.

Researchers and practitioners who want to parlay these theories in future research should consider how place-based research as a field has progressed. As stated in Chapter 2, because of the lack of research using place with rural talented students, this study sought to employ placebased education instead of a critical pedagogy of place. Yet, positive findings suggest that rural talented youth, both those recognized in school as gifted and other rural talented youth may benefit from a critical perspective in place-based education. Critical place-based education enables students to critically assess their situations, their culture, their places and call in to question the dominant or hegemonic practices that exist. In this study, for example, Jane could have facilitated an exploration of the power structures within the students' community and school. For example, her students might have explored the following: how they, as students, were positioned; how they, as identified gifted students, were positioned; how others might be positioned within these power structures, all the while looking at the privilege and/or oppression that each group of people possess (i.e., through a gendered, raced, or economic lens). Specifically, there was a large percentage of families living in poverty in the area, yet this percentage was not equally distributed or represented within the gifted class as most all students 
came from middle class families (Jane, Interview 1, February 5, 2019). Yet, there were clear narratives across all participants about the concern of lack of representativeness of gifted students in their place. Additionally, students were concerned with changing water bottle policy in school, but they did not consider students who may not have access to quality water or those that could not afford reusable water bottles or to purchase water during the school day. Tangentially, they could have examined the school's institutional power over student and teacher autonomy (i.e., regulations of when and how students hydrate) and why these policies might exist. A critical exploration of place would call into question some of these practices and highlight systematic fissures that exist within society; not everyone has the same experience in school or in life. When using a critical pedagogy of place two questions must guide practice: What about the students' place needs to be conserved? and What about the students' place needs to be transformed? (Gruenewald,2003a)

A final theory indicates that written and unwritten policies of place impact a gifted teacher's positioning, structural conceptions and programmatic enactments. The formal and informal policies of place worked to schematize Jane's gifted program in this study. In looking at the ecological sphere of influences, I begin the discussion with broad macro-policies (i.e., teacher credentials and job titling) and progress toward micro-polices in place (i.e., undervaluing of teachers' planning and gifted classroom time).

In Jane's journey to certification, she denounced the formal policy that indicated she needed essentially an additional Master's degree that included only a few gifted education courses to become certified in her state to teach gifted and talented. Instead, she took advantage of a loophole in reciprocity and certified through another state with greater ease. 
I found Tennessee and they would accept my classes that I'd already taken at [Big City University] and the degrees that I already had . . I was able to certify . . .versus if I had stayed in West Virginia and certified, I would've needed 36 hours to have done it. (Jane, Interview 1, February 5, 2019)

In fact, two of her predecessors, including myself, also attained certification in this manner. Essentially, gifted teachers credential route patterns in this rural place suggest that they/we created and enacted their own informal policy toward certification.

Second, recent county policy of Gifted AND___ roles also influenced the construction of and production of the gifted program. According to Jane's narrative, it is more accurate to state the policy of AND Gifted and its latter placement indicates it is perceived as less essential than other roles in which Jane was taxed. Jane's dual roles, mandated by the rural county, implicated her in the socio-educational consequence. Although not directly expressed by the county, the message Jane received was that her role as a gifted teacher was secondary to the first title listing of mathematics. Although, Jane claimed she "found her fit" (Interview 1) with gifted students, she identified as a STEM teacher, evidenced in the construction of her gifted curriculum bound by STEM. The county did not provide guidance or assistance to establish programs that meet gifted programmatic standards (i.e., NAGC's Pre-K-Grade 12 Gifted Education Programming Standards [Callahan et al., 2017; Miller \& Brigandi, forthcoming]). Therefore, when Jane felt she needed additional learning to support her gifted program, she sought an additional certification as a technology integration specialist instead of continued learning in gifted pedagogy or gifted curriculum. "STEM fields and those kind of activities were things that our students were interested in, and those were things that our students excelled at. So, I went back and got my TIS certification ..." (Jane, Interview 1, February 5, 2019). Jane's 
pursuit of an additional certificate in a STEM field to support her gifted program, instead of continued learning in gifted pedagogy or education, illustrates the implications of the county's placement of gifted as subsidiary.

At the school level, most policy was unwritten, and socio-culturally influenced. For example, it was an unwritten policy that Jane's gifted class was less prioritized over other extracurriculars such as band. Even her planning was repeatedly hijacked for other personnel needs. "Sometimes, the band director will be out, so I'll get pulled to cover that advisory or ... somebody will have an IEP meeting, so I'll get pulled to do that advisory. .." (Jane, Inteview 1). Additionally, teachers held stereotypical conceptions of what it meant to be a gifted teacher. "I was the youngest person in the building, the youngest person on the math team. I had one year of teaching experience" (Jane, Interview 1, February 5, 2019) and because of her novice credentials she was snubbed for receiving the gifted and advanced mathematics job.

In Jane's rural place, a dichotomy of ideology and practice occurred. Gifted service mandates, outlined in state policy, did not supersede place specific undervaluing of her gifted program. For example, the rural Appalachian state in which Jane lives is one of the very few states that mandates gifted services, requires credentials for teachers working directly with gifted students, and services students under special education law (i.e., Individualized Education Plans) (NAGC \& CSPD, 2015; WVDE Policy 2419, 2017) . Despite these stringent standards in state policy, Jane's gifted program was equally influenced by local systematic and structural conceptions of gifted education in place. She was first a mathematics teacher with gifted as a secondary role and her planning and gifted class was often underprioritized over other school personnel needs and extra-curricular activities. 
Therefore, I theorize that written and unwritten policies of a place influenced the conceptualization of the gifted program in place. This notion is consequential because few studies delineate how rural gifted programs are enacted in place and what influences such practices. Rurality is not homogenous, as rural Appalachian gifted programs, mandated under the same written state policy, have unwritten place polices that have as much impact. The policies of government affected Jane's gifted program in rural Appalachia as much as the written and unwritten policies within place. A next step for this finding is to continue to explore these different programs in rural Appalachia and how a place's conception of giftedness and gifted programs works to influence its conception.

\section{Implications}

Like many other gifted teachers, Jane was isolated, taxed with dual roles, restricted by time, and credentialed through alternate routes (Azano et al., 2014; Burton, et al., 2005; Miller \& Brigandi, forthcoming). Compounding these rural complexities, in-service professional development specific to gifted education was scarce (Floyd et al., 2011; Miller \& Brigandi, forthcoming). In fact, for the first time in Jane's tenure as a teacher, professional development was provided to gifted teachers in her county. Instituted through this research, the sessions focused on gifted curriculum and place which totaled 10 hours and spanned two sessions. Her gifted teacher peers within the county also attended the PD, but geographical and scheduling complexities, made collaboration between the gifted teachers near impossible (Floyd et al., 2011). All these structural inhibitors, made improving Jane's practice from the traditional professional development model more difficult.

As demonstrated in the findings, Jane required follow-up, in-the-moment professional development and support to guide her emerging conceptual and ideological understanding of 
what a place-based Enrichment Triad looked like in her practice. For example, when Jane questioned the next steps after problem finding, I was able to supply her with the Management Plan (Appendix G). The professional development sessions Jane engaged in were the beginning of her learning, not the totality of it. However, in places that rarely provide district initiated professional development specific to gifted education and amongst the historically pervasive barriers in rural places, stakeholders must consider how to effectively support rural gifted teachers' practices.

The most obvious answer is to provide professional development for this underserved group of teachers. It is well-documented that teachers trained in gifted pedagogy best facilitate student growth and success (i.e., Hanson \& Feldhusen, 1994). Thus, stakeholders need to advocate for rural talented youth through ongoing preparation and learning of their teachers. The recent revitalization of the ESSA (2015) mandated that a portion of monetary allotments that states receive for professional development be used to improve teachers' identification and instructional skills specific to gifted and talented students. Policy now supports continued learning for teachers working with gifted and talented students; therefore, stakeholders advocating for such practices have mandates to support their cause.

Once districts, administrators, or even teachers decide to provide gifted education professional development, there also need to be considerations for how it is enacted. Professional development needs to be reimagined in rural places to combat existing barriers and support teacher learning. For researchers enacting professional development in rural areas, specifically with rural gifted teachers, how to provide PD to best meet the teacher as a learner's contextual and situated needs becomes an ethical consideration. Should researchers position themselves as active participant observers where they take the role of collaborator or coach? Should researchers 
create learning communities even if they are not concerned with the totality of participants? This research would affirm that as researchers, we should contribute to teachers' growth and practices and thus student learning in the capacity in which we are capable and welcomed. After all, "researchers should have something of value to contribute to the school and to the teacher whose classrooms they enter" (Elbaz-Luwisch, 2007, p. 360).

Additionally, researchers and administrators instituting professional development must consider the most crucial aspect for teachers' learning are supports while in practice. How, in rural areas with large geographical distances between them, will PD be efficiently and effectively enacted? Maybe, as the teacher of this study asserted, support can be imagined through technology (i.e., video conferencing). In rural counties, lack of funding limits formal support roles such as gifted coordinators or specialists. Instead, the teachers are the experts in their field. Therefore, administrators might consider peer collaboration or teacher reflective forums through video-conferencing. Teachers could become classroom peer coaches or dialogic supports as they engage in learning and thinking about their practice, despite the potential geographic distance between them. Moreover, researchers might envision ongoing support through online forums and other digital venues that provide continued and collaborative learning opportunities. Learning communities, a turn toward more recent best practices in professional development termed professional learning communities (Darling-Hammond \& McLaughlin, 1995, 2011; Desimone et al., 2002; Weber \& Novak, 2018), can then be reimagined not as face-to-face supports but digital as well. Additionally, as Jane conceived, technology can also provide access to other experts or learning opportunities in the chosen topic, field, or pedagogy. Therefore, even those remote rural places that are 100 miles or more from formal supports (i.e. university personnel), can develop partnerships for learning and improved practice. 
Lastly, where professional development comes from must also be considered. Rural places are not homogenous, and as my findings indicate, gifted programs are conceptualized through place specific structures and ideologies. Top down models, a traditional approach to professional development, become less effective with potential variances across teachers and schools. Bottom-up or grassroots models where stakeholders, such as the teachers themselves, have a voice in the focus of the PD and how it is enacted mitigate the less effective blanket approach to PD. Centering teachers in PD decisions leads to increased and invested participation. In sum, stakeholders need to ensure that professional development specific to gifted education in rural places, be reimagined to best meet the needs of their teachers and students.

Additionally, this research conceptualized a new question: for what purpose should professional development be enacted? Beyond reimagining how professional development is enacted in rural places, stakeholders must also reconsider the content of the PD. Teachers are not being prepared to teach in rural schools (Azano \& Stewart, 2016) and as the findings of this study suggest, even teachers from rural areas with deep senses of place do not innately possess a repertoire of place conscious practices. Recent calls for teacher education on place sensitive curriculums (Azano \& Stewart, 2015; Azano \& Stewart, 2016; Howley \& Howley, 2005; Hudson \& Hudson, 2008; Floyd et al., 2011; White \& Reid, 2008), indicate an absence of place pedagogy in teacher preparatory programs and professional development. While research shows that professional development focused on learning strategies and content have positive effects on teachers' practices (Desimone, Porter, Garet, Yoon, \& Birman, 2002), what are the effects of this PD for rural youth's realities, identity perceptions, positioning, or cultural needs Rural students possess deep funds of knowledge (Moll et al., 1992; Edmonson \& Butler, 2010; Zipin, 2009) that go unrecognized and unappreciated in the classroom because teacher education, standards, and 
textbooks solely attend to students' compliance and academics (Comber, 2016; Theobald \& Wood, 2010). By disregarding rural students' funds of knowledge, we are essentially dismissing rural students. Dominant socio-cultural narratives already dismiss rural Appalachian youth; must their educational institutions continue to as well? Professional development in rural places must focus on culturally responsive, inclusive pedagogies as well as academics (Azano \& Stewart, 2015; Azano \& Stewart, 2016; Howley \& Howley, 2005; Hudson \& Hudson, 2008; White \& Reid, 2008).

\section{Limitations}

As with all studies, this research has its limitations. I highlight here the most salient of them. First, this case study was bound within one teacher's practice, which included the perspectives of the teacher, her students, and their parents. While the stories are their truths and are consequential to their realities, expanding the confines of the case to include additional rural programs provides a robust understanding of experiences within and across people and rural Appalachian places. Additionally, the scope of the research was bound within one semester. The teacher received professional development and the students conceptualized, enacted, and completed their Type III project within the span of a few months. If teacher learning requires extensive amounts of time spent learning and implementing the model (see Desimone et al., 2002) then this study did not capture all the facets and potential of Jane's learning of the place-based Enrichment Triad Model because of the restricted time frame. Additionally, while there are no time mandates within the Enrichment Triad, the totality of the model is best enacted across a longer scope than a few months. While these limitations were present, I do not perceive them as disqualifiers of this research, but as starting points for future research. 


\section{Final Thoughts}

My intent for this research was to facilitate the use of two distinct constructs in education: gifted education and place-based education to support rural gifted teachers' curricular practices and students' rural cultural sense of place. While my study showed that use of the place-based Enrichment Triad Model had value for the teacher's curricular development and student learning, it is by no means a totality of understanding. On the contrary, this study is just a first glimpse into exploring and understanding how rural gifted teachers take up such notions and how it affects their students and their learning. I look forward to continuing to explore the nuances of the findings in this study and invite others to bring different lenses and perspectives to this research to create more vibrant understandings.

\section{Coda}

I came to this research with theoretical understandings and visions of what place-based education could achieve with rural talented students; however I had little practical experience. Six years ago, as a gifted teacher, I largely ignored my students' situated and socialized understandings of their place. Instead, I centered my curriculum around activities that I considered challenging, yet engaging, but never considered my students cultural identities within my curriculum. Essentially, I was influenced by neo-liberal narratives of schooling and my students themselves were largely invisible. Neoliberalism is evidenced in schooling through individualism, standardization, and accountability. The complex nature of how teachers are situated, how I was situated, within these systematical and structural pressures, impeded my ability to foresee the value of and enact authentic and contextual practices.

This dissertation was situated within a gifted pull-out program; but these opportunities are valuable for all rural students. Joseph Renzulli based his Schoolwide Enrichment Model, 
which housed the Enrichment Triad Model, on the premise that "a rising tide lifts all ships" (Renzulli \& Reis, 1997; 2014). A critique of this theory is that ships "on the bottom" of the sea bed are not affected by the tides. These broken ships stay on the bottom. Our students, however, are not broken. In fact, when we re-focus our values beyond neoliberal schooling traditions (i.e., conformed academic achievement), the boats that were previously deemed deficient by systemic ideologies and practices, are now shown to be carrying a full hull (a.k.a. funds of knowledge). Therefore, even though Renzulli's (1977; Renzulli \& Reis, 1997; 2014) conception of the Enrichment Triad and my combining the model with place-based education were first enacted with gifted students, the models have value for all rural students.

For example, during analysis and write-up phases of the this dissertation, I returned to the classroom as a practitioner. I am still learning the curricular terrain of third grade, but through this dissertation I have begun to hear my students' funds of knowledge and at times their dark funds of knowledge. I am not only hearing the content of their local knowledge, but the processes of how they come to know them (Zilpin, 2009). Many of these opportunities have presented themselves in a spontaneous manner in class or individual discussions. For example, through honest and heartfelt discussions that emerged from my third graders' concerns with how drugs have effected them personally, students have shared their dark funds of knowledge on the matter. A student, not identified as gifted, but passionate about the topic decided to complete a Type III after several classroom discussions on the matter. Additionally, the processes of how my students come to know things are influenced by who or how they are socialized. For example, many of my students are not being raised by their genetic parents, which effects their processes of knowing. While my hearings are emergent, I am on a continuous and evolving path of understanding and learning, just as Jane. Even though Jane's understandings of the place- 
based Enrichment Triad were encapsulated within these pages, they continue to evolve and change. This research is a representation of Jane's narratives and experiences and my hearings and understandings of her journey within a temporal and contextual snapshot. I can only hope that engaging in this research set us both on a path of inclusion of place and students' identities through an open conception of what might constitute knowledge and talent. 


\section{REFERENCES}

ACT (2017a) The Condition of STEM 2017. Retrieved from

https://www.act.org/content/act/en/research/reports/act-publications/stem-education-inthe-us-2017.html

ACT (2017b) The condition of College \& Career Readiness 2017 West Virginia key findings.

Retrieved from

http://www.act.org/content/dam/act/unsecured/documents/cccr2017/West-VirginiaCCCR-2017-Final.pdf

Anyon, J. (1981). Social class and school knowledge. Curriculum Inquiry, 11(1), 3-42. Retrieved from: https://doi.org/10.2307/1179509

Arnold, M. (2005). Jump the shark: A rejoinder to Howley, Theobald, and Howley. Journal of Research in Rural Education, 20(20) 1-2. Retrieved from http://jrre.psu.edu/articles/20-20.pdf

Artz, G. (2003, December). Rural area brain drain: Is it a reality? Choices: A Publication of the American Agricultural Economics Association, 18(4), 11-16.

Ayers-Paul, K. A., \& Seward, K. K. (2016). Place-Based Investment Model of Talent Development: A proposed model for developing and reinvesting talents within the community. Journal of Advanced Academics, 27(4), 311-342.

Azano, A. P. (2009). The possibility of place: One teacher's use of place-based instruction for English students in a rural high school (Order No. 3400840). Available from ProQuest Dissertations \& Theses Global. (305009817). Retrieved from https://search-proquestcom.www.libproxy.wvu.edu/docview/305009817? accountid=2837 
Azano, A. P., Missett, T. C., Callahan, C. M., Oh, S., Brunner, M., Foster, L., \& Moon, T. R. (2011). Exploring the relationship between fidelity of implementation and academic achievement in a third-grade gifted curriculum: A mixed-methods study. Journal of Advanced Academics 22(5), 693-719.

Azano, A. P., Callahan, C. M., Missett, T. C., \& Brunner, M. (2014). Understanding the experiences of gifted education teachers and fidelity of implementation in rural schools. Journal of Advanced Academics, 25(2), 88-100.

Azano, A. P., Callahan, C. M., Brodersen, A. V., \& Caughey, M. (2017). Responding to the challenges of gifted education in rural communities. Global Education Review, 4(1), 6277.

Azano, A. P., \& Stewart, T. T. (2015). Exploring place and practicing justice: Preparing preservice teachers for success in rural schools. Journal of Research in Rural Education, $30(9), 1-12$.

Azano, A. P. \& Stewart, T. T. (2016). Confronting challenges at the intersection of rurality, place and teacher preparation: Improving efforts in teacher education to staff rural schools. Global Education Review, 3(1) 108-128.

Bain, S. K., \& Bell, S. M. (2004). Social self-concept, social attributions, and peer relationships in fourth, fifth, and sixth graders who are gifted compared to high achievers. Gifted Child Quarterly, 48(3), 167-178.

Bain, S. K., Bourgeois, S. J., \& Pappas, D. N. (2003). Linking theoretical models to actual practices: A survey of teachers in gifted education. Roeper Review, 25(4), 166-172.

Bartholomaeus, P. A. (2006). Some rural examples of place-based education. International Education Journal, 7(4), 480-489. 
Baum, S. (1988). An enrichment program for gifted learning disabled students. Gifted Child Quarterly, 32(1), 226-230.

Baum, S. M., Renzulli, J. S., \& Hébert, T. P. (1995). Reversing underachievement: Creative productivity as a systematic intervention. Gifted Child Quarterly, 39(4), 224-235.

Baxter, P., \& Jack, S. (2008). Qualitative case study methodology: Study design and implementation for novice researchers. The Qualitative Report, 13(4), 544-559.

Bell, S. E., \& York, R. (2010). Community economic identity: The coal industry and ideology construction in West Virginia. Rural Sociology, 75(1), 111-143.

Bensen, (2014) Art Interest-A-Lyzer. Found in Renzulli, J. S., \& Reis, S. M.'s The Schoolwide Enrichment Model: A how-to guide for talent development (3rd ed.). Waco, TX: Prufrock Press.

Blaisdell, E. (2019, April 4). Expansion bringing 500 new jobs to area. Cumberland Times News. Retrieved from: https://www.times-news.com/news/local_news/abl-expansion-bringingjobs-to-area/article_3f0c4b12-562f-11e9-a139-3b5339008d20.html

Borland, J. H. (2012). Problematizing gifted education. In Fundamentals of gifted education (pp. 93-104). New York, NY: Routledge.

Brigandi, C. B. (2015). Gifted secondary school students: The perceived relationship between enrichment and achievement orientation. Unpublished Doctoral Dissertation. Retrieved from https://opencommons.uconn.edu/dissertations/731

Brigandi, C. B., Gilson, C. M., \& Miller, M. (2019). Professional development and differentiated instruction in an elementary school pullout program: A gifted education case study. Journal for the Education of the Gifted. Retrieved from: https://doi.org/10.1177/0162353219874418:. 
Brigandi, C.B. \& Miller, M. (2018) Professional learning and classroom practice in gifted education. In Novak \& Weber (Eds.), Best practices in professional learning and teacher preparation: methods and strategies for gifted professional development (pp. 23- 38). Waco, TX: National Association for Gifted Children \& Prufrock Press.

Brigandi, C. B., Siegle, D., Weiner, J. M., Gubbins, E. J., \& Little, C. A. (2016). Gifted secondary school students: The perceived relationship between enrichment and goal valuation. Journal for the Education of the Gifted, 39(4), 263-287.

Brigandi, C.B., Waterson, R., Waicanus, N.S., \& Renzulli, J.S. (2018a). The Schoolwide Enrichment Model in Social Studies: A hands on approach to developing investigative skills in social studies. Waco, TX: Prufrock Press.

Brigandi, C. B., Weiner, J. M., Siegle, D., Gubbins, E. J., \& Little, C. A. (2018b). Environmental Perceptions of Gifted Secondary School Students Engaged in an Evidence-Based Enrichment Practice. Gifted Child Quarterly, 62(3), 289-305. https://doi.org/10.1177/0016986218758441

Britzman, D. P. (2012). Practice makes practice: A critical study of learning to teach. Albany, NY: Suny Press.

Brooks, J. G., \& Brooks, M. G. (1999). In search of understanding: The case for constructivist classrooms. Alexandria, VA: Association for Supervision and Curriculum Development.

Brooke, R. (Ed.). (2003). Rural voices: Place-conscious education and the teaching of writing (Vol. 25). New York, NY: Teachers College Press.

Bucholtz, M. (2005). Identity and interaction: A sociocultural linguistic approach. Discourse Studies, 7(4-5), 585-614. https://doi.org/10.1177/1461445605054407 
Burton, M., Brown, K, \& Johnson, A. (2013). Storylines about rural teachers in the United States: A narrative analysis of the literature. Journal of Research in Rural Education, 28(12), 1-18. Retrieved from http://jrre.psu.edu/articles/28-12.pdf

Budge, K. (2006). Rural leaders, rural places: Problem, privilege, and possibility. Journal of Research in Rural Education, 21(13) 1-10. Retrieved from http://jrre.psu.edu/articles/21-13.pdf

Burnell, B. A. (2003). The "real world" aspirations of work-bound rural students. Journal of Research in Rural Education, 18(2), 104-113.

Burns, D. E. (1990). The effects of group training activities on students' initiation of creative investigations. Gifted Child Quarterly, 34(1), 31-36. https://doi.org/10.1177/001698629003400107

Burton, M., Brown, K., \& Johnson, A. (2013). Storylines about rural teachers in the United States: A narrative analysis of the literature. Journal of Research in Rural Education, 28(12), 1-18.

Callahan, C. M., Moon, T. R., \& Oh, S. (2017). Describing the status of programs for the gifted: A call for action. Journal for the Education of the Gifted, 40(1), 20-49.

Campbell, J. R., \& Walberg, H. (2011). Olympiad Studies: Competitions Provide Alternatives to Developing Talents That Serve National Interests. Roeper Review, 33(1), 8-17. https://doi-org.www.libproxy.wvu.edu/10.1080/02783193.2011.530202

Carr, P. J., \& Kefalas, M. J. (2009). Hollowing out the middle: The rural brain drain and what it means for America. Boston, MA: Beacon Press. 
Casareno, A. B., Ellis, E. S., Gregg, M., Larkin, M. J., Mayfield, P., Rountree, B. S., \& Schichter, C. L. (1997). Partners in enrichment. TEACHING Exceptional Children, 29(4), $5-14$.

Centers for Disease Control and Prevention. (2018). 1991-2017 High School Youth Risk Behavior Survey [Data set]. Retrieved from http://nccd.cdc.gov/YouthOnline/App/Default.aspx

Comber, B. (2016). Poverty, place and pedagogy in education: research stories from front-line workers. The Australian Educational Researcher, 43(4), 393-417. https://doi.org/10.1007/s13384-016-0212-9

Comber, B., Thomson, P., \& Wells, M. (2001). Critical literacy finds a "place": Writing and social action in a low-income Australian grade 2/3 classroom. The Elementary School Journal, 101(4), 451-464. https://doi.org/10.1086/499681

Corbett, M. (2007). Learning to leave: The irony of schooling in a coastal community. Nova Scotia, Canada: Fernwood Publishing.

Corbett, M. (2009). Rural schooling in mobile modernity: Returning to the places I've been. Journal of Research in Rural Education (Online), 24(7), 1-13.

Corbett, M. (2010). Wharf talk, home talk, and school talk: The politics of language in a coastal community. In K.A. Schafft \& A. Y. Jackson (Eds) Rural education for the twenty-first century: Identity, place, and community in a globalizing world, (pp. 115-131) University Park, PA: The Pennsylvania University Press.

Coughlin, C. A., \& Kirch, S. A. (2010). Place-based education: a transformative activist stance. Cultural Studies of Science Education, 5(4), 911-921. https://doi.org/10.1007/s11422010-9290-6 
Coxon, S. V. (2012). Innovative Allies. Gifted Child Today, 35(4), 277. https://doiorg.www.libproxy.wvu.edu/10.1177/1076217512455480

Cresswell, T. (2015). Place: An introduction. Malden, MA: John Wiley \& Sons.

Croft, L. (2015) Rural teachers of the gifted: The importance of professional development. In Stambaugh, T. \& Woods, S.M. (Ed.) Serving gifted students in rural settings, (pp. 341362). Waco, TX: Prufrock Press.

Crotty, M. (1998). The foundations of social research: Meaning and perspective in the research process. London, England: Sage Publications.

Darling-Hammond, L., \& McLaughlin, M. W. (1995). Policies that support professional development in an era of reform. Phi Delta Kappan, 76(8), 597-604.

Darling-Hammond, L., \& McLaughlin, M. W. (2011). Policies that support professional development in an era of reform. Phi Delta Kappan, 92(6), 81-92.

Davalos, R., \& Griffin, G. (1999). The impact of teachers' individualized practices on gifted students in rural, heterogeneous classrooms. Roeper Review, 21(4), 308-314.

Delcourt, M. A. B. (1988). Characteristics related to high levels of creative productive behavior in secondary school students: A multi-case study (Unpublished doctoral dissertation). University of Connecticut, Storrs.

Delcourt, M. A. B. (1993). Creative productivity among secondary school students: Combining energy, interest, and imagination. Gifted Child Quarterly, 37(1), 23-31.

Delcourt, M.A.B. (1995) Characteristics related to high levels of creative/productive behavior in secondary school students: A multi-case study. In Gubbins, E. J., \& National Research Center on the Gifted and Talented, S. C. (Eds). Research Related to the Enrichment Triad Model. 
Porter, A. C., Garet, M. S., Desimone, L., Yoon, K. S., \& Birman, B. F. (2000). Does professional development change teaching practice? Results from a three-year study. Washington, DC.: U.S. Department of Education

Diezmann, C. M. and Watters, J. J. (2001). The collaboration of mathematically gifted students on challenging tasks. Journal for the Education of the Gifted. 25(1):7-31

Desimone, L. M., Porter, A. C., Garet, M. S., Yoon, K. S., \& Birman, B. F. (2002). Effects of professional development on teachers' instruction: Results from a three-year longitudinal study. Educational Evaluation and Policy Analysis, 24(2), 81-112. doi:10.3102/01623737024002081

Diezmann, Carmel M and Watters, James J (2001). The collaboration of mathematically gifted students on challenging tasks. Journal for the Education of the Gifted. 25(1):7-31.

Duhn, I. (2012). Places for pedagogies, pedagogies for places. Contemporary Issues in Early Childhood, 13(2): 99-107. Doi: https://doi.org/10.2304/ciec.2012.13.2.99

Dwyer, S. C., \& Buckle, J. L. (2009). The space between: On being an insider-outsider in qualitative research. International Journal of Qualitative Methods, 8(1), 54-63. https://doi.org/10.1177/160940690900800105

Ekaputra, G., Lim, C., \& Eng, K. I. (2013). Minecraft: A game as an education and scientific learning tool. ISICO 2013, 2013.

Elbaz-Luwisch, F. (2007). Studying teachers' lives and experience: narrative inquiry into K-12 teaching. In Clandinin, D. (Eds). Handbook of narrative inquiry: Mapping a methodology. (pp. 357-382). Thousand Oaks, CA: SAGE Publications, Inc. https://doi.org/10.4135/9781452226552

Elementary and Secondary Education Act of 1965. Pub.L. 89-10 
Emerick (1995). Academic Underachievement Among the Gifted: Reversing School Failure. In Gubbins, E. J., \& National Research Center on the Gifted and Talented, S. C. (Ed.) Research Related to the Enrichment Triad Model. (pp. 1-33). Storrs, CT: The National Research Center on the Gifted and Talented.

Erickson, F. (1986). Qualitative methods in research on teaching. In M.C. Wittrock (Ed.) Handbook of research on teaching ( $3^{\text {rd }}$ ed., pp. 119-161).

Every Student Succeeds Act (2015).

Fears Floyd, E., McGinnis, J. L., \& Grantham, T. C. (2011). Gifted education in rural environments. In J. A. Castellano \& A. D. Frazier (Eds.), Special populations in gifted education (pp. 27-46). Waco, TX: Prufrock Press.

Food Research and Action Center (2018). Eligibility for Community Eligibility Provision Retrieved from https://frac.org/community-eligibility-database/

Gavin, M.K. \& Renzulli, J.S. (2018). Using the Schoolwide Enrichment Model in Mathematics: A how-to guide for developing student mathematicians. Waco, TX: Prufrock Press.

Gentry, M., Rizza, M. G., \& Gable, R. K. (2001). Gifted Students' Perceptions of Their Class Activities: Differences Among Rural, Urban, and Suburban Student Attitudes. Gifted Child Quarterly, 45(2), 115-129. https://doi.org/10.1177/001698620104500205

Gibson, S., \& Efinger, J. (2001). Revisiting the Schoolwide Enrichment Model: An approach to gifted programming. TEACHING Exceptional Children, 33(4), 48-53. https://doi.org/10.1177/004005990103300407

Gore, J. S., Wilburn, K. R., Treadway, J., \& Plaut, V. (2011). Regional Collectivism in Appalachia and Academic Attitudes. Cross-Cultural Research, 45(4), 376-398. https://doi.org/10.1177/1069397111403396 
Grbich, C. (2013). Qualitative data analysis: An introduction. Thousand Oaks, CA: Sage.

Guba, E. G. (1981). Criteria for assessing the trustworthiness of naturalistic inquiries. Educational Technology Research and Development. 29(2), 75-91.

Guskey, T. R., \& Yoon, K. S. (2009). What works in professional development?. Phi delta kappan, 90(7), 495-500.

Gomez, B. (1996). Service-learning and school-to-work strategies for revitalizing urban education and communities. Education and Urban Society, 28(2), 160-166.

Gore, J. S., Wilburn, K. R., Treadway, J., \& Plaut, V. (2011). Regional collectivism in appalachia and academic attitudes. Cross-Cultural Research, 45(4), 376-398. https://doi.org/10.1177/1069397111403396

Gottfried, A. W., Cook, C. R., Gottfried, A. E., \& Morris, P. E. (2005). Educational characteristics of adolescents with gifted academic intrinsic motivation: A longitudinal investigation from school entry through early adulthood. Gifted Child Quarterly, 49(2), $172-186$.

Graffam, B. (2006). A case study of teachers of gifted learners: Moving from prescribed practice to described practitioners. Gifted Child Quarterly, 50(2), 119-131.

Graham, M. A. (2007). Art, ecology and art education: Locating art education in a critical placebased pedagogy. Studies in Art Education, 48(4), 375-391.

Greenwood, D. (2013). A critical theory of place-conscious education. In Stevenson, R.B., Brody, M., Dillon, J. Wals, A. (Eds) International handbook of research on environmental education, (pp. 93-100). New York, NY: Routledge. 
Greenwood, D. (2010). Why place matters: Environment, culture, and education. In S. Tozer, B. Gallegos, A. Henry, M. B. Greiner \& P. Groves-Price (Eds.), Handbook of research in the social foundations of education (pp. 632-640). New York, NY: Routledge.

Gruenewald, D. A. (2003a). Foundations of place: A multidisciplinary framework for placeconscious education. American Educational Research Journal, 40(3), 619-654. https://doi.org/10.3102/00028312040003619

Gruenewald, D. A. (2003b). The best of both worlds: A critical pedagogy of place. Educational Researcher, 32(4), 3-12.

Gubbins, E. J. (1982). Revolving Door Identification Model: Characteristics of talent pool students. University of Connecticut, Ann Arbor: ProQuest.

Hamilton, R., McCoach, D. B., Tutwiler, M. S., Siegle, D., Gubbins, E. J., Callahan, C. M., ... \& Mun, R. U. (2018). Disentangling the roles of institutional and individual poverty in the identification of gifted students. Gifted Child Quarterly, 62(1), 6-24.

Hammer, P. C., Hughes, G., McClure, C., Reeves, C., \& Salgado, D. (2005). Rural teacher recruitment and retention practices: A review of the research literature, national survey of rural superintendents, and case studies of programs in Virginia. Charleston, WV: Edvantia. (ERIC Document Reproduction Service No. ED489143).

Hansen, J. B., \& Feldhusen, J. F. (1994). Comparison of trained and untrained teachers of gifted students. Gifted Child Quarterly, 38(3), 115-121.

Hayes, S. B. (2008). The Discursive Nature of Mentoring: How Participation in a Mentoring Relationship Transforms the Identities and Practices of Prospective and Practicing Teachers. Unpublished doctoral dissertation, University of Florida, Florida. 
Heinisch, B. P. (2018). Rural students' sense of belonging at a large public university (Order No. 10787122). Available from ProQuest Dissertations \& Theses Global. (2029902297). Retrieved from http://www.libproxy.wvu.edu/login?url=https://search-proquestcom.www.libproxy.wvu.edu/docview/2029902297?accountid=2837

Heggoy, S. J., Battle, D., \& Grant, D. (1995, April). Rural gifted adolescent females: Perceptions of curriculum at elementary and secondary levels. Paper presented at the annual meeting of the national convention of the Council for Exceptional Children, Indianapolis, IN. Retrieved from http://www.libproxy.wvu.edu/login?url=http://search.ebscohost.com/login.aspx?direct=tr $\mathrm{ue} \& \mathrm{db}=$ eric $\& \mathrm{AN}=\mathrm{ED} 386835$

Hernández, A (2019, June 1). It was the backbone of this town for 131 years. Now Luke paper mill is gone. Washington Post. Retrieved from https://www.washingtonpost.com/local/itwas-the-backbone-of-this-town-for-131-years-now-luke-paper-mill-isgone/2019/05/31/d4e53198-82d1-11e9-95a9e2c830afe24f_story.html\#targetText=Felt\%20used\%20on\%20paper\%20machines,Odd\% 20smells\%20signaled $\% 20$ coming\%20storms.\&targetText=The $\% 20$ closure $\% 20$ eliminates $\% 20675 \% 20$ jobs,state\%20estimates\%20and\%20union\%20officials.

Hebert, T. P. (1993). Reflections at Graduation: The Long-Term Impact of Elementary School Experiences in Creative Productivity. Roeper Review, 16(1), 22-28. Retrieved from http://www.libproxy.wvu.edu/login?url=http://search.ebscohost.com/login.aspx? direct $=$ true $\& \mathrm{db}=$ eric $\& \mathrm{AN}=\mathrm{EJ} 472624$

Heilbronner, N. \& Renzulli, J.S. (2015). The Schoolwide Enrichment Model in Science: A hands on approach to engaging young scientists. Waco, TX: Prufrock Press. 
Helton, L. R. (2010). Faculty perceptions of differences between teaching rural Appalachian and urban social work students. Contemporary Rural Social Work, 2(1), 66-74.

Housand, A., Housand, B., \& Renzulli, J.S. (2016). Using the Schoolwide Enrichment Model with technology. Waco, TX: Prufrock Press.

Howley, C. W. (2006). Remote possibilities: Rural children's educational aspirations. Peabody Journal of Education, 81(2), 62-80.

Howley, C. B., Harmon, H. L., \& Leopald, G. D. (1996). Rural scholars or bright rednecks? Aspirations for a sense of place among rural youth in Appalachia. Journal of Research in Rural Education, 12(3), 150-160.

Howley, A., \& Howley, C. B. (2005). High-quality teaching: providing for rural teachers' professional development. Rural Educator, 26(2), 1-5.

Howley, C., Policy and Planning Center (Appalachia Educational Laboratory), \& United States. Office of Educational Research and Improvement. (1986). Intellectually gifted students: Issues and policy implications (Policy issues). Charleston, W. Va.: Policy and Planning Center, Appalachia Educational Laboratory.

Hsieh, H. F., \& Shannon, S. E. (2005). Three approaches to qualitative content analysis. Qualitative health research, 15(9), 1277-1288.

Hudson, P., \& Hudson, S. (2008). Changing preservice teachers' attitudes for teaching in rural schools. Australian Journal of Teacher Education, 33(4) 67-77.

Jensen, E. (1996). Brain-based learning. Delmar, CA: Turning Point Publishing.

Jones, L. (1994). Appalachian values. Ashland, KY: Jesse Stuart Foundation. 
Kaplan, S. N. (2005). Layering differentiated curriculum for the gifted and talented. In F. A. Karnes \& S. M. Bean (Eds.), Methods and materials for teaching gifted students, 2nd ed. (pp. 107-132). Waco, TX: Prufrock Press.

Kaplan, S. N. (2014). Collaboration: Assumed or Taught? Gifted Child Today, 37(4), 261-263. Retrieved from http://search.ebscohost.com.www.libproxy.wvu.edu/login.aspx?direct=true $\& d b=$ eric $\& A$ $\mathrm{N}=\mathrm{EJ} 1044708$

Kaufman, J. C., \& Sternberg, R. J. (Eds.). (2006). The international handbook of creativity. New York, NY: Cambridge University Press. Retrieved from https://ebookcentral.proquest.com

Kentucky Health Facts (2018). Demographics indicator: Total population. Retrieved from http://kentuckyhealthfacts.org/data/topic/show.aspx?ind=1

Kettler, T. (2014). Critical thinking skills among elementary school students: Comparing identified gifted and general education student performance. Gifted Child Quarterly, 58(2), 127-136.

Kettler, T., Russell, J., \& Puryear, J. S. (2015). Inequitable access to gifted education: Variance in funding and staffing based on locale and contextual school variables. Journal for the Education of the Gifted, 38(2), 99-117.

Knapp, C. E. (2005). The "I - Thou" relationship, place-based education, and Aldo Leopold. Journal of Experiential Education, 27(3), 277-285.

Kvale, S., \& Brinkmann, S. (2009). Interviews: Learning the craft of qualitative research. Thousand Oaks, CA: SAGE. 
Lepper, M. R., Corpus, J. H., \& Iyengar, S. S. (2005). Intrinsic and extrinsic motivational orientations in the classroom: Age differences and academic correlates. Journal of Educational Psychology, 97(2), 184.

Lewis, J.D. (2015). Programming and rural gifted learners: A review of models and applications. In Stambaugh, T. \& Woods, S.M. (Ed.) Serving gifted students in rural settings, (pp. 179218). Waco, TX: Prufrock Press

Lewis, R. L. (1999). Beyond isolation and homogeneity: Diversity and the history of Appalachia. In Billings, D.B., Norman, G., Ledford, K. (Eds): Confronting Appalachian stereotypes: Back talk from an American region. (pp. 21-43). Lexington, KY: University Press of Kentucky.

Loh, J. (2013). Inquiry into issues of trustworthiness and quality in narrative studies: A perspective. The Qualitative Report, 18(33), 1-15. Retrieved from https://nsuworks.nova.edu/tqr/vol18/iss33/1

Lyons, N., \& LaBoskey, V. K. (Eds.). (2002). Narrative inquiry in practice: Advancing the knowledge of teaching (Vol. 22). New York, NY: Teachers College Press.

Massey, D. (1994) Space, place, and gender. Cambridge, MA: Polity Press \& Minneapolis, University of Minnesota Press.

McCoach, D. B., \& Siegle, D. (2007). What predicts teachers' attitudes toward the gifted? Gifted Child Quarterly, 51(3), 246-254.

Miles, M. B. \& Huberman, A. M. (1994). Qualitative data analysis: An expanded sourcebook. Thousand Oaks, CA: Sage. 
Merriam, S. B., \& Tisdell, E. J. (2015). Qualitative research: A guide to design and implementation. San Francisco, CA: John Wiley \& Sons. Retrieved from https://ebookcentral.proquest.com

Miles, M. B., Huberman, A. M., \& Saldaña, J. (2013). Qualitative data analysis. Thousand Oaks, CA: Sage.

Miller, M., \& Brigandi, C. B. (forthcoming). Rural gifted education: Teachers' perceptions and practices.

Moll, L. C., Amanti, C., Neff, D., \& Gonzalez, N. (1992). Funds of knowledge for teaching: Using a qualitative approach to connect homes and classrooms. Theory into Practice, 31(2), 132-141.

Montoya, R., Matias, C. E., Nishi, N. W., \& Sarcedo, G. L. (2016). Words are wind: using Du Bois and Bourdieu to 'unveil' the capricious nature of gifted and talented programs. Journal for Critical Education Policy Studies (JCEPS), 14(1), 127-143.

Moon, T. R., \& Brighton, C. M. (2008). Primary teachers' conceptions of giftedness. Journal for the Education of the Gifted, 31(4), 447-480.

Morris, J., Slater, E., Fitzgerald, M. T., Lummis, G. W., \& van Etten, E. (2019). Using local rural knowledge to enhance STEM learning for gifted and talented students in Australia. Research in Science Education, 1-19. Retrieved from https://doi.org/10.1007/s11165-019-9823-2

National Association for Gifted Children (NAGC) (n.d.) Frequently asked questions about gifted education. Retrieved from https://www.nagc.org/resourcespublications/resources/frequently-asked-questions-about-gifted-education 
National Association for Gifted Children (NAGC) \& Council of State Directors of Programs for the Gifted (CSDPG) (2015). 2014-2015 State of the states in gifted education: Policy and practice data. Washington, DC: Author.

National Association for Gifted Children. (2010). Pre-K-Grade 12 Gifted Programming Standards. Washington, DC: Author.

National Center for Education Statistics (2008) U.S. Department of Education, Office for Civil Rights, Civil Rights Data Collection: 2004 and 2006; Table 49: Percentage of gifted and talented students in public elementary and secondary schools, by sex, race/ethnicity, and state: 2004 and 2006.

Nespor, J. (2008). Education and place: A review essay. Educational Theory, 58(4), 475-489. Retrieved from: https://doi.org/10.1111/j.1741-5446.2008.00301.x

Olenchak, F. R. (1991). Assessing program effects for gifted/learning disabled students. In R. Swassing \& A. Robinson (Eds.). NAGC 1991 Research Briefs. Washington, DC: National Association for Gifted Children.

Ortlipp, M. (2008). Keeping and using reflective journals in the qualitative research process. The Qualitative Report, 13(4), 695-705. Retrieved from https://nsuworks.nova.edu/tqr/vol13/iss4/8

Ozturk, M. A., \& Debelak, C. (2008). Affective Benefits From Academic Competitions for Middle School Gifted Students. Gifted Child Today, 31(2), 48. https://doiorg.www.libproxy.wvu.edu/10.4219/gct-2008-758

Patton, M. (1999). Enhancing the quality and credibility of qualitative analysis. Health Services Research, 34(5, II), 1189-1208. 
Patton, M. (2002). Qualitative research and evaluation methods (3rd ed.). Thousand Oaks, CA: Sage.

Petrin, R. A., Schafft, K. A., \& Meece, J. L. (2014). Educational sorting and residential aspirations among rural high school students: What are the contributions of schools and educators to rural brain drain? American Educational Research Journal, 51(2), 294-326.

Pitsoe, V. J., \& Maila, W. M. (2012). Towards constructivist teacher professional development. Journal of Social Sciences, 8(3), 318-324.

Plucker, J. A. (2013). Students from rural environments. In C. Callahan \& H. Hertzberg-Davis (Eds.), Fundamentals of gifted education (pp. 301-314). New York, NY: Routledge.

Plucker, J. A., Burroughs, N., \& Song, R. (2010). Mind the (Other) Gap! The Growing Excellence Gap in K-12 Education. Bloomington, Indiana: Center for Evaluation and Education Policy \& Indiana University.

Reis, S. M. (1981). An analysis of the productivity of gifted students participating in programs using The Revolving Door Identification Model. (Unpublished Doctoral Dissertation) Retrieved from https://opencommons.uconn.edu/dissertations/AAI8213232

Reis, S. M., \& Renzulli, J. S. (1994). Promoting creativity in talented adolescents. Storrs, CT: The University of Connecticut. Retrieved from http://www.gifted.uconn.edu/general/faculty/reis/Promoting_Creativity_Talented_Adoles cents.html

Reis, S. M., \& Renzulli, J. S. (2010). Is there still a need for gifted education? An examination of current research. Learning and Individual Differences, 20(4), 308-317.

Renzulli, J. S. (1977). The Enrichment Triad Model: A guide for developing defensible programs for the gifted and talented. Mansfield Center, CT: Creative Learning Press. 
Renzulli, J. (1982). Dear Mr. and Mrs. Copernicus: We regret to inform you. Gifted Child Quarterly, 26(1), 11-14.

Renzulli, J. S. (1978). What makes giftedness: Reexamining a definition. Phi Delta Kappan, 60(3), 180-184.

Renzulli, J.S. (2002). Emerging conceptions of giftedness: Building a bridge to the new century, Exceptionality: A Special Education Journal 10(2), 67-75.

Renzulli, J. S. (2005). The Three-Ring Conception of Giftedness: A developmental model for promoting creative productivity. In R. J. Sternberg \& J. E. Davidson (Eds.), Conceptions of giftedness (2nd ed., pp. 246-279). Cambridge: Cambridge University Press. https://doi.org/10.1017/CBO9780511610455.015

Renzulli, J. S., \& Reis, S. M. (1997). The Schoolwide Enrichment Model: A how-to guide for educational excellence (2nd ed.). Mansfield Center, CT: Creative Learning Press.

Renzulli, J. S., \& Reis, S. M. (2014). The Schoolwide Enrichment Model: A how-to guide for talent development (3rd ed.). Waco, TX: Prufrock Press.

Richards, C. J., \& Stambaugh, T. (2015). National context of rural schools. In Stambaugh, T. \& Woods, S.M. (Ed.) Serving gifted students in rural settings, (pp. 1-21). Waco,TX: Prufrock Press.

Ridder, M (2019, May 10). Mill closing has impact on Mineral school's budget. Cumberland Times News. Retrieved from: https://www.times-news.com/news/local_news/millclosing-has-impact-on-mineral-schools-budget/article_2fd3815e-ad92-5705-b7b2a40d3276beec.html

Riessman, C. K. (2008). Narrative methods for the human sciences. Thousand Oaks, CA: Sage. 
Riley, T. L., \& Karnes, F. A. (1998). Mathematics + competitions = a winning formula! Gifted Child Today Magazine, 21(4), 42. https://doiorg.www.libproxy.wvu.edu/10.1177/107621759802100413

Roberts, J. L. (2010). Talent Development in STEM Disciplines: Diversity--Cast a Wide Net. NCSSSMST Journal, 16(1), 10-12.

Rogers, K. B. (2007). Lessons learned about educating the gifted and talented: A synthesis of the research on educational practice. Gifted Child Quarterly, 51(4), 382-396.

Rymes, B \& Wortham, S (2011). Concepts and methods for using narrative in teacher education. In Rex, L. \& Juzwik, M (Eds.) Narrative discourse analysis for teacher educators: Managing cultural differences in the classroom (pp. 37-54). New York, NY: Hampton Press.

Saldaña, J. (2011). Fundamentals of qualitative research ( $3^{\text {rd }}$ ed.). New York, NY: Oxford University Press. Retrieved from https://ebookcentral.proquest.com

Saldaña, J. (2015). The coding manual for qualitative researchers. Thousand Oaks, CA: Sage Publications.

Satterwhite, E. (2010). Objecting to insider/outsider politics and the uncritical celebration of Appalachia. In Smith, B. E., Fisher, S., Obermiller, P., Whisnant, D., Satterwhite, E., \& Cunningham, R. Appalachian identity: A roundtable discussion. Appalachian Journal, 38(1), 56-76.

Schwartz, A. T. (2006). Contextualized chemistry education: The American experience. International Journal of Science Education, 28(9), 977-998.

Seidman, I. (2013). Interviewing as qualitative research: A guide for researchers in education and the social sciences $\left(4^{\text {th }}\right.$ ed). New York, NY: Teachers College Press. 
Shapiro, H (1978) Appalachia on Our Mind: the Southern Mountains and Mountaineers in the American Consciousness, 1870-1920. Chapel Hill: UNC Press.

Shenton, A. K. (2004). Strategies for ensuring trustworthiness in qualitative research projects. Education for information, 22(2), 63-75.

Schack, G. D. (1989). Self-efficacy as a mediator in the creative productivity of gifted children. Journal for the Education of the Gifted, 12(3), 231-249.

Schack, G. D. (1991). Self-Efficacy and Creative Productivity: Three Studies of above Average Ability Children. Journal of Research in Education, 1(1), 44-52.

Seal, K. R., \& Harmon, H. L. (1995). Realities in rural school reform. Phi Delta Kappan, 77(2), 119-124.

Semken, S., \& Freeman, C. B. (2008). Sense of place in the practice and assessment of placebased science teaching. Science Education, 92(6), 1042-1057.

Sherman, J., \& Sage, R. (2011). Sending off all your good treasures: Rural schools, brain-drain, and community survival in the wake of economic collapse. Journal of Research in Rural Education, 26(11), 1-14.

Silva, J. P., White, G. P., \& Yoshida, R. K. (2011). The direct effects of principal-student discussions on eighth grade students' gains in reading achievement: An experimental study. Educational Administration Quarterly, 47(5), 772-793.

Slater, G.B. \& Griggs, C.B. (2015). Standardization and subjection: An autonomist critique of neoliberal school reform, Review of Education, Pedagogy, and Cultural Studies, 37(5), 438-459, DOI: 10.1080/10714413.2015.1091259

Smith, G. A. (2002]. Place-based education: Learning to be where we are. Phi Delta Kappa, 83(8), 584-594. 
Smith, G. A. (2007). Place-based education: breaking through the constraining regularities of public school. Environmental Education Research, 13(2), 189-207. https://doi.org/10.1080/13504620701285180

Sobel, D. (2004). Place-based education: Connecting classroom and community. Nature and Listening, 4(1), 1-7.

Sparkes, \& Smith, (2008) Narrative Constructionist Inquiry. In Holstein, J., \& Gubrium, J. (Eds.), Handbook of constructionist research (pp. 295-314). New York: Guilford Press.

Spencer, N. (28 September 2019) Majority of West Virginia counties rank worst in US for water quality. International Committee of the Fourth International (ICFI). Retrieved from https://www.wsws.org/en/articles/2019/09/28/wate-s28.html

Spotlight on Poverty and Opportunity (2018). Spotlight on the states. Retrieved from https://spotlightonpoverty.org/states/

Stake, R. (1995). The art of case study research. Thousand Oaks: Sage Publications.

Starko, A. J. (1986). Effects of the Revolving Door Identification Model on creative productivity and self-efficacy (Order No. 8700085). Available from ProQuest Dissertations \& Theses Global. (303465891). Retrieved from https://search-proquestcom.www.libproxy.wvu.edu/docview/303465891?accountid=2837

Starko, A. J. (1988). Effects of the revolving door identification model on creative productivity and self-efficacy. Gifted Child Quarterly, 32(3), 291-297

Starko, A. J., \& Schack, G. D. (1989). Perceived Need, Teacher Efficacy, and Teaching Strategies for the Gifted and Talented. Gifted Child Quarterly, 33(3), 118122. https://doi.org/10.1177/001698628903300305 
Stedtnitz, U. (1985). The Influence Of Educational Enrichment On Self-efficacy In Young Children (gifted, Pre-school) (Order No. 8601720). Available from ProQuest Dissertations \& Theses Global. (303356596). Retrieved from https://search-proquest com.www.libproxy.wvu.edu/docview/303356596?accountid=2837

Stedtnitz, U. (1986). The influence of educational enrichment on self-efficacy and interest levels in young children. Topics in Early Childhood Special Education, 6(1), 39-49.

Sternberg, R.J. (2006). Introduction. In Kaufman, J. C., \& Sternberg, R. J. (Eds.). The International Handbook of Creativity (pp. 1-9). Retrieved from https://ebookcentral.proquest.com

Sternberg \& J. E. Davidson (2005). Conceptions of giftedness (2nd ed.). Cambridge: Cambridge University Press

Sternberg, R. J., \& Lubart, T. I. (1999). The concept of creativity: Prospects and paradigms. In Sternberg Robert J (Ed.), Handbook of creativity (pp. 3-15) New York, NY: Cambridge University Press.

Sternberg, R. J., Wagner, R. K., \& Okagaki, L. (1993). Practical intelligence: The nature and role of tacit knowledge in work and at school. In Puckett \& Reece (Eds) Mechanisms of Everyday Cognition, (pp. 205-227) Hillsdale, NJ: Lawrence Erlbaum Associates

Stevenson, R. (1987) Schooling and environmental education: contradictions in purpose and practice, in Robottom (Ed.) Environmental education: practice and possibility (69-82). Geelong, Australia: Deakin University Press.

Street, B. (1993). Culture is a verb: Anthropological aspects of language and cultural process. In Graddol, D., Thompson, L., \& Bryan, M. Language and culture, (pp 23-43) Tonawanda, NY: Multilingual Matters. 
Terman, A. R. (2016). Intersections of Appalachian Identity. Appalachia Revisited: New Perspectives on Place, Tradition, and Progress, edited by William Schumann, and Rebecca Adkins Fletcher, University Press of Kentucky, 2016. ProQuest Ebook Central, https://ebookcentral.proquest.com/lib/wvu/detail.action?docID=4532880.

Theobald, P. (1997). Teaching the Commons: Place. Pride, and the Renewal of Community. Boulder, CO: Westview.

Theobald, P \& Siska, J. (2007). Place: Where diversity and community can converge. In Smith, G., \& Gruenewald, D. (Eds). Place-based education in the global age: Local diversity. (pp. 197-220). NY: Routledge.

Tomlinson, C. A. (2001). How to differentiate instruction in mixed-ability classrooms (2nd ed.). Alexandria, VA: Association for Supervision and Curriculum Development.

Theobald, P., \& Wood, K. (2010). Learning to be rural: Identity lessons from history, schooling, and the US corporate media. In Schaft, K.A. \& Jackson A.Y. (Ed) Rural education for the twenty-first century: Identity, place, and community in a globalizing world, (pp. 1733). University Park: Pennsylvania State University Press.

Tomlinson, C. A., \& ERIC Clearinghouse on Elementary and Early Childhood Education. (2000). Differentiation of instruction in the elementary grades. Champaign, IL: ERIC Clearinghouse on Elementary and Early Childhood Education, University of Illinois. United States Census Bureau (2010) Quick Facts Appalachian County, West Virginia. Retrieved from https://www.census.gov/quickfacts/fact/table/mineralcountywestvirginia/PST045218 United States Congress Public Law 107-110. (2002, January). No Child Left Behind Act. Retrieved from http://www.ed.gov/policy/elsec/leg/esea02/107-110.pdf. 
Wakeman, Heather (2015) Power in Place-Based Education: Why a critical pedagogy of place needs to be revived and how narratives or collective biographies support its practice. Doctoral Projects, Masters Plan B, and Related Works. Paper 9. http://repository.uwyo.edu/plan_b/9

Webster, L., \& Mertova, P. (2007). Using narrative inquiry as a research method: An introduction to using critical event narrative analysis in research on learning and teaching. New York, NY: Routledge.

West Virginia Board of Pharmacy \& West Virginia Department of Health and Human Resources (2017) Prescription Opioid Problematic Prescribing Indicators County Report. Retrieved from:

https://helpandhopewv.org/docs/PFS_County_Reports/Mineral_PfS\%20County\%20Repo rts_Final.pdf

West Virginia Department of Education [WVDE] (2014) Gifted Education Fact Sheet for school year 2013-2014. Retrieved from https://wvde.state.wv.us/osp/Gifted_Fact_Sheet2014.pdf

West Virginia Department of Education [WVDE] Policy 5202 (2019). Minimum requirements of the licensure of professional/paraprofessional personnel and advanced salary classifications. Retrieved from http://apps.sos.wv.gov/adlaw/csr/readfile.aspx?DocId=51036\&Format=PDF

West Virginia Department of Education [WVDE] (2019). Early and Elementary Learning. Retrieved from https://wvde.us/early-and-elementary-learning/ 
West Virginia Department of Education [WVDE] Policy 2419 (2017). Regulations for the Education of Students with Exceptionalities: Policy 2419. p.31. Charleston: WV: Author. Retrieved from https://wvde.state.wv.us/osp/Policy2419_2017.pdf

West Virginia Senate Bill 451, $84^{\text {th }}$ Cong. (2019).

White, S. \& Reid, J. (2008). Placing teachers? Sustaining rural schooling through place consciousness in teacher education. Journal of Research in Rural Education, 23(7), 1-11. Retrieved [date] from http://jrre.psu.edu/articles/23-7.pdf

Woodhouse, J., \& Knapp, C. (2000). Place-based curriculum and instruction: Outdoor and environmental education approaches. ED448012. Charleston, WV: ERIC Clearinghouse on Rural Education and Small Schools.

Wright, C. J. (2012). Becoming to remain: Community college students and postsecondary pursuits in central Appalachia. Journal of Research in Rural Education, 27(6). Retrieved from http://jrre./psu.edu/articles/27-6.pdf

Yin, R. (2003). Case study research : Design and methods (3rd ed. Applied social research methods series, v. 5). Thousand Oaks, CA: Sage Publications.

Yosso, T. J. (2005). Whose culture has capital? A critical race theory discussion of community cultural wealth. Race ethnicity and education, 8(1), 69-91.

Zipin, L. (2009). Dark funds of knowledge, deep funds of pedagogy: Exploring boundaries between lifeworlds and schools. Discourse: Studies in the cultural politics of education, 30(3), 317-331. 


\section{Appendix A}

\section{Email Script to Teachers}

Dear

This email is a request for you to take part in a research project that will be exploring teachers' experiences as they implement a gifted framework in their small rural schools. The study will also be exploring students' perceptions of the value of learning about the places they live. The project is being conducted by Myriah Miller, a Doctoral Candidate in the department of Curriculum and Instruction at West Virginia University (WVU) as partial fulfillment of her degree. Supervising Myriah is Dr. Sharon Hayes an associate professor in the College of Education and Human Services at WVU.

Attached for your review is a cover letter and consent form explaining the research and your participation as well as the interview questions to be asked within the study. Your participation in this project is greatly appreciated and is estimated to take 12 hours of your time spread out across a sixth month period.

I hope that you will participate in this research project, as it will be beneficial to understanding rural gifted teachers' experiences. Thank you very much for your time. Should you be interested in participating or have any questions about this letter or the research project, please contact Myriah Miller at (304) 290-7431 or by e-mail at mtasker@mix.wvu.edu to discuss this research further.

Thank you for your time and help with this project.

Sincerely, Myriah Miller 


\section{Appendix B}

\section{TEACHER INTERVIEW PROTOCOLS}

\section{$1^{\text {st }}$ Interview Protocol}

INTRODUCTION:

Do I have permission to audio record our conversation?

Thanks for letting me interview you. I have scripted some questions, but along the way if there is anything that you would like to talk about that I have not directly asked, please feel free to discuss any aspect of the gifted program you like.

1. To begin, I just want to get a little background information. Can you please walk me through your daily schedule or weekly schedule if the days differ?

a. How many students do you service?

b. Demographics: What is the approximate breakdown with regard to student race/ethnicity? Gender? SES?

c. How often do you meet with your students and for what length of time?

d. What content areas do you service?

e. If itinerant, how many schools do you serve and how many days do you typically spend at each school per week?

f. How long have you lived in the area?

g. How long have you been teaching the gifted?

h. Credentials for working with gifted students, such as experience, advanced degrees, certifications.

2. Can you tell me how you came to teaching?

3. Can you tell me how you came to teaching the gifted?

4. Tell me about your gifted curriculum.

a. Clarification. Tell me about what you teach, how you teach it, and what influences your decision to teach this.

b. How do you ensure your gifted curriculum fits your learners' needs?

5. Describe a typical class on a typical day in your gifted program.

6. What is it like to be a gifted teacher in a small school in a rural place?

7. Can you describe a specific lesson or activity that you feel was really beneficial or meaningful to the students?

a. Why was it beneficial or meaningful? 
8. Tell me about your best lesson or activity that you did with your gifted class from either last year or this year so far?

a. Why do you consider it your "best"?

9. Is there anything else related to the teaching gifted education in a rural place that you'd like to talk about today?
a. Is there anything else you think I should know?
b. Is there anything you would like to ask?

\section{Interview 2's}

\section{INTRODUCTION:}

Do I have permission to audio record our conversation?

Thanks for letting me interview you. I have scripted some questions, but along the way if there is anything that you would like to talk about that I have not directly asked, please feel free to discuss any aspect of the gifted program you like.

1. Last time we talked, you talked about Did that sound right?
a. Is there anything else you would like to add to that?

\section{$\underline{\text { Only in } 1^{\text {st }} \text { number } 2 \text { interview }}$}

1. Were there any parts of Type I's that you already implement in your classroom before the professional development sessions? If so, please tell me about them.
a. Type II's?
b. Type III's?

All subsequent number 2 interviews

2. Tell me about what happened in class today/recently.

3. Tell me about your current curricular development.

a. Clarification - tell me about what you teaching (or facilitating), how you are teaching it (or facilitating it), and why?

4. Describe how place is being incorporated into the curriculum.

4. How is the implementation going?

b. What is going well?

i. how do you know it's going well? 
c. What is challenging you? How are you addressing these challenges?

d. What is going well or is a struggle for the students?

5. How could you better be supported right now as you are going through the process of implementing the Enrichment Triad?

6. Is there anything else related to the gifted class, the professional development, or the Triad Model that you'd like to talk about?

a. Is there anything else you think I need to know?

b. Is there anything you would like to ask?

\section{Interview 3}

\section{INTRODUCTION:}

Do I have permission to audio record our conversation?

Thanks for letting me interview you. I have scripted some questions, but along the way if there is anything that you would like to talk about that I have not directly asked, please feel free to discuss any aspect of the gifted program you like.

1. What does being a gifted teacher mean to you? How has your thinking evolved/changed?

2. How did your experience implementing the Enrichment Triad with a place focus influence your curriculum development?

a. Influence your teaching?

b. Influence your relationships/interactions with students?

c. Influence student learning?

3. Now that you have gone through the process of implementing the Triad, what value might the Triad have for a small rural pull-out program?

4. How would you describe the differences between your previous curriculum and the curriculum you developed this semester?

a. How did these differences influence your students' learning?

b. How might these differences influence their futures?

i. How might these differences influence their future perception of place (insert place name)?

5. Describe what your gifted program might "look like" next year?

6. Is there anything else related to the gifted class, the professional development, or the Triad Model that you'd like to talk about?

a. Is there anything else you think I need to know? 
b. Is there anything you would like to ask?

Prompts:

Can you please tell me a little more about...

What I hear you saying is....

What do you think about that?

How do you feel about that? 


\section{Appendix C}

\section{Follow-up Phone Call Protocol}

Hello, my name is Myriah Miller and I am a doctoral student at West Virginia University. I recently sent you some information on a study that I am conducting on understanding the experiences of rural gifted teachers and students. If you are interested, would it be possible to schedule a meeting to discuss your participation in the research study?

$\underline{\text { If answer is yes }}$

We could have a phone or in person meeting whichever is more convenient for you.

(After scheduling of meeting time and place)

Thank you for your time and I look forward to our meeting. (End Call)

$\underline{\text { If answer is no }}$

Okay, thank you for your time. (End Call) 


\section{Appendix D}

\section{Student Interview Protocols}

\section{$1^{\text {st }}$ Interview Protocol}

\section{Student Assent:}

My name is Myriah Miller and I am a student at West Virginia University. I am here doing a study on how gifted students in rural places, like , feel about what they do in their gifted classrooms. I would like to ask you some questions about this and audio record our conversation. If at any time the questions make you feel uncomfortable or you do not want to answer them, just let me know and we will move to another question. At any time you are allowed to stop being in the study and I delete the audio recording. Part of my job is to disguise our conversation. For example, I will not use your real name or the real name of the school when I write my paper, but there is a small chance that someone could find out about our conversation. You decide if you want to be in the study or not. I would like to ask you some questions about what you learn in gifted class and how you feel about certain parts of gifted class. Do you agree to answer my questions, and to let me audio record our conversation?

1. Think back to kindergarten all the way through till now, can you tell me about something you have done in school that was meaningful to you? Why was it meaningful?

a. Clarification-something that was important to you

2. Can you tell me about a something you have done in gifted class that was meaningful to you?

a. Why was that meaningful/important?

3. Can you tell me about how you came to be in a gifted class?

a. In what area do you think you are "gifted"?

4. Can you tell me about your gifted classes up until now -so tell me about gifted class in (i.e. $1^{\text {st }}$ grade, $2^{\text {nd }}$ grade or $1^{\text {st }}-5$ th grade).

5. Can you describe to me what it is like to be gifted at (insert school name)?

6. Can you describe to me what it is like to be gifted in (insert town name)?

7. How is your gifted classroom the same as your general classroom?

a. How is your gifted classroom different from your general classroom?

8. Is there anything else related to your gifted class that you'd like to talk about today?

a. Is there anything else you think I should know?

b. Is there anything you would like to ask?

\section{2nd Interview Protocol}

Student Assent: 
My name is Myriah Miller and I am a student at West Virginia University. I am here doing a study on how gifted students in rural places, like , feel about what they do in their gifted classrooms. I would like to ask you some questions about this and audio record our conversation. If at any time the questions make you feel uncomfortable or you do not want to answer them, just let me know and we will move to another question. At any time you are allowed to stop being in the study and I will erase the audio recording. Part of my job is to disguise our conversation. For example, I will not use your real name or the real name of the school when I write my paper, but there is a small chance that someone could find out about our conversation. You decide if you want to be in the study or not. I would like to ask you some questions about what you learn in gifted class and how you feel about certain parts of gifted class. Do you agree to answer my questions, and to let me audio record our conversation?

Student

1. Last time we talked, you talked about . Did that sound right?

a. Is there anything else you would like to add to that?

2. Tell me about what has been happening in gifted class.

3. How is what you did in class today different than what you do in class most days?

a. How is it the same

4. Tell me about your project.

a. How did you come to that decision?

b. How is the project going? Please tell me about that.

5. Tell me about how the teacher has helped you with your project so far.

a. Tell me about anybody else (parents, mentors, classmates) that has helped you during your project so far

6. How do you see what you do in gifted class relating to your life outside of school?

a. Clarification: Does anything you do in gifted class help you or others outside of school?

7. Pretend you are the teacher and get to make all the decisions, what would you change about your gifted class? Why?

a. What would you make sure to keep? Why?

8. Is there anything else related to your gifted class that you'd like to talk about today?

a. Is there anything else you'd like me to know?

b. Is there anything you would like to ask?

\section{$3^{\text {rd }}$ Interview Protocol}

Student 


\section{Student Assent:}

My name is Myriah Miller and I am a student at West Virginia University. I am here doing a study on how gifted students in rural places, like feel about what they do in their gifted classrooms. I would like to ask you some questions about this and audio record our conversation. If at any time the questions make you feel uncomfortable or you do not want to answer them, just let me know and we will move to another question. At any time you are allowed to stop being in the study and I will erase the audio recording. Part of my job is to disguise our conversation. For example, I will not use your real name or the real name of the school when I write my paper, but there is a small chance that someone could find out about our conversation. You decide if you want to be in the study or not. I would like to ask you some questions about what you learn in gifted class and how you feel about certain parts of gifted class. Do you agree to answer my questions, and to let me audio record our conversation?

1) Tell me about the project you just completed.

a. How did you choose the topic?

b. Tell me about your goals of your project.

i. Tell me about how you met or did not meet your goals.

c. How did you decide to present it as a (insert product type)?

d. What did you think about doing a project related to (topic of project)

e. Tell me a time you were proud about your work.

f. What have you learned through doing this project?

9. Tell me about a time you were frustrated during the project.

10. How do you see this project in gifted class relating to your life outside of school?

a. Clarification-how is what you do in your gifted class important to what your life outside of school? -important to you; important to your family; important to the people in your community; important to the environment:

11. How do you think working on this project is going to help you in the future?

12. Imagine you get to decide what you will learn in gifted class next year, what would you choose to learn about?

13. How does what you are doing in your gifted classroom connect with what you are doing in your general education classroom?

a. How does what you are doing in your general education classroom connect to what you are doing in your gifted classroom?

b. How is your gifted classroom different from your general classroom?

14. Is there anything else related to your gifted class that you'd like to talk about today?

a. Is there anything else you'd like me to know? 
b. Is there anything you would like to ask?

Prompts:

Can you please tell me a little more about...

What I hear you saying is....

What do you think about that?

How do you feel about that? 


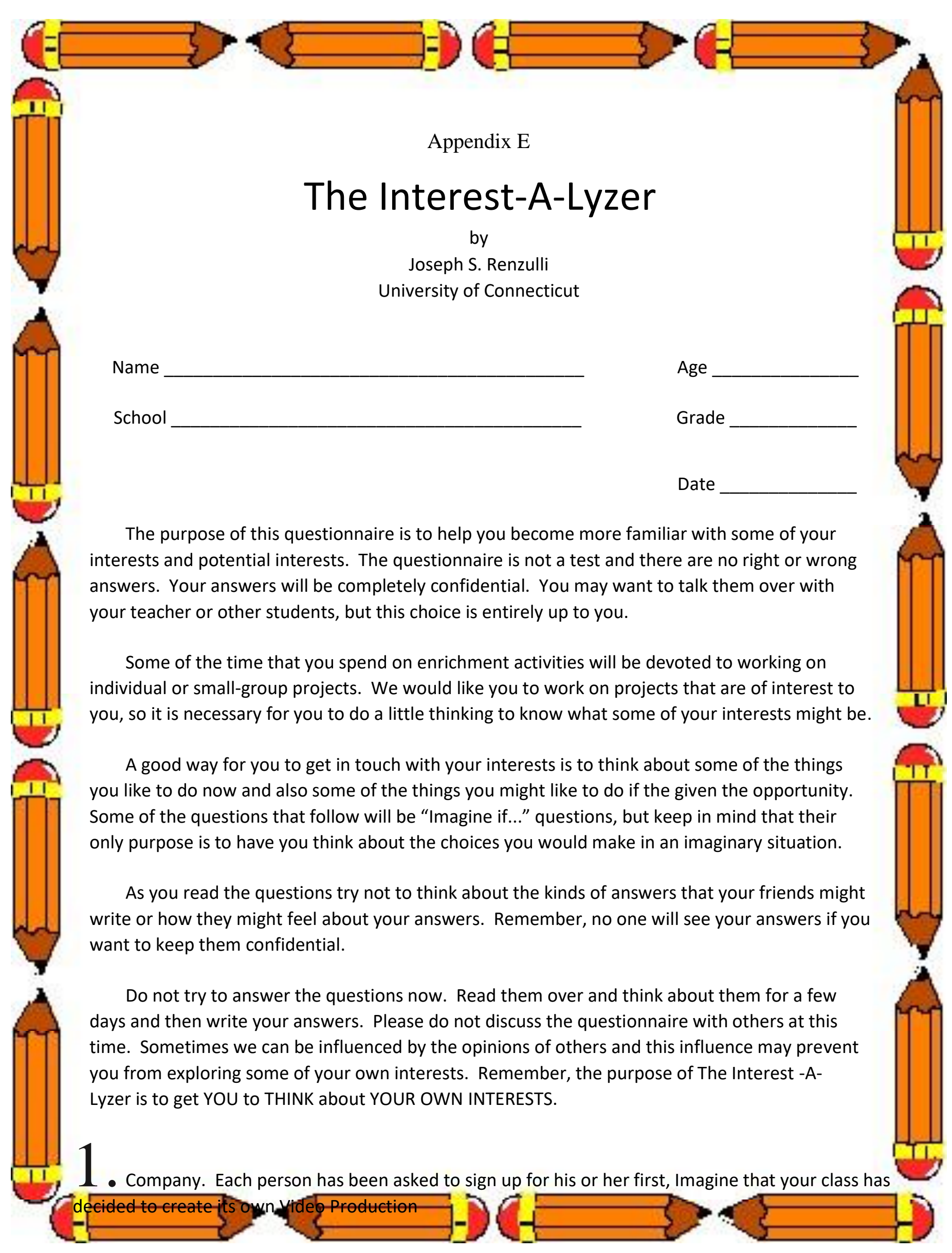


second or third choice for one of the jobs listed below.

Mark your first choice with a 1 , second choice with a

2 , and third choice with a 3 .

Actor/Actress

Director

Musician

Costume Designer

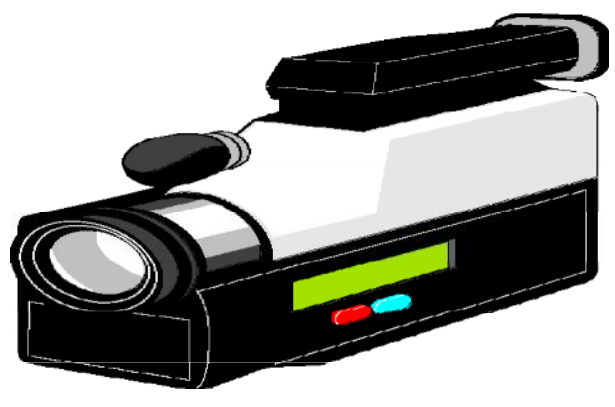

Business Manager

_ Computer Effects Specialist

Fine Arts

Writing

Athletics
Prop Person

Advertising Agent

Script Writer

Business

History

Mathematics

Mathematics

Advertising Agent
Script Writer

\section{2}

- Imagine that you have become a famous author of a well-known book. What is the general subject of your book? Circle One.

Performing Arts

What will it be about?

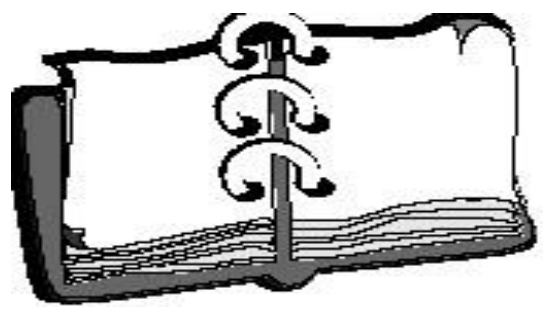


What would be a good title for your book?

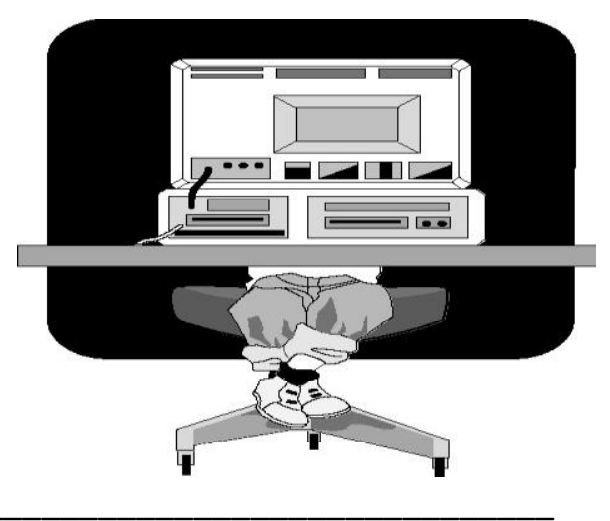

3.

- Computers and telephone technology allow us to communicate with people all over the world.

Imagine that your school has installed an Internet or telephone system that will allow you to communicate with anyone in the world. With whom would you correspond?

\section{First Choice}

Second Choice

Third Choice

4.

Imagine that a time machine has been invented that will allow famous people from the past to travel through time. If you could invite some of these people to visit your class, who would you invite?

First Choice

Second Choice

Third Choice 
- Are you a collector? Do you collect stamps, coins, autographs, baseball cards, or other things? List the things that you collect and the number of years you have been collecting.

Things I Collect

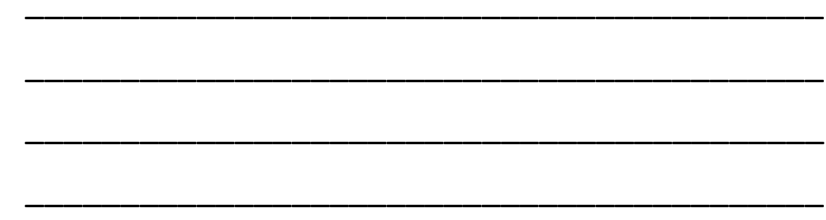

Number of Years

I Have Been Collecting

Imagine you have the time and the money to collect anything you wanted. What would you collect?

6.

Imagine you have the opportunity to travel to a new and exciting city. You can select three places to visit. Mark your first, second and third choice by placing a 1, 2, and 3 in the spaces below.

$\ldots$ Art Gallery
$\ldots \ldots$ Professional Sport Training Camp
Historical Sites
$\ldots$
Science Center

Ballet or Modern Dance

Musical Concert

State Senate Meeting

Computer Center

Court Room

Zoo

Stage Play

Newspaper Office 
- Imagine that you have been assigned to a space station for your next school year. You are allowed to take a few personal possessions (books, games, hobbies, projects) with you to help you spend your free time. List the things you would take.

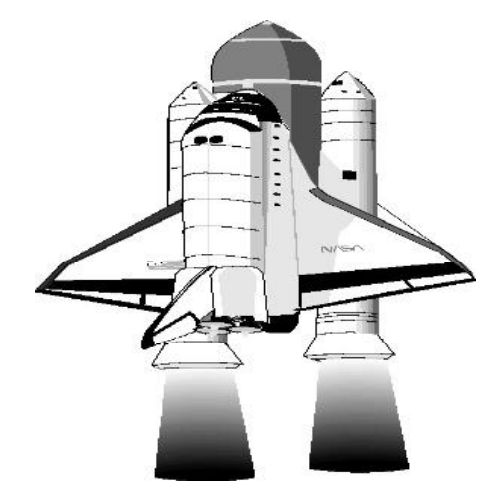

8. Imagine that you can spend a week "job shadowing" any person in your community to investigate a career you might like to have in the future. List the occupations of the persons you would select.

First Choice

Second Choice

Third Choice

9.

- Newspapers often have special feature columns or sections such as the ones listed below. Imagine you have been given a job as a feature writer. Which of the following columns would you like to write? Mark your first, second, and third choice with a 1, 2, and 3.

Movie Reviews
B__ Book Reviews
Political Cartoons

Fashion Column
Science Facts
Cross Word Puzzles


Local History

Stock Market Analysis

Personal Advice

Video Game Reviews

Editorials

Famous People

Cars and Bikes

Travel

Internet Connections

Social Action News
Camping

Music Critic

Business Trends

Humor

Mathematics Puzzles

Advice on Chess

Sports Analyst

Pet Care

Computer Column

Advice to Consumers

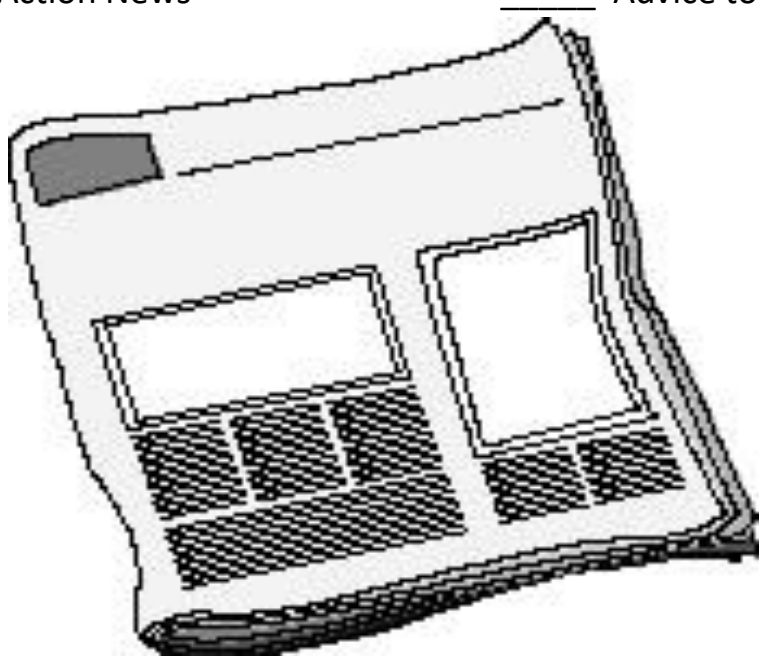


10.

Some schools offer extra-curricular activities and clubs that coincide with student interest areas.

In fact, students sometimes don't know they

have an interest in something until they get to try it out in a club or activity. Enrichment Clusters are another good place to find out about interest areas. Listed below are some examples of clubs, activities, and clusters.

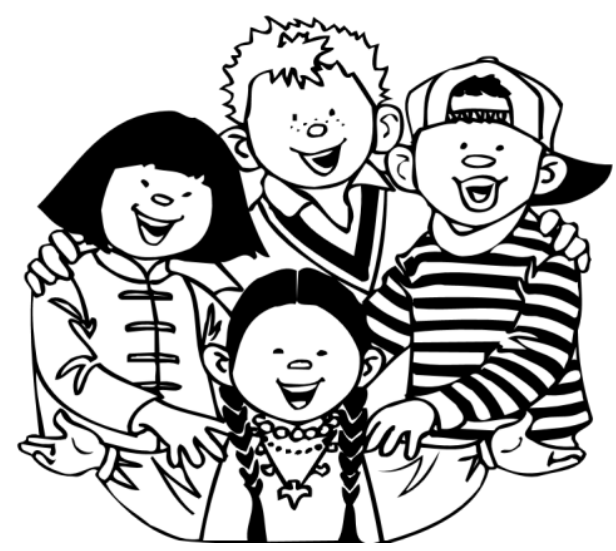

Mark the ones that you have been involved in with an "X". Circle the ones you would like to try someday.

Newspaper
Y_H
G_H Girl or Boy Scouts
Cooking Club
Math Club
Chess
Babysitting Club
Math Olympiad
O_ Odyssey of the Mind

$\ldots$ Language Club
Collections Club
Ecology Club
Drama
Invention Convention
Science Club
Literary Magazine
Computer Club
Future Problem Solving
Sports (List here):

Are there any we forgot? You can use space below to tell us which clubs, activities, or clusters you have participated in:

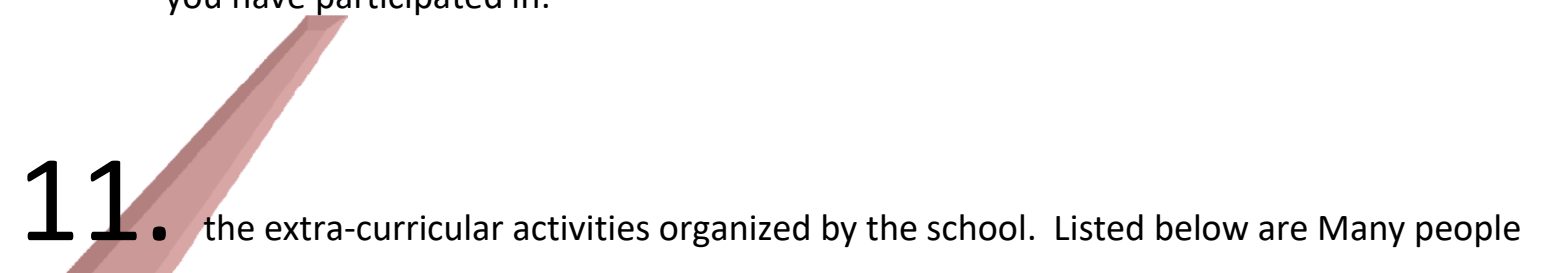

take part in activities that are not connected with school work or 
examples of such activities. Indicate how often you have participated in each activity by marking the appropriate column. Please do NOT check any activities that were part of your school work or were organized by the school which you attend.

1. Wrote a short story, play or poem.

2. Repaired a broken radio, toy, machine or piece of furniture.

3. Conducted a science experiment.

4. Programmed a computer.

5. Printed a newspaper.

6. Took photographs of landscapes, interesting people or unusual objects.

7. Studied the weather by keeping daily records of temperature, barometric pressure, rain fall etc.

8. Used the Internet to locate information.

9. Organized a team or club.

10. Organized a musical group.

11. Was a member of a musical or theatrical group.

12. Put on a puppet show for younger children.

13. Started a business (for example: car wash, bicycle repairs, lemonade stand).

14. Designed a comic strip.

15. Painted or sketched interesting people, objects or landscapes.

16. Used a computer graphics program to design original artwork.

17. Wrote a letter or sent e-mail to the editor of a newspaper or a public official (Mayor, Congressperson, etc.).

18. Learned to play a musical instrument.

19. Wrote a song, opera or other musical composition.

20. Learned a handicraft such as weaving, wood carving, 
or making jewelry.

21. Designed costumes, clothes or furniture.

22. Entered a contest (Example: chess, writing, art, athletic).

23. Put on a backyard show (circus, magic show, exhibition).

24. Built or designed a vehicle (model aircraft, rocket, hot air balloon, go-cart).

25. Developed film and printed photographs.

26. Created a spread sheet program to keep track of finances.

27. Designed a physical fitness program for yourself.

28. Learned another language.

29. Made up and used a secret code.

30. Used a computer software program to create a newsletter.

31. Kept a journal or diary for over a year.

32. Made and recorded observations of people or animals on a regular basis.

33. Planted and cultivated a garden.

34. Started a neighborhood project (paper drive, building a park, recycling program, etc.).

35. Read a news, science or literary magazine on a regular basis.

36. Raised animals to sell or to enter in a show or contest.

37. Made a video.

38. Performed as a comic, using original material.

39. Designed and maintained a computer bulletin board.

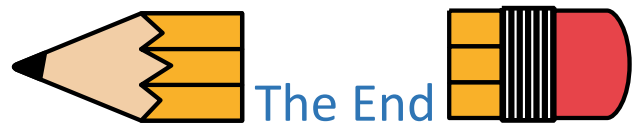




\section{Appendix F \\ Guide for Place Discussions and Topic Finding}

1) What are two of the best things in your life?

2) If you had three wishes, what would you wish for and why would you wish for these things?

3) Pretend you have the power to change things. What would you change about your school?

4) What would you change about your neighborhood/town?

5) What would you change about the world?

6) If you could go anywhere in your town, where would you go?

7) Is there anything that you see that is changing, that should stay the same. (For example: a playground being turned into a parking lot)

8) Do you believe that young people have the power to change things in their classrooms? Schools? Towns? Explain your answer. 
9) Who are some interesting people in your school/town/community?

a. Why are they interesting?

10) Where do you like to spend your free time?

11) If you could start a club, what would it be? (Example: chess club, technology club, comic book club, magic club, and many more!)

12) Imagine a new student just moved into the community. What are three important things you can tell that student about where you live?

13) Pretend someone is bragging on you, what good things would they say about you?

14) Describe a time when something in your family or school changed.

a. How did you feel?

15) Is there anything else about where you live that you think is important to talk about? 


\section{Appendix G}

\section{Management Plan for Individual and Small-Group Investigations}

\begin{tabular}{|c|c|c|c|}
\hline \multicolumn{2}{|c|}{$\begin{array}{l}\text { Name: } \\
\text { Teacher: __ School ___ Grade: }\end{array}$} & - & $\begin{array}{l}\text { Estimated Beginning Date: } \ldots \text { Ending Date: } \\
\text { Progress Reports Due on Following Dates: }\end{array}$ \\
\hline $\begin{array}{ll}\text { General Area(s) of Study (Check all } \\
\square \text { Language Arts/ } & \square \text { Science } \\
\text { Humanities } & \\
\square \text { Social Studies } & \square \text { Music } \\
\square \text { Mathematics } & \square \text { Art }\end{array}$ & $\begin{array}{l}\text { hat apply) } \\
\qquad \text { Personal and Social } \\
\text { Development } \\
\square \text { Other (Specify) } \\
\square \text { Other (Specify) }\end{array}$ & $\begin{array}{l}\text { Specify } \\
\text { Write a b } \\
\text { are the of }\end{array}$ & $\begin{array}{l}\text { Area of Study } \\
\text { rief description of the problem that you plan to investigate. What } \\
\text { bjectives of your investigation? What do you hope to find out? }\end{array}$ \\
\hline $\begin{array}{l}\text { Intended Audiences } \\
\text { Which individuals or groups would } \\
\text { be most interested in the find- } \\
\text { ings? List the organized groups } \\
\text { (clubs, societies, teams) at the local, } \\
\text { regional, state, and national levels. } \\
\text { What are the names and addresses } \\
\text { of contact persons in these groups? } \\
\text { When and where do they meet? } \\
\text { 1. } \\
\text { 2. } \\
\text { 3. } \\
\text { 4. } \\
\text { 5. }\end{array}$ & $\begin{array}{l}\text { Intended Product(s) and Outlets } \\
\text { What form(s) will the final product } \\
\text { take? How, when, and where will } \\
\text { you communicate the results of } \\
\text { your investigation to an appropriate } \\
\text { audience(s)? What outlet vehicles } \\
\text { (journals, conferences, art shows, } \\
\text { etc.) are typically used by profession- } \\
\text { als in this field? }\end{array}$ & $\begin{array}{l}\text { Methodo } \\
\text { List the n: } \\
\text { attacking } \\
\text { of study. } \\
\text { equipmer } \\
\text { ous recor }\end{array}$ & $\begin{array}{l}\text { ological Resources and Activities } \\
\text { uames and addresses of persons who might provide assistance in } \\
\text { this problem. List the how-to books that are available in this area } \\
\text { List other resources (films, collections, exhibits, etc) and special } \\
\text { ent (e.g. camera, tape recorder, questionnaire, etc.). Keep continu- } \\
\text { rd of all activities that are part of this investigation. }\end{array}$ \\
\hline \multicolumn{2}{|c|}{$\begin{array}{l}\text { Getting Started } \\
\text { What are the first steps you should take to begin this investigation? What } \\
\text { types of information or data will be needed to solve the problem? If "raw } \\
\text { data" how can it be gathered, classified, and presented? If you plan to use } \\
\text { already categorized information or data, where is it located and how can } \\
\text { you obtain what you need? }\end{array}$} & & \\
\hline
\end{tabular}




\section{Appendix H}

\section{Parent Interview Protocol}

\section{PARENT INTERVIEW PROTOCOL}

Do I have permission to audio record our conversation?

Thanks for letting me interview you. I have scripted some questions, but along the way if there is anything that you would like to talk about that I have not directly asked, please feel free to discuss any aspect of the gifted program you like.

1) Your child participated in a Type III project this semester in gifted class. He/She worked on . Could you tell me about your child's project?

2) How do you think studying (insert student project topic) was beneficial or not beneficial for your child?

3) Had your child ever engaged in something like this before? Please explain.

4) How was your child challenged during this semester in gifted class?

5) How do you think your child felt about doing the project?

6) How has their learning experiences this semester compared to other learning experiences in the past?

7) How might your child have gained a better appreciation for their local place through this project? How so?

8) What type learning experiences would you like to see for your child in the future?

9) Is there anything else about your child's project that you would like to talk about?

Prompts:

Can you please tell me a little more about...

What I hear you saying is....

What do you think about that?

How do you feel about that? 


\section{Appendix I}
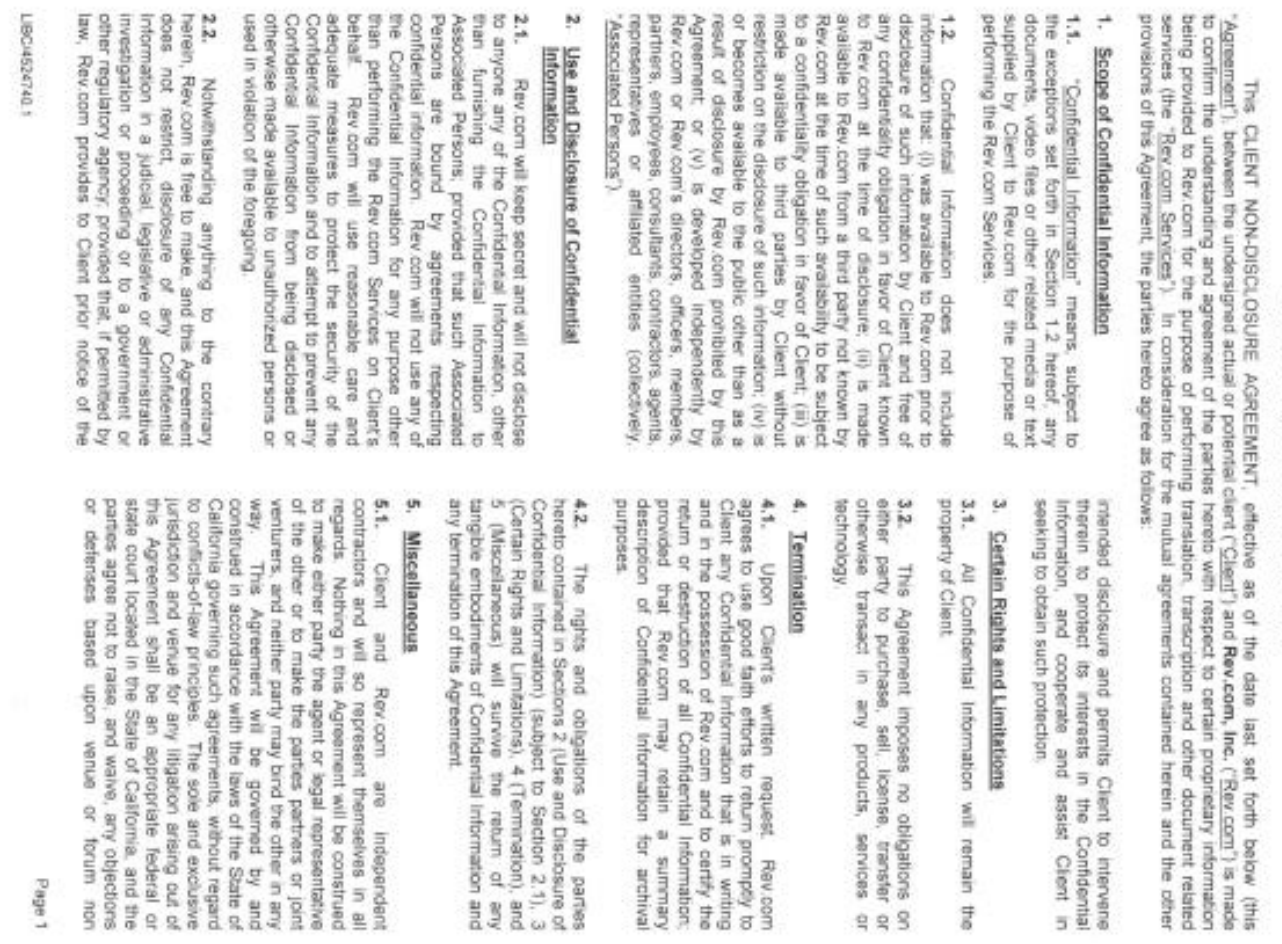

$\frac{\mathrm{E}}{\mathrm{E}}$
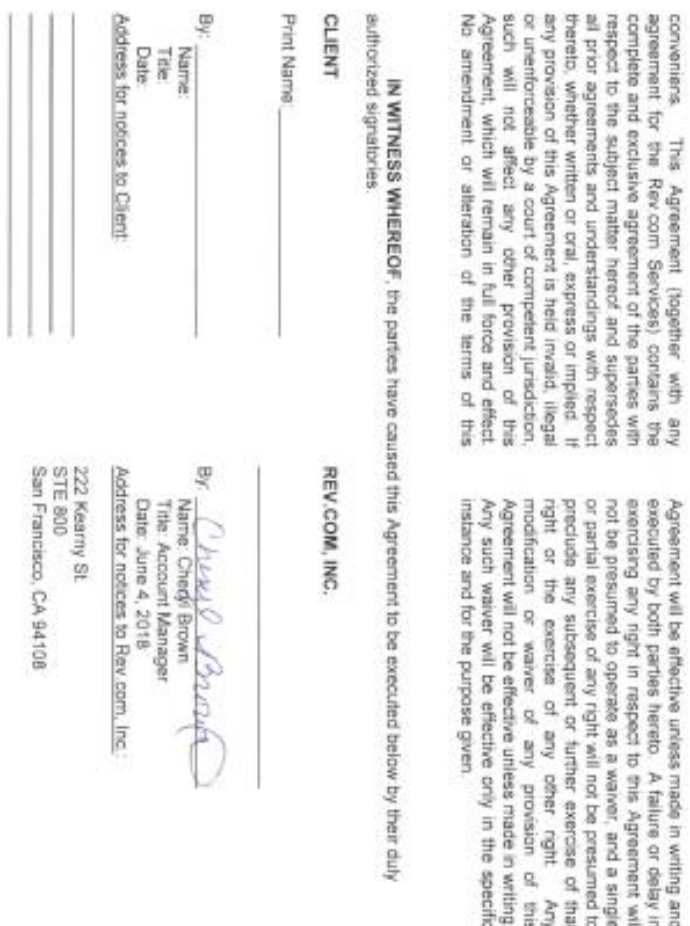